\title{
A "Motif-Oriented" Total Synthesis of Nannocystin Ax. Preparation and Biological Assessment of Analogues
}

\author{
Zhanchao Meng, $^{\dagger}$ Laetitia Souillart, $^{\dagger}$ Brendan Monks, $^{\dagger}$ Nikolas Huwyler, ${ }^{\dagger}$ Jennifer Herrmann, ${ }^{\ddagger}$ \\ Rolf Müller, ${ }^{\ddagger}$ and Alois Fürstner* ${ }^{*} \dagger$ \\ ${ }^{\dagger}$ Max-Planck-Institut für Kohlenforschung, D-45470 Mülheim/Ruhr, Germany \\ ${ }^{\ddagger}$ Helmholtz Institute for Pharmaceutical Research Saarland, Saarland University, 66123 Saarbrücken, Germany
}

Supporting Information

ABSTRACT: The highly cytotoxic cyclodepsipeptides of the nannocystin family are known to bind to the eukaryotic translation elongation factor $1 \alpha(\mathrm{EF}-1 \alpha)$. Analysis of the docking pose, as proposed by a previous in silico study, suggested that the trisubstituted alkene moiety and the neighboring methyl ether form a domain that might be closely correlated with biological activity. This hypothesis sponsored a synthetic campaign which was designed to be "motif-oriented": specifically, a sequence of ring closing alkyne metathesis (RCAM) followed by hydroxy-directed trans-hydrostannation of the resulting cycloalkyne was conceived, which allowed this potentially anchoring

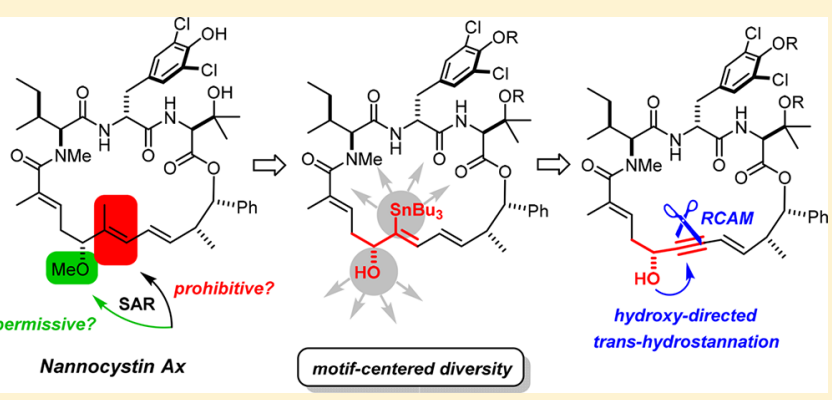
substructure to be systematically addressed at a late stage. This inherently flexible approach opened access to nannocystin Ax (1) itself as well as to 10 non-natural analogues. While the biological data confirmed the remarkable potency of this class of compounds and showed that the domain in question is indeed an innate part of the pharmacophore, the specific structure/activity relationships can only partly be reconciled with the original in silico docking study; therefore, we conclude that this model needs to be carefully revisited.

\section{INTRODUCTION}

Myxobacteria are a prolific source of bioactive natural products. ${ }^{1}$ In accord with this notion, the hitherto fairly untapped genus Nannocystis sp. has recently been shown to produce a small family of cyclodepsipeptides endowed with remarkable antifungal and cytotoxic properties. ${ }^{2,3}$ An extensive screening exercise revealed that the naturally occurring nannocystins exhibit desirable differential activity across a comprehensive panel of up to 472 cancer cell lines, including cell lines that are resistant to clinically approved drugs. Importantly, they seem to interfere neither with the actin nor the tubulin cytoskeleton and do not inhibit a number of representative kinases either; ${ }^{2,3}$ rather, the eukaryotic translation elongation factor $1 \alpha(\mathrm{EF}-1 \alpha)$ was identified as the primary biological target. ${ }^{3}$ Apart from the potential relevance in a medicinal chemistry context, ${ }^{4,5}$ the nannocystins are therefore valuable probe molecules for chemical biology to interrogate translation and protein transport processes in eukaryotic cells.

As the source organism produces a small compound collection, some preliminary insights into structure/activity relationships (SAR) have been established by the two independent isolation teams (Scheme 1). ${ }^{2,3}$ Specifically, nannocystin Ax (1) and nannocystin A (2) were found almost equipotent against the HCT-116 colon carcinoma cell line, which suggests that the epoxide ring might not be required for high activity ${ }^{3}$ (although one of the isolation teams had originally concluded otherwise). ${ }^{2}$ The chlorine substituents on the D-tyrosine unit are not essential either and can be replaced by $-\mathrm{H}$ or $-\mathrm{Br}$ without much loss
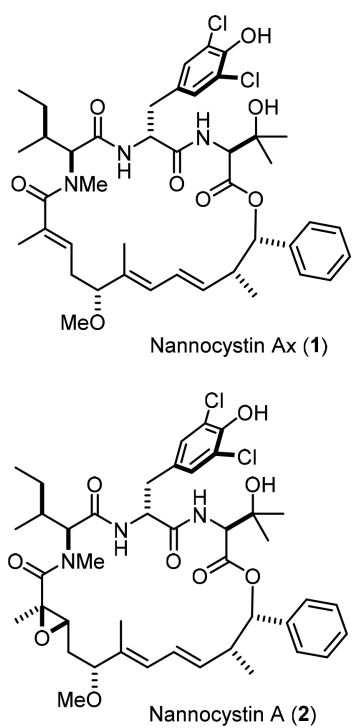

in potency. ${ }^{2,3}$ In this context, it is interesting to note that epoxidation and chlorination occur late in the biosynthesis pathway, only after the macrocyclic framework has been forged

Special Issue: Synthesis of Antibiotics and Related Molecules

Received: November 13, 2017

Published: December 21, 2017 
Scheme 1. Color-Coded Summary of Confirmed and Anticipated ("?") SAR (Green/Red = Permissive/Prohibitive Site $)^{a}$
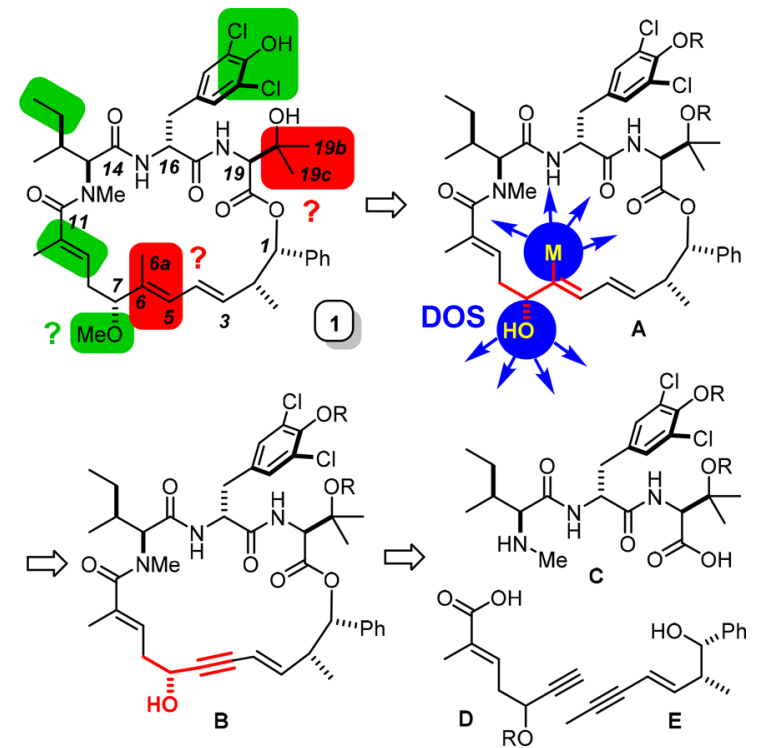

${ }^{a}$ See text; retrosynthetic analysis of nannocystin A focusing on the presumably critical trisubstituted alkene entity; "DOS" indicates the envisaged sites for "motif-oriented" diversity.

by lactonization with concomitant cleavage of the mixed polyketide/peptide chain off the carrier protein. ${ }^{3}$ In silico docking studies suggested that nannocystin A (2) binds to a rather shallow cavity on the surface of EF- $1 \alpha,{ }^{6}$ whereby hydrophobic interactions seem to prevail over hydrogen bonding between guest and host. ${ }^{3}$ In line with this analysis, derivatization of the phenol $-\mathrm{OH}$ group or exchange of L-isoleucine for L-valine did not alter the cytotoxicity by much. ${ }^{2,3}$

For their potency and relevance, the nannocystins immediately caught the attention of the synthetic community; no less than six different total syntheses have been reported in short order. ${ }^{7-12}$ While two of them resorted to macrolactamization to form the 21-membered backbone, ${ }^{10,12}$ it is chemically telling that all other successful approaches targeted the conspicuous diene unit embedded into the polyketide sector, using either robust crosscoupling $^{7,9,11}$ or equally well-established alkene metathesis to form the ring (although the latter was not stereoselective). ${ }^{8,13}$ The total synthesis outlined below is conceptually different in that it was not designed for the sake of rapid conquest of a single representative of this family but rather meant to open access to structural variants that allow the pharmacophore to be mapped at a potentially critical but as yet uncharted domain. Although certainly in keeping with the general concept of "diverted total synthesis", 14,15 the logic of the approach is more focused in that it is strictly oriented toward a potential key motif within the pharmacophore.

\section{RESULTS AND DISCUSSION}

Strategic Considerations. As alluded to above, the computed docking pose of nannocystin A (2) seems to result from weak but likely additive hydrophobic interactions with its EF- $1 \alpha$ protein host. ${ }^{3} \mathrm{~A}$ closer look reveals only two somewhat deeper subpockets within an overall rather shallow binding site: one of them accommodates the gem-dimethyl group of the 3-hydroxy-Lvaline unit, whereas the other one embraces the C6a-Me substituent on the diene; the neighboring C7-OMe group, in contrast, was computed to point away from the protein surface, just as the epoxide ring does, which is known not to be mandatory for high activity. ${ }^{3}$ One can therefore expect that the allylic methyl ether is also a potentially forgiving site: if so, it might qualify for chemical modification in order to adjust the physicochemical properties of the compounds or to attach appropriate linkers. On the other hand, excision of the C6a and the C19b,c methyl substituents is forecasted to be detrimental, while their formal replacement by other hydrophobic residues might allow potency and lipophilicity to be fine-tuned.

Based on this analysis, we considered the trisubstituted C5-C6 double bond flanked by the -OMe group to be the strategic site for disconnection (Scheme 1): it is this substructure which we wished to address for the purpose of late-stage diversification. The stereoselective and-at the same time-flexible formation of highly substituted alkenes embedded into a macrocyclic scaffold, however, is far from trivial. Ring closing alkyne metathesis $(\mathrm{RCAM}){ }^{16}$ followed by regioselective trans-hydrometalation ${ }^{17,18}$ of the ensuing alkyne might allow this challenge to be met, even though this tactic has not yet been applied within a similarly challenging chemical environment. Although RCAM had previously excelled with complex peptidic substrates, ${ }^{19,20}$ it was by no means clear at the outset of this investigation whether trans-hydrometalation qualifies in the present context: this transformation gains high regioselectivity only if a protic substituent on the substrate steers the incoming $[\mathrm{Cp} * \mathrm{Ru}-\mathrm{Cl}]$ catalyst via hydrogen bonding to the chloride ligand and, in doing so, imposes directionality on the transition state (Scheme 2). ${ }^{21,22}$

Scheme 2. Directing Effect Exerted by a Propargylic - OH Group onto the Regiochemical Course of transHydrometalation Catalyzed by $[\mathrm{Cp} * \mathrm{Ru}-\mathrm{Cl}]^{a}$

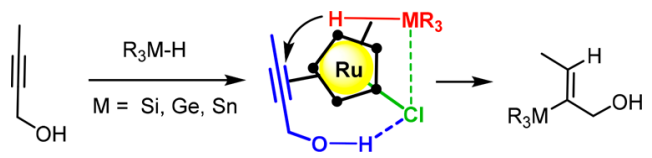

${ }^{a}$ In the Newman-type projection of the putative loaded catalyst, “•” denotes the Me substituents of the $\mathrm{Cp}^{*}$ ring.

While the C7-OMe ether of 1 can obviously be traced back to a propargylic $-\mathrm{OH}$ group which then provides the necessary handle, we felt unable to assess with any level of certainty whether or not the protic amide linkages in transannular proximity in a substrate of type $\mathbf{B}$ interfere with or potentially even disrupt this crucial preorganization. ${ }^{23}$ If regioselective trans-hydrometalation is successful, however, the $-\mathrm{OH}$ substituent in the resulting product $\mathbf{A}$ provides an additional opportunity for late-stage modification: under the premise that the -OR group truly points away of the protein surface once the compound is bound to $\mathrm{EF}-1 \alpha,{ }^{3}$ it should not matter much whether this group remains unprotected, is converted into the parental methyl ether, or is transformed into another biologically viable substituent.

Preparation of the Building Blocks and Fragment Coupling. Since one of the isolation teams had shown that the epoxide ring is not necessary for high potency, ${ }^{3}$ we chose nannocystin $\mathrm{Ax}(\mathbf{1})$ as our lead target. For the preparation of the required enyne fragment $\mathbf{E}$ (Scheme 1), we adapted the coppercatalyzed asymmetric carbonyl addition chemistry recently developed by Buchwald and co-workers. ${ }^{24}$ This transformation was described only for ketone substrates, most likely because aldehydes are subject to competing reduction by the copper hydride species generated in situ. As the projected application required nothing but benzaldehyde, it was deemed acceptable to 
drive the conversion by using this cheap substrate in excess. In doing so, optically active 4 (ee $=99.5 \%)$ became available in only two steps from vinyl bromide (Scheme 3 ). The brevity of the

Scheme 3. Preparation of the Enyne Building Block

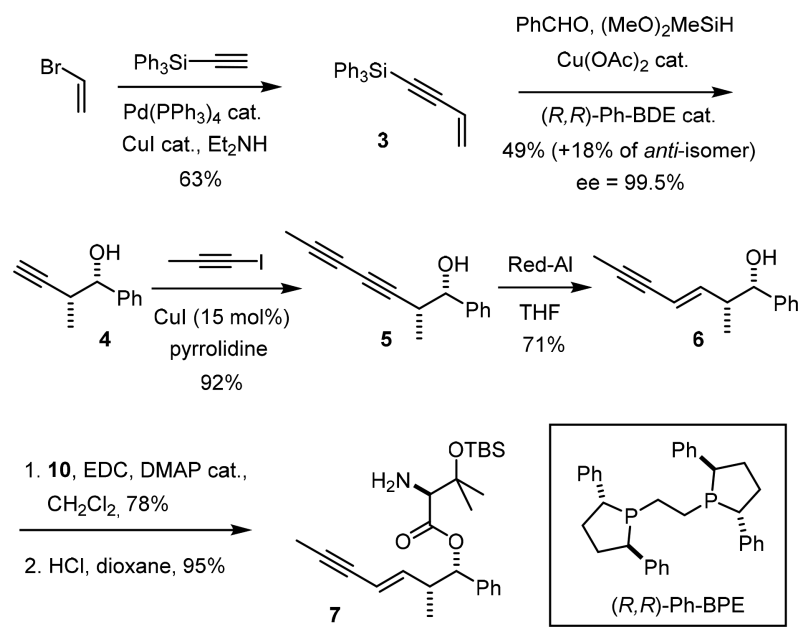

approach, the attractive catalyst loading ( $0.5 \mathrm{~mol} \%$, unoptimized), and the excellent optical purity of product 4 clearly outweighed the modest diastereoselectivity $(\mathrm{dr}=2.8: 1)$, not least because the anti-isomer could be removed by flash chromatography. Alkyne 4 was then cross-coupled with iodopropyne, ${ }^{25}$ followed by a regioand stereoselective semireduction of the propargylic triple bond of 1,3-diyne 5 thus formed. ${ }^{26}$ The resulting product 6 was esterified with protected 3-hydroxyvalinate 10, which in turn was readily available from D-serinate 8 by taking advantage of the hidden symmetry (Scheme 4$){ }^{27}$

Scheme 4. Preparation of the 3-Hydroxyvalinate Building Block

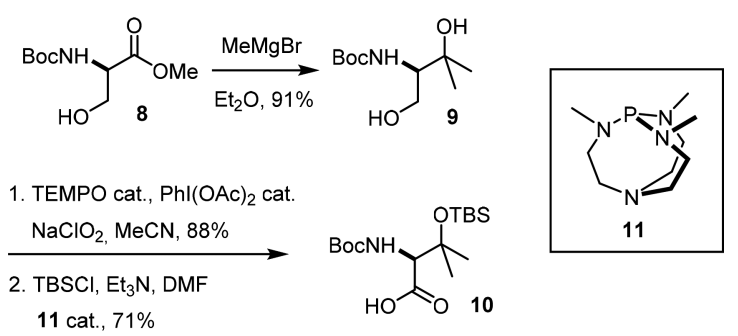

Since the asymmetric allylation of propynal derivatives such as 12 tend to be unsatisfactory under a multitude of conditions, ${ }^{28}$ the preparation of the acid fragment commenced with enzymatic resolution of $\mathrm{rac}-\mathbf{1 3}$, which furnished optically pure 14 (ee $>99 \%$ ) on multigram scale (Scheme 5); ${ }^{29}$ the recovered alcohol $(S)-13$ can also be converted into 14 by a Mitsunobu reaction. ${ }^{30}$ The elaboration of 14 into acid 16 involved selective ozonolysis of the double bond in the presence of the alkyne, Wittig olefination, ${ }^{31}$ saponification of the two ester units, and attachment of a TBS protecting group. Ghosez's chloroenamine reagent proved most adequate for the conversion of the acid $\mathbf{1 6}$ into the required acid chloride $17 .^{32,33}$

The synthesis of the dipeptide fragment $\mathbf{2 2}$ largely followed established routes (Scheme 6). Specifically, selective dichlorination of methyl tyrosinate $\mathbf{1 8}$ and condensation with commercially available $N$-Boc- $N$-methyl isoleucine 20 furnished 21 . $^{34,35}$ An acetyl group was initially considered as the protecting group
Scheme 5. Preparation of the Acid Segment

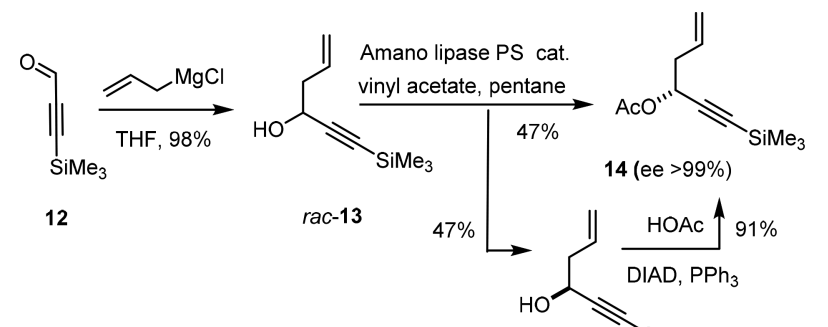

$(\mathrm{S})-13(\mathrm{ee}>99 \%) \mathrm{SiMe}_{3}$

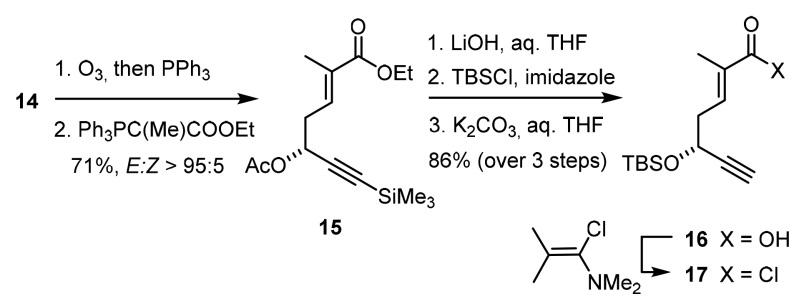

for the phenol to avoid problems in the subsequent esterification and peptide coupling events; this group, however, later turned out to engage in transannular acyl migration (see below). The phenacyl group proved to be a practical and more stable alternative. ${ }^{36}$ Whereas coupling of amine 7 with dipeptide 22 proceeded without incident, the missing amide linkage at the sterically hindered $\mathrm{N}$-methyl-L-isoleucine terminus was more difficult to form (Scheme 6). ${ }^{37}$ To this end, $\mathbf{2 3}$ was treated with a

Scheme 6. Preparation of the Cyclization Precursor
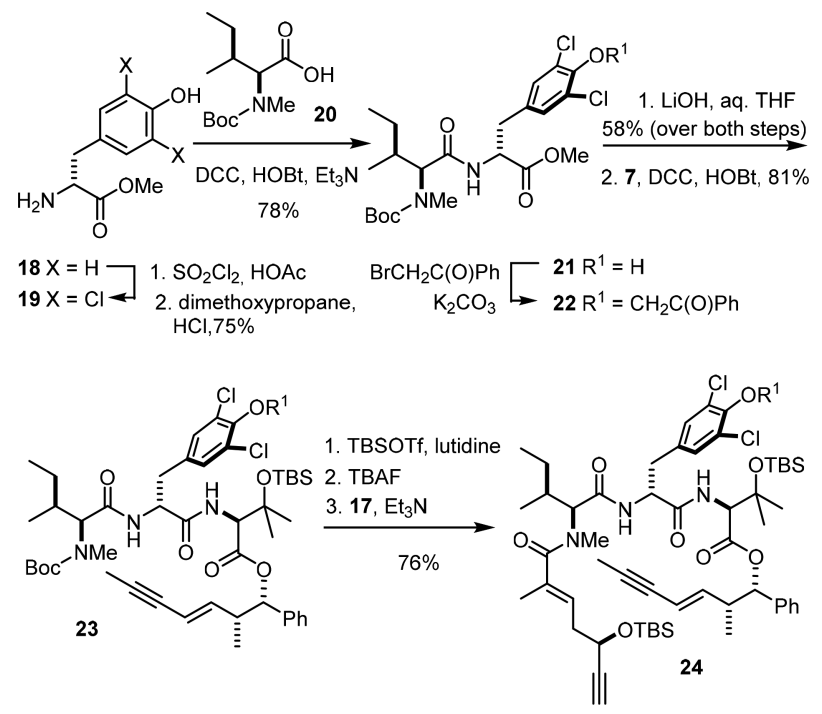

large excess of TBSOTf/lutidine because (partial) silylation of the amides preceded cleavage of the N-Boc residue; workup of the crude material with TBAF gave the desired free amine; this compound reacted well with acid chloride 17 , which was prepared from 16 on demand as mentioned above.

Macrocyclization and Completion of the Total Synthesis. With compound $\mathbf{2 4}$ in hand, the stage was set for ring closure by RCAM and downstream elaboration of the resulting cycloalkyne into nannocystin Ax (1) (Scheme 7). While metathesis of two terminal alkynes remains erratic in our hands, ${ }^{38}$ previous work from this laboratory has shown that reactions of substrates comprising one terminal and one internal alkyne are robust and scalable. ${ }^{39,40}$ Indeed, the molybdenum 
Scheme 7. Completion of the Total Synthesis of Nannocystin Ax (1)

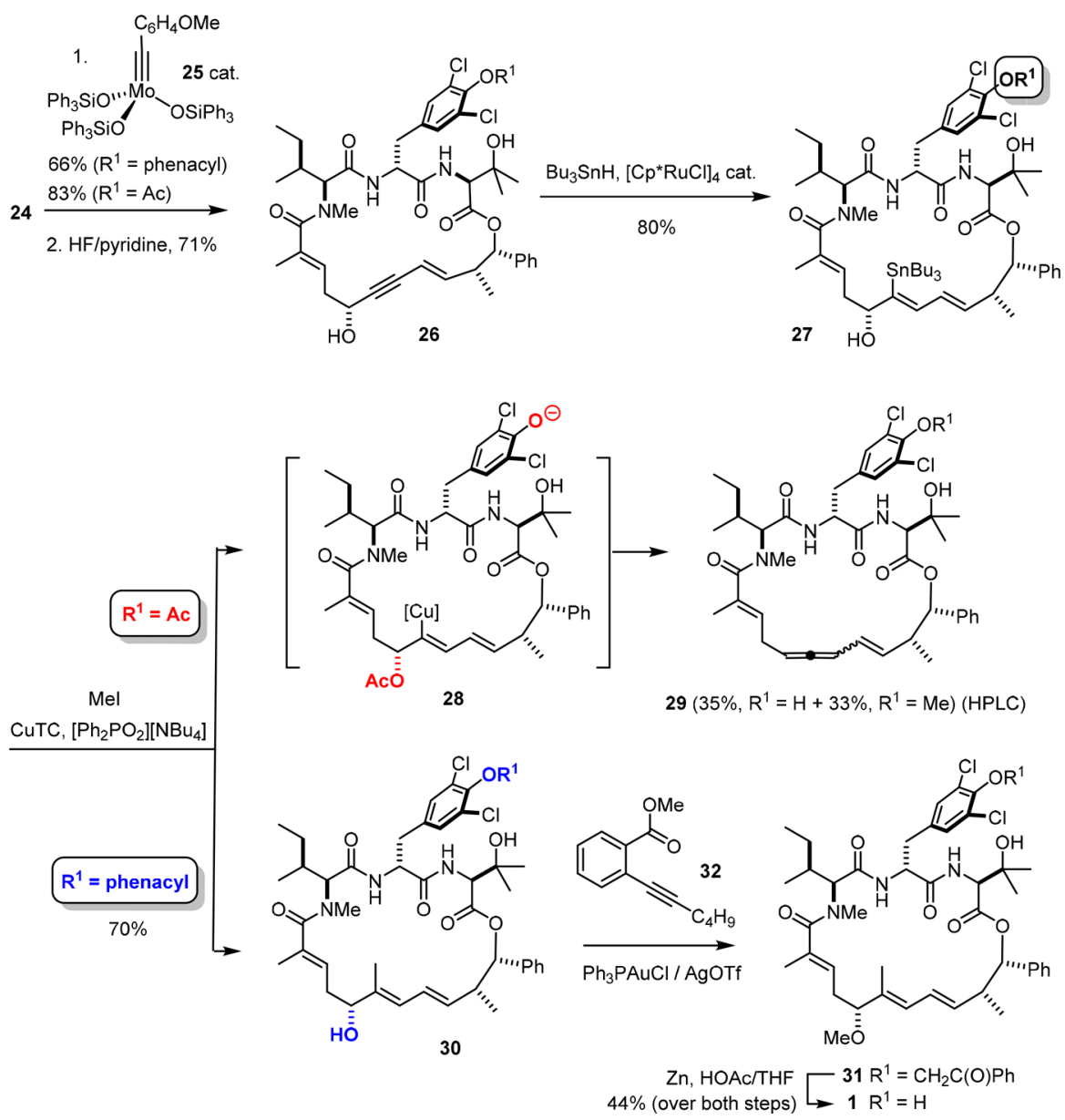

alkylidyne catalyst $25^{41}$ endowed with silanolate ligands converted compound 24 within no more than $15 \mathrm{~min}$ at ambient temperature into the corresponding macrocyclic enyne, which was desilylated to give $\mathbf{2 6}$ in readiness for the projected trans-hydrostannation. This example highlights the reactivity and functional group tolerance of $\mathbf{2 5}$ as the prototype member of the arguably most selective generation of alkyne metathesis catalysts currently available. Since Schrock alkylidynes are inherently nucleophilic at carbon, ${ }^{42}$ the compatibility with protic sites as well as different carbonyl groups is by no means obvious. ${ }^{43}$ Equally important in the present case is the ability of $\mathbf{2 5}$ to distinguish between triple and double bonds: whereas alkynes react smoothly, olefins are inert independent of their electronic nature, degree of substitution, and chemical microenvironment. ${ }^{16,44,45}$

After the propargylic - $\mathrm{OH}$ group had been unveiled, which is needed to impose directionality on the projected trans-hydrostannation (see Scheme 2) and has to overwrite any detrimental influence of the two other protic sites embedded into the macrocyclic array, ${ }^{21,22}$ alkyne 26 was reacted with $\mathrm{Bu}_{3} \mathrm{SnH}$ and catalytic amounts of $[\mathrm{Cp} * \mathrm{RuCl}]_{4}$ in $\mathrm{CH}_{2} \mathrm{Cl}_{2}$. Gratifyingly, this transformation proceeded cleanly, provided that the stannane was slowly added to the reaction mixture. Under these conditions, product $\mathbf{2 7}$ was basically formed as a single regio- and stereoisomer, ${ }^{46}$ which was isolated in $80 \%$ yield. The structure of the enyne substrate $\mathbf{2 6}$ in the solid state (Figure 1) might help to explain why this transformation proceeded so selectively: it shows that the directing hydroxy group at $\mathrm{C} 7$ as well as the flanking C5-C6 alkyne to be hydrometalated are well exposed to the sterically demanding $[\mathrm{Cp} * \mathrm{RuCl}]$ catalyst. $^{47}$ In any case, this

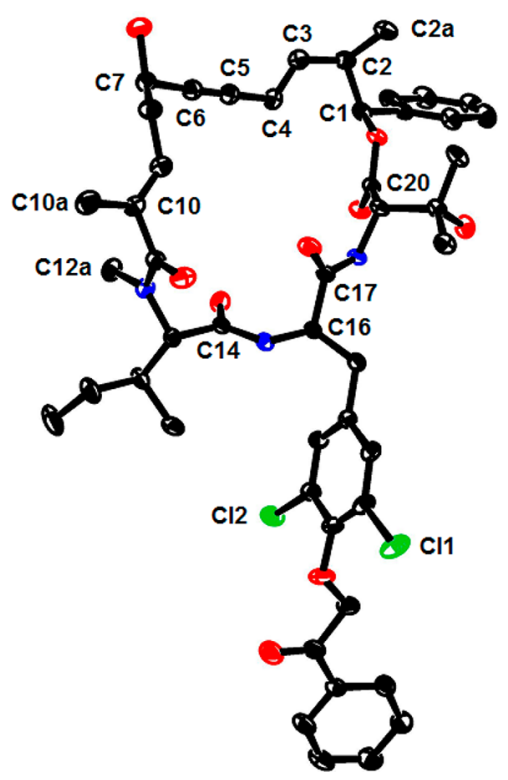

Figure 1. Structure of cycloalkyne 26 in the solid state; the compound crystallized as a monohydrate (not shown for clarity); numbering scheme as introduced by the isolation team and used throughout this paper. Anisotropic displacement parameters are shown at 50\% probability level.

elaborate example illustrates the robustness of this emerging methodology that has already served total synthesis well on several other occasions. $^{48}$ 
The alkenylstannane unit in $27 \mathrm{a}\left(\mathrm{R}^{1}=\right.$ phenacyl) was amenable to $\mathrm{C}$-methylation under conditions previously developed in our laboratory; ${ }^{49}$ thus, treatment with CuTC, $\left[\mathrm{Ph}_{2} \mathrm{PO}_{2}\right]\left[\mathrm{NBu}_{4}\right]$, and MeI furnished the desired alkene $\mathbf{3 0}$ in good yield without scrambling of the double bond geometry. It was at this stage that the phenacyl protecting group proved necessary: compound $\mathbf{2 7 b}$ $\left(\mathrm{R}^{1}=\mathrm{Ac}\right)$ differing only in the presence of an acetyl moiety on the tyrosine's phenolic - $\mathrm{OH}$ reacted much less cleanly; actually, allene formation prevailed (with or without concomitant methylation of the liberated phenol). We feel confident to ascribe this outcome to transannular acyl migration prior to/concomitant with tin/copper exchange; the presence of the good leaving group at the allylic position of the putative organocopper intermediate $\mathbf{2 8}$ entails rapid elimination that outcompetes the desired $\mathrm{C}$-methylation. Although allene formation was undesirable in the present context, it provides an opportunity for alternative downstream processing of the products available by hydroxy-directed trans-hydrometalation. Studies along these lines are underway and will be reported in due course.

With access to 30 secured, the completion of the total synthesis appeared to be straightforward. Yet, the seemingly trivial $\mathrm{O}$-methylation proved to be rather challenging. Although the desired product 31 could be formed under a variety of conditions (e.g., $\mathrm{MeI} / \mathrm{Ag}_{2} \mathrm{O},\left[\mathrm{Me}_{3} \mathrm{O}\right] \mathrm{BF}_{4} /$ proton sponge, $\mathrm{MeOTs} / \mathrm{K}_{2} \mathrm{CO}_{3}$ ), the reactions were not overly clean and the yields fairly erratic. After considerable experimentation, we conceived of a somewhat unorthodox yet potentially widely applicable alternative method (Scheme 8): the required $\left[\mathrm{H}_{3} \mathrm{C}^{+}\right]$equivalent was generated

Scheme 8. Base-Free, Gold-Catalyzed Formation of Methyl Ethers

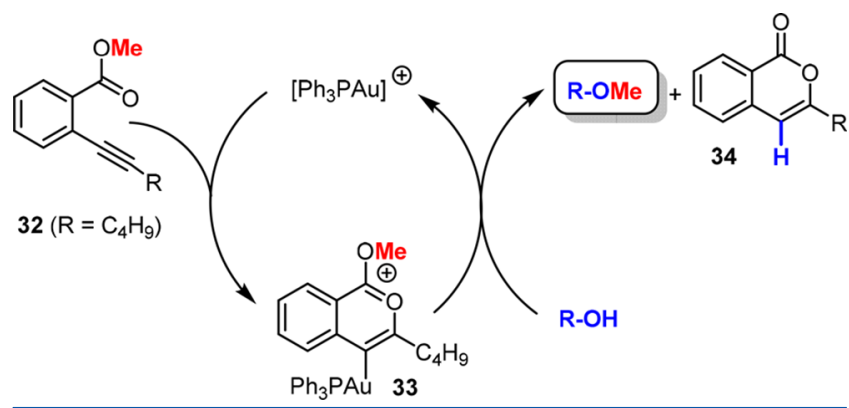

in situ by a gold-catalyzed cyclization of $32 ;^{50}$ in this case, addition of an external base is not necessary as the proton of the alcohol to be methylated gets trapped upon protodeauration of intermediate 33, which releases the $\left[\mathrm{LAu}^{+}\right]$fragment and closes the catalytic cycle. When applied to 30 , this method proved indeed more reliable than the classical alternatives; the resulting crude methyl ether 31 was subjected to reductive cleavage of the phenacyl group with zinc dust in acidic medium ${ }^{36}$ to furnish nannocystin Ax (1). Although the spectra of our synthetic samples were in good accord with the published data, we noticed the presence of a second set of signals which had not been described by the isolation team. ${ }^{3}$ Variable-temperature NMR proved that this characteristic spectral signature is caused by a second conformer and not by any isomer that might have gone unrecognized throughout the synthesis. Liu and co-workers have recently described a similar observation. $^{11}$

Late-Stage Diversification. For its convergence, the route to nannocystin $\mathrm{Ax}$ (1) described above provides many opportunities for structural modifications of the skeleton and variation of the stereostructure, if desirable. In a first foray, we intended to alter the trisubstituted alkene and its flanking - OR substituent to probe whether this substructure is critical for the biological activity or not. It is emphasized, however, that none of the transformations leading to the analogues shown in Scheme 9 has been fully optimized at this point.

Deprotection of compound 30 prior to O-methylation afforded product 35 , differing from the natural product 1 only by the absence of the methyl ether; the comparison should hence reveal if this substituent, which is supposed to point away from the binding side, ${ }^{3}$ exerts any noticeable influence on cytotoxicity. In contrast, the C6a-methyl group branching off the alkene was computed to be immersed into one of only two deeper hydrophobic subpockets of the binding site; ${ }^{3}$ formal deletion should therefore have a quite pronounced effect. This structural modification was readily attained by protodestannation of 27 , which paved the way to the desired nor-methyl compound in O-unprotected (36) as well as O-methylated format (37).

Along the same lines, formal replacement of the C6a-methyl group by a fluorine atom was deemed interesting. ${ }^{51}$ To this end, fluoro-destannation of $\mathbf{2 7}$ according to a procedure recently developed in our laboratory ${ }^{52}$ furnished the fluoroalkene analogue in the form of the corresponding alcohol 38 and the derived methyl ether 39. In this particular case, O-methylation had actually been carried out before the new gold-catalyzed procedure was developed, using MeOTs $/ \mathrm{K}_{2} \mathrm{CO}_{3}$ in acetone. Under these basic conditions, partial cleavage of the tert-alcohol group of the 3-hydroxyvaline unit took place. This unexpected but certainly not implausible retro-aldol reaction warrants further optimization because it might allow for profound modifications of the skeleton at a late stage. Comparison of the fluorinated analogues 40 and 39 with a truncated and intact backbone, respectively, should show whether this site is critically important for activity as the in silico docking study insinuates.

Additional analogues for testing were the chloro-olefin $41^{53}$ as well as the alkynylogous nannocystins $\mathbf{4 2}$ and 43, differing only in the presence or absence of the methyl ether cap. Finally, a Lindlar-type semireduction of $\mathbf{4 3}$ furnished the geometrical isomer 44, which-upon comparison with 35 and 36-should indicate whether the stereochemical integrity of the diene is relevant or not.

From the conceptual viewpoint, we like to emphasize that all compounds described herein were fairly straightforward to make; yet, they invariably feature deep-seated structural modifications that could not be reached-without undue effort-by chemical derivatization of the natural product. Therefore, this set of 10 non-natural analogues exemplifies the concept of "diverted total synthesis" as a means to explore chemical space surrounding a prevalidated natural lead. ${ }^{14,15}$ Yet, the modifications are not random but "motif-oriented" in that they exclusively address a presumably relevant domain.

Biological Assessment. The first round of screening assessed the cytotoxicity of this panel of compounds using the HCT-116 human colon carcinoma and the HL-60 human promyelocytic leukemia cell lines. Synthetic nannocystin Ax (1) allowed for comparison with the literature and hence served as the calibration point. Actually, the $\mathrm{IC}_{50}$ for synthetic $\mathbf{1}$ was lower than that reported for natural $\mathbf{1}$ in the literature (Table 1 ), ${ }^{3}$ but both data points lie in the low single-digit nanomolar range. Whether this difference is due to different assay conditions or is caused by other reasons cannot be decided; in this context, however, we like to point out that the two different isolation teams reported a similar differential in the $\mathrm{IC}_{50}$ for the sister compound 2.,3 Therefore, we feel confident that the data are relevant and comparable. 
Scheme 9. Preparation of a Focused Library of Analogues (Structural Modifications Relative to the Parent Compound 1 Are Indicated in Red $)^{a}$

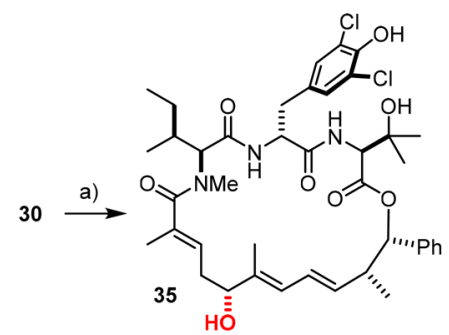

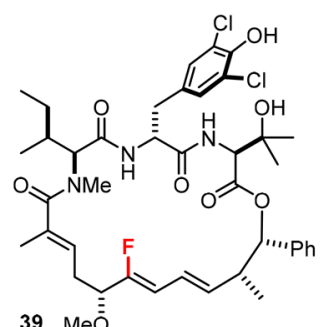

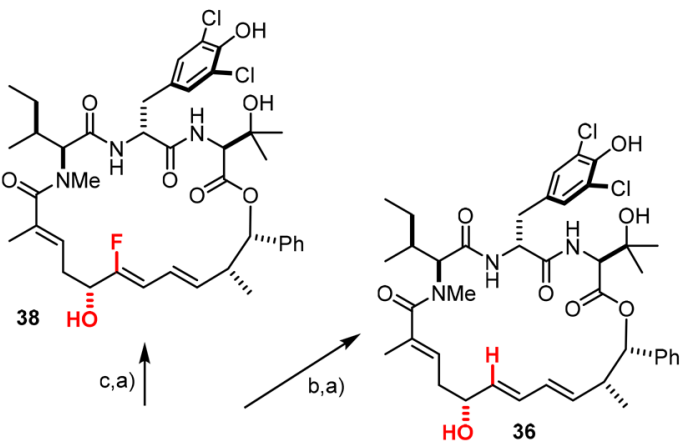

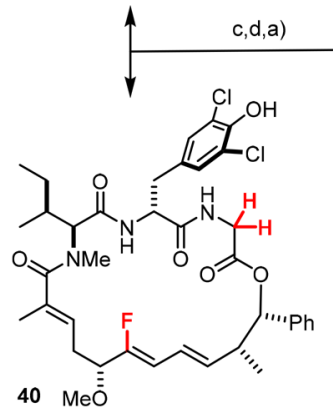

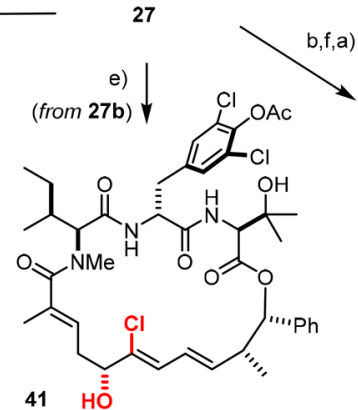

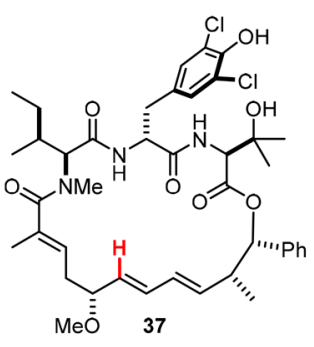

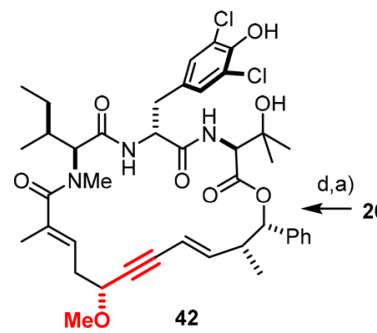

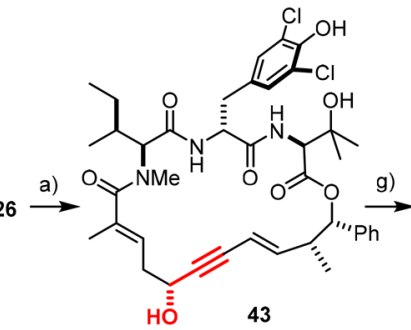

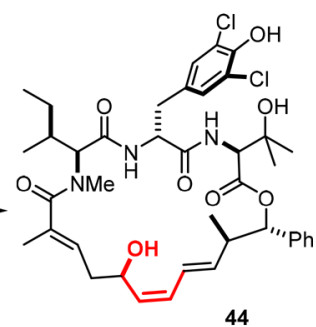

${ }^{a}$ Reagents and conditions: (a) Zn, HOAc, THF, 78\% (35), 75\% (36), 37\% (37) (over steps f,a), 87\% (38), [34\% (39) + 28\% (40)] (over steps d,a), 45\% (42, over steps d,a), 80\% (43); (b) CuTC, $\left[\mathrm{Ph}_{2} \mathrm{PO}_{2}\right]\left[\mathrm{NBu}_{4}\right]$, DMF, 86\%; (c) AgOP(O) $\mathrm{Ph}_{2}$, F-TEDA-PF , acetone, 54\%; (d) $\mathrm{K}_{2} \mathrm{CO}_{3}, \mathrm{MeOTs}$, acetone; (e) $\mathrm{CuCl}_{2}$, lutidine, THF, $82 \%$; (f) 32, $\mathrm{Ph}_{3} \mathrm{PAuCl}$, AgOTf, benzene; (g) $\mathrm{Zn}(\mathrm{Cu} / \mathrm{Ag}$ ), aq $\mathrm{MeOH} / 1,4-d i o x a n e, 62 \%$.

The results compiled in Table 1 show several clear-cut trends: nannocystin $\mathrm{Ax}$ (1) itself proved to be the most potent compound of the series, but the desmethyl derivative 37 as well as the fluoro-analogue 39 are almost as active; even the alkynylogous derivative $\mathbf{4 2}$ retains appreciable potency, most notably against the HCT-116 cell line. However, these findings are difficult to reconcile with the forecast from the in silico docking experiments, which had suggested that the C6a-Me group occupies a privileged site within an otherwise rather featureless and shallow binding pocket. ${ }^{3}$ Its excision, as manifest in 37 , or its replacement by a strongly polarized $\mathrm{C}-\mathrm{F}$ unit as in $\mathbf{3 9}$ had therefore been expected to entail a stronger biological response.

Equally if not even more surprising was the other remarkable pattern manifest in the data: nannocystin $\mathrm{Ax}(\mathbf{1})$ is more than 2 orders of magnitude more potent than its alcohol sibling 35, although the -OMe substituent had been computed to point out of the binding pocket. ${ }^{3}$ Therefore, this dramatic difference was unexpected but is consistently found for all alcohol/ether pairs $(35 / 1,36 / 37,38 / 39)$. None of the other $\mathrm{C} 7-\mathrm{OH}$ derivatives $(41,44)$ showed appreciable activity either. Within the $-\mathrm{OH}$ subseries, however, 35 and 36 comprising the E,E-configured diene are more potent than is the geometrical isomer 44 with an E,Z-entity.

Of arguably very high relevance is the fact that the truncated fluoroalkene analogue 40 is $>2.6 \times 10^{3}$ times less active than fluoroalkene 39 featuring the intact backbone. 40 is actually the least cytotoxic compound of the entire series, which advocates the notion that 3-hydroxyvaline is a very critical segment within the pharmacophore, likely because the two methyl groups engage in hydrophobic contacts with the protein host. ${ }^{3}$ 
Table 1. Initial Profiling of Nannocystins in Terms of Cytotoxic Activity (Half-Inhibitory Concentrations after 5 days of Incubation, $\mathrm{IC}_{50}[\mathrm{nM}]$ ) on HCT-116 and HL-60 Cells

compound
1
2
39
37
42
35
41
38
36
43
44
40

HCT-116
$0.8[5.4]^{3}$
$[1.2]^{2} /[5.1]^{3}$
1.5
4.3
22.2
198
1190
1345
1549
1761
2472
3918

HL-60
5.9
$[12]^{2}$
58.6
46.4
245
767
2964
2702
2108
4254
4366
10229

This conclusion warrants a much more detailed assessment in future studies.

Nannocystin Ax (1) and the three single most potent analogues were then screened more broadly. As can be seen from Table 2, the ranking in terms of potency between the

Table 2. Half-Inhibitory Concentrations $\left(\mathrm{IC}_{50}[\mathrm{nM}]\right)$ of the Most Potent Nannocystin Derivatives on a Panel of Six Cancer Cell Lines of Human Origin ${ }^{a}$

$\begin{array}{ccccccc}\text { cmpound } & \text { HCT-116 } & \text { HL-60 } & \text { KB-3.1 } & \text { THP-1 } & \text { U-2 OS } & \text { U937 } \\ \mathbf{1} & 0.8 & 5.9 & 1.7 & 1.3 & 0.2 & 5.0 \\ 39 & 1.5 & 58.6 & 7.8 & 33.4 & 11.2 & 141 \\ 37 & 4.3 & 46.4 & 5.9 & 20.5 & 3.5 & 33.5 \\ 42 & 22.2 & 245 & 83.6 & 81.2 & 20.2 & 198\end{array}$

${ }^{a_{T}}$ The histotypes are as follows: HCT-116, colon carcinoma; HL-60, promyelocytic leukemia; KB-3.1, cervical carcinoma; THP-1, acute monocytic leukemia; U-2 OS, osteosarcoma; U937, histiocytic lymphoma.

fluoro-analogue 39 and the nor-methyl derivative 37 observed with HCT-116 was inverted in all other cell lines, although the differences are rather small and must not be overinterpreted. Importantly, the sensitivity of the chosen six human cancer cell lines toward the individual compounds provides a consistent picture. Therefore, it seems that the trisubstituted alkene motif of nannocystin Ax is a more permissive site for structural modification than anticipated, whereas changes to the flanking -OMe ether substituent are much more critical than forecasted by the currently only binding model published in the literature. ${ }^{3}$ Although our data suggest that this purely computational proposal needs to be revisited and calibrated in more detail, we like to emphaisze that cell toxicity is the total score of various factors. Therefore, additional SAR data are necessary before a final conclusion can be drawn.

\section{CONCLUSIONS}

In contrast to all previous syntheses of members of the nannocystin family, ${ }^{7-12}$ the approach described herein is "motif-focused" rather than purely "target-oriented" in conceptual terms. ${ }^{54}$ It was deliberately designed to alter and hence interrogate a subsite embedded into the molecular frame that was suggested to play a critical role in the binding of these highly cytotoxic agents to EF- $1 \alpha$ as their primary biological target. This goal was accomplished with the aid of a reaction sequence comprising ring closing alkyne metathesis followed by hydroxy-directed trans-hydrostannation of the resulting macrocyclic propargyl alcohol derivative. This tactic opened a selective yet flexible entry into di- as well as trisubstituted alkenes including nannocystin Ax itself and a set of 10 nonnatural analogues; these derivatives are distinguished by deepseated structural "point mutations" that would not be accessible by derivatization of the natural lead. Moreover, the chosen strategy is almost certainly of interest in entirely different chemical contexts, too. Assessment of the cytotoxicity of the synthetic compound collection provided important insights into the SAR of the critical motif, which calls for reassessment of the only available model meant to describe the binding of the cyclodepsipeptides of the nannocystin family to their protein host. $^{3}$

\section{EXPERIMENTAL SECTION}

Cytotoxic Activity $\left(\mathrm{IC}_{50}\right)$. Cell lines were obtained from the German Collection of Microorganisms and Cell Cultures (Deutsche Sammlung für Mikroorganismen and Zellkulturen, DSMZ) or the American Type Culture Collection (ATCC). All cell lines were cultured under conditions recommended by the depositor. Cells were seeded at $5 \times 10^{4}$ cells per well in 96-well plates in $180 \mu \mathrm{L}$ of medium supplemented with $10 \%$ FBS (McCoy's 5A modified medium for HCT-116, U-2OS, and KB-3.1 cells; RPMI 1640 medium for HL-60, THP-1, and U937 cells) and treated with nannocystins dissolved in DMSO in serial dilution after $2 \mathrm{~h}$ of equilibration. Cells were treated for 5 days. For adherent cells, $20 \mu \mathrm{L}$ of $5 \mathrm{mg} / \mathrm{mL}$ MTT (thiazolyl blue tetrazolium bromide) in PBS (phosphate-buffered saline; $\mathrm{pH}$ 7.4) was added per well, and cells were incubated for an additional $2 \mathrm{~h}$ at $37^{\circ} \mathrm{C}$ and $5 \% \mathrm{CO}_{2}$. The medium was discarded, and $100 \mu \mathrm{L}$ of 2-propanol/ $\mathrm{HCl}(10 \mathrm{M}, 250: 1)$ was added in order to dissolve formazan granules. The absorbance at $570 \mathrm{~nm}$ was measured using a microplate reader (Tecan M200Pro). For suspension cell lines, $20 \mu \mathrm{L}$ of $0.2 \mathrm{mg} / \mathrm{mL}$ alamar blue (resazurin sodium salt) in PBS was added per well, and cells were incubated for an additional $24 \mathrm{~h}$ at $37^{\circ} \mathrm{C}$ and $5 \% \mathrm{CO}_{2}$. The fluorescence intensity at $570 \mathrm{~nm}$ (excitation wavelength: $540 \mathrm{~nm}$ ) was measured using a microplate reader (Tecan M200Pro). Cell viability correlates with the absorbance and fluorescence intensity values and was expressed as percentage relative to the respective solvent control. Half-inhibitory concentrations $\left(\mathrm{IC}_{50}\right)$ were determined by sigmoidal curve fitting.

General Remarks. Unless stated otherwise, all reactions were carried out under argon in flame-dried glassware using anhydrous solvents. The solvents were purified by distillation over the following drying agents and were transferred under $\mathrm{Ar}$ : THF, $\mathrm{Et}_{2} \mathrm{O}$ ( $\mathrm{Mg} /$ anthracene), $\mathrm{CH}_{2} \mathrm{Cl}_{2}$, toluene $(\mathrm{Na} / \mathrm{K}), \mathrm{MeOH}(\mathrm{Mg}$, stored over $3 \AA \mathrm{MS})$; DMF, DMSO, $\mathrm{Et}_{3} \mathrm{~N}, 1$,4-dioxane, and pyridine were dried by an adsorption solvent purification system based on molecular sieves; anhydrous (99.9\%) cyclopentyl methyl ether (CPME) purchased from Aldrich was kept in a flame-dried Schlenk flask containing $4 \AA$ MS under argon. Thin layer chromatography (TLC): Macherey-Nagel precoated plates (POLYGRAMSIL/UV254). Preparative TLC: Macherey-Nagel precoated plates (SIL G-100 UV 254; silica gel layer: $1.0 \mathrm{~mm}$ ). Flash chromatography: Merck silica gel $60(40-63 \mu \mathrm{m})$ with predistilled or HPLC grade solvents; Celite was dried at $170{ }^{\circ} \mathrm{C}$ for $48 \mathrm{~h}$ under high vacuum $\left(1 \times 10^{-3} \mathrm{mbar}\right)$ and stored under argon. NMR: Spectra were recorded on Bruker DPX 300, AV 400, AV 500, or AVIII 600 spectrometers in the solvents indicated; chemical shifts $(\delta)$ are given in parts per million relative to TMS, and coupling constants $(J)$ are in $\mathrm{Hz}$. The solvent signals were used as references, and the chemical shifts converted to the TMS scale $\left(\mathrm{CDCl}_{3}, \delta_{\mathrm{C}}=77.16 \mathrm{ppm}\right.$; residual $\mathrm{CHCl}_{3}$ in $\mathrm{CDCl}_{3}, \delta_{\mathrm{H}}=$ $7.26 \mathrm{ppm} ; \mathrm{CD}_{3} \mathrm{OD}, \delta \mathrm{C}=49.0 \mathrm{ppm}$; residual $\mathrm{CHD}_{2} \mathrm{OD}, \delta_{\mathrm{H}}=3.31 \mathrm{ppm}$; $\left(\mathrm{CD}_{3}\right)_{2} \mathrm{CO}, \delta_{\mathrm{C}}=29.8,206.3 \mathrm{ppm}$; residual $\mathrm{CD}_{3} \mathrm{CHD}_{2} \mathrm{OD}, \delta_{\mathrm{H}}=$ $2.05 \mathrm{ppm},\left(\mathrm{CD}_{3}\right)_{2} \mathrm{SO}, \delta_{\mathrm{C}}=39.5 \mathrm{ppm}$; residual $\mathrm{CD}_{3} \mathrm{CHD}_{2} \mathrm{SO}, \delta_{\mathrm{H}}=$ $2.50 \mathrm{ppm}$ ). IR: Spectrum One (PerkinElmer) spectrometer, wavenumbers $(\nu)$ in $\mathrm{cm}^{-1}$. MS (EI): Finnigan MAT $8200(70 \mathrm{eV}$, doubly focused sectorfield MS), ESI-MS: ESQ3000 (Bruker, ion trap), accurate mass determinations; Bruker APEX III FTMS (7 T magnet, ion cyclotron resonance MS) or Mat 95 (Finnigan, doubly focused sectorfield MS). Optical rotations $\left([\alpha]_{\mathrm{D}}{ }^{20}\right)$ were measured with a PerkinElmer 
model 343 polarimeter. LC-MS analyses were conducted on a Shimadzu LCMS 2020 instrument (pumps LC-20AD, autosampler SIL-20AC, column oven CTO-20AC, diode array detector SPD-M20A, controller CBM-20A, ESI detector, and Labsolutions software) with an ZORBAX Eclipse Plus C18 $1.8 \mu \mathrm{m}, 3.0$ or $4.6 \mathrm{~mm}$ i.d. $\times 50 \mathrm{~mm}$ (Agilent). A binary gradient of $\mathrm{MeCN}$ or $\mathrm{MeOH}$ in water or aqueous triethylammonium acetate buffer $(10 \mathrm{mmol}, \mathrm{pH} 8)$ was used at a flow rate of $0.5(3.0 \mathrm{~mm}$ i.d.) or 0.8 ( $4.6 \mathrm{~mm}$ i.d.) $\mathrm{mL} / \mathrm{min}$. The oven temperature was kept at $35{ }^{\circ} \mathrm{C}$ and the detection wavelength at $254 \mathrm{~nm}$. Preparative LC was performed with a Shimadzu LC-20A prominence system (pumps LC-20AP, column oven CTO-20AC, diode array detector SPD-M20A, fraction collector FRC-10A, controller CBM-20A and LC-solution software); conditions for each compound are specified below. Determinations of the enantiomeric excess (ee) were performed by HPLC or GC using the chiral stationary phases and conditions specified below. Unless stated otherwise, all commercially available compounds (Alfa Aesar, Aldrich, TCI, Strem Chemicals) were used as received.

But-3-en-1-yn-1-yltriphenylsilane (3). ${ }^{55}$ Ethynyltriphenylsilane $(5.00 \mathrm{~g}, 17.6 \mathrm{mmol})$ and vinyl bromide $(1.0 \mathrm{M}$ in THF, $22.9 \mathrm{~mL}$, $22.9 \mathrm{mmol})$ were added to a solution of $\mathrm{CuI}(67.0 \mathrm{mg}, 0.352 \mathrm{mmol})$ and $\left[\mathrm{Pd}\left(\mathrm{Ph}_{3} \mathrm{P}\right)_{4}\right](101 \mathrm{mg}, 87.4 \mu \mathrm{mol})$ in diethylamine $(8.7 \mathrm{~mL})$. The resulting mixture was stirred at ambient temperature for $24 \mathrm{~h}$ before the reaction was quenched with water. The aqueous layer was extracted with pentane/ diethyl ether $(1: 1,100 \mathrm{~mL})$, and the combined extracts were washed with $\mathrm{HCl}(1 \mathrm{M})$, dried over $\mathrm{Na}_{2} \mathrm{SO}_{4}$, and evaporated. The residue was purified by flash chromatography on silica gel (hexanes) to afford the title compound as a white solid $(3.41 \mathrm{~g}, 63 \%): \mathrm{mp}=99.0-99.8{ }^{\circ} \mathrm{C}$; ${ }^{1} \mathrm{H}$ NMR $\left(400 \mathrm{MHz}, \mathrm{CDCl}_{3}\right) \delta=7.71-7.66(\mathrm{~m}, 6 \mathrm{H}), 7.48-7.37(\mathrm{~m}$, $9 \mathrm{H}), 5.98(\mathrm{dd}, J=17.6,11.0 \mathrm{~Hz}, 1 \mathrm{H}), 5.87(\mathrm{dd}, J=17.6,2.4 \mathrm{~Hz}, 1 \mathrm{H})$, $5.64(\mathrm{dd}, J=11.0,2.4 \mathrm{~Hz}, 1 \mathrm{H}) \mathrm{ppm} ;{ }^{13} \mathrm{C} \mathrm{NMR}\left(101 \mathrm{MHz}, \mathrm{CDCl}_{3}\right) \delta=$ $135.7,133.6,130.1,129.4,128.1,117.3,108.2,90.0$ ppm; IR (film) $\nu=$ $3068,2152,1428 \mathrm{~cm}^{-1}$; MS (EI) $\mathrm{m} / z$ (\%) 105 (94), 129 (50), 155 (41), 181 (100), 203 (20), 232 (83), 310 (29); HRMS (ESI) $\mathrm{m} / z$ calcd for $\mathrm{C}_{22} \mathrm{H}_{18} \mathrm{Si}\left[\mathrm{M}^{+}\right] 310.1172$, found 310.1177 .

(1S,2R)-2-Methyl-1-phenylbut-3-yn-1-ol (4). Dimethoxymethylsilane $(1.3 \mathrm{~mL}, 10.5 \mathrm{mmol})$ was added at $0{ }^{\circ} \mathrm{C}$ to a stirred solution of $\mathrm{Cu}(\mathrm{OAc})_{2}(1.9 \mathrm{mg}, 10.5 \mu \mathrm{mol}),(R, R)-\mathrm{Ph}-\mathrm{BPE}(6.4 \mathrm{mg}, 12.6 \mu \mathrm{mol}), 3$ $(650 \mathrm{mg}, 2.09 \mathrm{mmol})$, benzaldehyde $(640 \mu \mathrm{L}, 6.30 \mathrm{mmol})$, and $t$-BuOH $(200 \mu \mathrm{L}, 2.10 \mathrm{mmol})$ in cyclohexane $(4.2 \mathrm{~mL})$. The mixture was stirred at this temperature for $10 \mathrm{~h}$. The reaction was carefully quenched with $\mathrm{NaOH}$ solution in $\mathrm{MeOH}(2 \mathrm{M}$, ca. $30 \mathrm{~mL}$ ) (Caution: gas evolution) and stirring continued for $10 \mathrm{~h}$ before the mixture was diluted with $\mathrm{H}_{2} \mathrm{O}$. The aqueous layer was extracted with EtOAc $(3 \times 100 \mathrm{~mL})$, and the combined organic phases were washed with brine $(5 \mathrm{~mL})$, dried over $\mathrm{Na}_{2} \mathrm{SO}_{4}$, filtered, and concentrated. After recrystallization from hexane, the crude material was purified by flash chromatography on silica gel (hexanes/tert-butyl methyl ether, 10:1 to $8: 1$ ) to afford the title compound 4 (165 mg, 49\%, 99.5\% ee) and the anti-isomer (61.4 mg, 18\%, 98.7\% ee), each as a colorless oil. [The ee was determined by HPLC analysis: Daicel Chiralpak IA $(4.6 \mathrm{~mm} \times 250 \mathrm{~mm})$, $n$-heptane $/ 2$-propanol $=98 / 2, v=1.0 \mathrm{~mL} \cdot \mathrm{min}^{-1}, \lambda=220 \mathrm{~nm}, t$ (minor) $=$ $13.42 \mathrm{~min}, t$ (major) $=14.81 \mathrm{~min}$; HPLC analysis of the anti-isomer: Daicel Chiralpak IC-3 $(4.6 \mathrm{~mm} \times 150 \mathrm{~mm}), n$-heptane $/ 2$-propanol $=99.5 /$ $0.5, v=1.0 \mathrm{~mL} \cdot \mathrm{min}^{-1}, \lambda=220 \mathrm{~nm}, t$ (minor) $=10.33 \mathrm{~min}, t$ (major) $=$ $14.92 \mathrm{~min}$.

Analytical data of 4: $[\alpha]_{\mathrm{D}}{ }^{20}=-47.6\left(\right.$ c 1.0, $\left.\mathrm{CHCl}_{3}\right)$; ${ }^{1} \mathrm{H}$ NMR $\left(400 \mathrm{MHz}, \mathrm{CDCl}_{3}\right) \delta=7.42-7.28(\mathrm{~m}, 5 \mathrm{H}), 4.75(\mathrm{dd}, J=5.5,3.6 \mathrm{~Hz}$, $1 \mathrm{H}), 2.88(\mathrm{qdd}, J=7.0,5.5,2.5 \mathrm{~Hz}, 1 \mathrm{H}), 2.22(\mathrm{~d}, J=3.6 \mathrm{~Hz}, 1 \mathrm{H}), 2.12$ $(\mathrm{d}, J=2.4 \mathrm{~Hz}, 1 \mathrm{H}), 1.14(\mathrm{~d}, J=6.9 \mathrm{~Hz}, 3 \mathrm{H}) \mathrm{ppm} ;{ }^{13} \mathrm{C} \mathrm{NMR}(101 \mathrm{MHz}$, $\left.\mathrm{CDCl}_{3}\right) \delta=141.3,128.3,128.0,126.6,86.0,76.3,71.0,34.2,15.7 \mathrm{ppm}$; IR (film) $\nu=3292,2977,2936 \mathrm{~cm}^{-1}$; MS (ESI) $\mathrm{m} / z 178\left[\mathrm{M}+\mathrm{NH}_{4}^{+}\right]$, $183\left[\mathrm{M}+\mathrm{Na}^{+}\right]$; HRMS (ESI) $m / z$ calcd for $\mathrm{C}_{11} \mathrm{H}_{12} \mathrm{ONa}\left[\mathrm{M}+\mathrm{Na}^{+}\right]$ 183.0780, found 183.0782 .

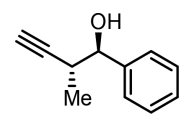

Analytical data of the anti-isomer: $[\alpha]_{\mathrm{D}}{ }^{20}=+68.3\left(\right.$ c 1.1, $\left.\mathrm{CHCl}_{3}\right)$; ${ }^{1} \mathrm{H} \mathrm{NMR}\left(400 \mathrm{MHz}, \mathrm{CHCl}_{3}\right) \delta=7.42-7.28(\mathrm{~m}, 5 \mathrm{H}), 4.52$ (dd, $J=7.2$, $3.6 \mathrm{~Hz}, 1 \mathrm{H}), 2.81(\mathrm{pd}, J=7.1,2.4 \mathrm{~Hz}, 1 \mathrm{H}), 2.50(\mathrm{~d}, J=3.8 \mathrm{~Hz}, 1 \mathrm{H}), 2.22$ $(\mathrm{d}, J=2.4 \mathrm{~Hz}, 1 \mathrm{H}), 1.11(\mathrm{~d}, J=7.0 \mathrm{~Hz}, 3 \mathrm{H}) \mathrm{ppm} ;{ }^{13} \mathrm{C} \mathrm{NMR}(101 \mathrm{MHz}$, $\left.\mathrm{CDCl}_{3}\right) \delta=141.4,128.5,128.2,126.8,85.6,77.6,71.5,35.3,17.5 \mathrm{ppm}$; IR (film) $\nu=3293,2977,2936 \mathrm{~cm}^{-1}$; MS (EI) $\mathrm{m} / z$ (\%)79 (100), 107 (74); HRMS (ESI) $m / z$ calcd for $\mathrm{C}_{11} \mathrm{H}_{12} \mathrm{ONa}\left[\mathrm{M}+\mathrm{Na}^{+}\right]$183.0780, found 183.0781 .

(1S,2R)-2-Methyl-1-phenylhepta-3,5-diyn-1-ol (5). ${ }^{56} \mathrm{CuI}$ $(24.9 \mathrm{mg}, 0.131 \mathrm{mmol})$ was added to a stirred solution of $4(140 \mathrm{mg}$, $0.874 \mathrm{mmol}$ ) and freshly prepared iodopropyne (excess, ca. 10 equiv) ${ }^{25}$ in degassed pyrrolidine ( $44 \mathrm{~mL}$ ), causing an immediate color change to green. After being stirred for $10 \mathrm{~h}$, the then yellow mixture was diluted with $\mathrm{HCl}(2 \mathrm{M}, 50 \mathrm{~mL})$ and extracted with tert-butyl methyl ether $(3 \times 100 \mathrm{~mL})$. The combined organic phases were washed with brine $(15 \mathrm{~mL})$, dried over $\mathrm{MgSO}_{4}$, filtered, and concentrated. The residue was purified by flash chromatography (hexanes/tert-butyl methyl ether, $10: 1)$ to afford the title compound as a pale yellow oil (159 mg, 92\%): $[\alpha]_{\mathrm{D}}{ }^{20}=-9.0$ (c 2.2, $\mathrm{CHCl}_{3}$ ); ${ }^{1} \mathrm{H}$ NMR $\left(400 \mathrm{MHz}, \mathrm{CDCl}_{3}\right) \delta=$ 7.39-7.33 (m, $4 \mathrm{H}), 7.32-7.27(\mathrm{~m}, 1 \mathrm{H}), 4.72(\mathrm{~d}, J=5.5 \mathrm{~Hz}, 1 \mathrm{H})$, $2.95-2.86(\mathrm{~m}, 1 \mathrm{H}), 2.17(\mathrm{~d}, J=3.2 \mathrm{~Hz}, 1 \mathrm{H}), 1.90(\mathrm{~d}, J=1.1 \mathrm{~Hz}, 3 \mathrm{H})$, $1.13(\mathrm{~d}, J=7.0 \mathrm{~Hz}, 3 \mathrm{H}) \mathrm{ppm} ;{ }^{13} \mathrm{C}$ NMR $\left(101 \mathrm{MHz}, \mathrm{CDCl}_{3}\right) \delta=141.3$, $128.3,128.0,126.6,77.6,76.4,74.7,68.1,64.3,35.0,15.6,4.4$ ppm; IR (film) $\nu=3420,2975,2932,2914,1453 \mathrm{~cm}^{-1}$; MS (ESI) $\mathrm{m} / z 198$ $\left[\mathrm{M}+\mathrm{NH}_{4}^{+}\right], 221\left[\mathrm{M}+\mathrm{Na}^{+}\right]$; HRMS (ESI) $m / z$ calcd for $\mathrm{C}_{14} \mathrm{H}_{14} \mathrm{ONa}$ $\left[\mathrm{M}+\mathrm{Na}^{+}\right]$221.0937, found 221.0938.

(1S,2R,E)-2-Methyl-1-phenylhept-3-en-5-yn-1-ol (6). Red-Al (3.5 $\mathrm{M}$ in toluene, $0.57 \mathrm{~mL}, 2.0 \mathrm{mmol}$ ) was added to a stirred solution of $5(100 \mathrm{mg}, 0.504 \mathrm{mmol})$ in THF $(1.0 \mathrm{~mL})$ at room temperature. The mixture was stirred at $65^{\circ} \mathrm{C}$ for $2 \mathrm{~h}$ before the reaction was carefully quenched with $\mathrm{HCl}(1 \mathrm{M}, 4.0 \mathrm{~mL})$. The aqueous phase was extracted with EtOAc $(3 \times 10 \mathrm{~mL})$, and the combined extracts were washed with brine and dried with $\mathrm{Na}_{2} \mathrm{SO}_{4}$. The solvent was evaporated and the residue purified by chromatography on silica gel (hexanes/EtOAc, 20:1) to afford the title compound as a colorless oil $(71.3 \mathrm{mg}, 71 \%):[\alpha]_{\mathrm{D}}{ }^{20}=$ $+8.5\left(c 0.8, \mathrm{CHCl}_{3}\right) ;{ }^{1} \mathrm{H}$ NMR $\left(400 \mathrm{MHz}, \mathrm{CDCl}_{3}\right) \delta=7.39-7.24(\mathrm{~m}$, $5 \mathrm{H}), 5.97(\mathrm{ddd}, J=16.0,7.6,0.8 \mathrm{~Hz}, 1 \mathrm{H}), 5.44(\mathrm{dqd}, J=16.0,2.3,1.3 \mathrm{~Hz}$, $1 \mathrm{H}), 4.60(\mathrm{dd}, J=5.6,3.6 \mathrm{~Hz}, 1 \mathrm{H}), 2.69-2.54(\mathrm{~m}, 1 \mathrm{H}), 1.91(\mathrm{~d}, J=$ $2.3 \mathrm{~Hz}, 3 \mathrm{H}), 1.87(\mathrm{~d}, J=3.6 \mathrm{~Hz}, 1 \mathrm{H}), 1.01(\mathrm{~d}, J=6.8 \mathrm{~Hz}, 3 \mathrm{H}) \mathrm{ppm}$; ${ }^{13} \mathrm{C}$ NMR $\left(101 \mathrm{MHz}, \mathrm{CDCl}_{3}\right) \delta=144.2,142.4,128.3,127.7,126.6$, 111.1, 85.4, 78.2, 44.4, 14.5, 4.4 ppm; IR (film) $\nu=3428$, 3029, 2964, 2916, 1494, 1453, $1376 \mathrm{~cm}^{-1}$; MS (EI) $\mathrm{m} / z$ (\%) 79 (100), 94 (38), 105 (20), 107 (37); HRMS (ESI) $m / z$ calcd for $\mathrm{C}_{14} \mathrm{H}_{16} \mathrm{ONa}\left[\mathrm{M}+\mathrm{Na}^{+}\right]$ 223.1093, found 223.1095.

(1S,2R,E)-2-Methyl-1-phenylhept-3-en-5-yn-1-yl (S)-2-((tertButoxycarbonyl)amino)-3-((tert-butyldimethylsilyl)oxy)-3methylbutanoate (S1).

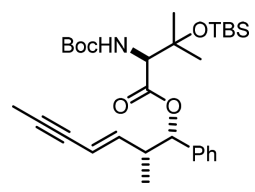

$\mathrm{N}$-Ethyl- $\mathrm{N}^{\prime}$-(dimethylamino-propyl)-carbodiimide hydrochloride $(143.6 \mathrm{mg}, 0.750 \mathrm{mmol})$ was added to a stirred solution of 6 (100 mg, $0.500 \mathrm{mmol}), 10(208 \mathrm{mg}, 0.600 \mathrm{mmol})$, and DMAP (12.2 mg, $0.100 \mathrm{mmol})$ in $\mathrm{CH}_{2} \mathrm{Cl}_{2}(0.66 \mathrm{~mL})$ at $0{ }^{\circ} \mathrm{C}$. After being stirred for $15 \mathrm{~min}$ at $0{ }^{\circ} \mathrm{C}$ and for $5 \mathrm{~h}$ at ambient temperature, the mixture was partitioned between EtOAc and saturated aqueous $\mathrm{NH}_{4} \mathrm{Cl}$. The aqueous layer was extracted with EtOAc $(3 \times 10 \mathrm{~mL})$ before it was acidified to $\mathrm{pH} 2$ with $\mathrm{HCl}(2 \mathrm{M})$ and extracted again with EtOAc $(3 \times 10 \mathrm{~mL})$. The combined organic layers were washed with brine $(20 \mathrm{~mL})$, dried over $\mathrm{Na}_{2} \mathrm{SO}_{4}$, filtered, and concentrated. The crude material was purified by flash chromatography on silica gel (hexanes/EtOAc, 10:1) to afford the title compound as a colorless oil (206 mg, 78\%): $[\alpha]_{\mathrm{D}}{ }^{20}=-17$ (c 1.0, $\mathrm{CHCl}_{3}$ ); ${ }^{1} \mathrm{H}$ NMR (400 MHz, $\mathrm{CDCl}_{3}$ ) $\delta=7.33-7.22(\mathrm{~m}, 5 \mathrm{H}), 5.79$ $(\mathrm{dd}, J=16.0,7.7 \mathrm{~Hz}, 1 \mathrm{H}), 5.62(\mathrm{~d}, J=7.7 \mathrm{~Hz}, 1 \mathrm{H}), 5.33$ (ddd, $J=16.0$, 2.4, $1.3 \mathrm{~Hz}, 1 \mathrm{H}), 5.26(\mathrm{~d}, J=9.5 \mathrm{~Hz}, 1 \mathrm{H}), 4.10(\mathrm{~d}, J=9.5 \mathrm{~Hz}, 1 \mathrm{H})$, $2.84-2.75(\mathrm{~m}, 1 \mathrm{H}), 1.87(\mathrm{~d}, J=2.4 \mathrm{~Hz}, 3 \mathrm{H}), 1.44(\mathrm{~s}, 9 \mathrm{H}), 1.25(\mathrm{~s}, 3 \mathrm{H})$, $1.17(\mathrm{~s}, 3 \mathrm{H}), 1.06(\mathrm{~d}, J=6.8 \mathrm{~Hz}, 3 \mathrm{H}), 0.77(\mathrm{~s}, 9 \mathrm{H}), 0.01(\mathrm{~s}, 3 \mathrm{H}),-0.12$ $(\mathrm{s}, 3 \mathrm{H}) \mathrm{ppm} ;{ }^{13} \mathrm{C} \mathrm{NMR}\left(101 \mathrm{MHz}, \mathrm{CDCl}_{3}\right) \delta=170.2,155.9,142.4$, $137.9,128.2,128.2,127.9,111.5,85.4,79.9,79.8,78.2,75.0,62.9,42.2$, 28.5, 28.4, 27.6, 25.8, 18.1, 16.2, 4.4, -2.2, -2.4 ppm; IR (film) $\nu=3453$, 
2930, 2956, 2857, 1802, 1720, $1495 \mathrm{~cm}^{-1}$; MS (ESI) $m / z 530\left[\mathrm{M}+\mathrm{H}^{+}\right]$, $547\left[\mathrm{M}+\mathrm{NH}_{4}^{+}\right], 552\left[\mathrm{M}+\mathrm{Na}^{+}\right]$; HRMS (ESI) $m / z$ calcd for $\mathrm{C}_{30} \mathrm{H}_{47} \mathrm{NO}_{5} \mathrm{SiNa}\left[\mathrm{M}+\mathrm{Na}^{+}\right] 552.3116$, found 552.3118 .

$(1 S, 2 R, E)$-2-Methyl-1-phenylhept-3-en-5-yn-1-yl (S)-2Amino-3-((tert-butyldimethylsilyl)oxy)-3-methylbutanoate (7). $\mathrm{HCl}$ (4 M in 1,4-dioxane, $7.5 \mathrm{~mL}, 30.0 \mathrm{mmol}$ ) was added to a solution of compound $\mathbf{S} 1(200 \mathrm{mg}, 0.370 \mathrm{mmol})$ in 1,4-dioxane $(3.8 \mathrm{~mL})$ at $0{ }^{\circ} \mathrm{C}$. The mixture was stirred at $0{ }^{\circ} \mathrm{C}$ for $15 \mathrm{~min}$ and then at room temperature for $5 \mathrm{~h}$. The reaction was quenched with saturated aqueous $\mathrm{Na}_{2} \mathrm{CO}_{3}$, and the aqueous layer was extracted with EtOAc $(3 \times 10 \mathrm{~mL})$. The combined extracts were washed with brine $(40 \mathrm{~mL})$, dried over $\mathrm{Na}_{2} \mathrm{SO}_{4}$, filtered, and concentrated. The residue was purified by flash chromatography on silica gel (hexanes/EtOAc, 4:1) to afford the title compound as a colorless oil (154 mg, 95\%): $[\alpha]_{\mathrm{D}}^{20}=-2.0($ c 2.2, $\mathrm{CHCl}_{3}$ ); ${ }^{1} \mathrm{H}$ NMR (400 MHz, $\mathrm{CDCl}_{3}$ ) $\delta=7.34-7.24$ (m, 5H), 5.81 $(\mathrm{ddd}, J=16.0,7.7,0.8 \mathrm{~Hz}, 1 \mathrm{H}), 5.63(\mathrm{~d}, J=7.4 \mathrm{~Hz}, 1 \mathrm{H}), 5.33(\mathrm{ddd}, J=$ 16.0, 2.3, $1.2 \mathrm{~Hz}, 1 \mathrm{H}), 3.36(\mathrm{~s}, 1 \mathrm{H}), 2.84-2.76(\mathrm{~m}, 1 \mathrm{H}), 1.94-1.83(\mathrm{~m}$, $3 \mathrm{H}), 1.64(\mathrm{~s}, 2 \mathrm{H}), 1.25(\mathrm{~s}, 3 \mathrm{H}), 1.09-1.04(\mathrm{~m}, 6 \mathrm{H}), 0.81(\mathrm{~s}, 9 \mathrm{H}), 0.06$ $(\mathrm{s}, 3 \mathrm{H}),-0.01(\mathrm{~s}, 3 \mathrm{H}) \mathrm{ppm} ;{ }^{13} \mathrm{C}$ NMR $\left(101 \mathrm{MHz}, \mathrm{CDCl}_{3}\right) \delta=172.6$, 142.4, 137.9, 128.3, 128.2, 127.8, 111.5, 85.6, 79.5, 78.1, 75.3, 65.1, 42.1, 28.2, 25.9, 25.5, 18.2, 16.2, 4.4, $-2.1,-2.1 \mathrm{ppm}$; IR (film) $\nu=3394$, $2929,2955,2856,1738,1687,1461 \mathrm{~cm}^{-1}$; MS (ESI) $\mathrm{m} / z 430\left[\mathrm{M}+\mathrm{H}^{+}\right]$; HRMS (ESI) $m / z$ calcd for $\mathrm{C}_{25} \mathrm{H}_{40} \mathrm{NO}_{3} \mathrm{Si}\left[\mathrm{M}+\mathrm{H}^{+}\right] 430.2772$, found 430.2772 .

tert-Butyl (R)-(1,3-Dihydroxy-3-methylbutan-2-yl)carbamate (9). ${ }^{27}$ A solution of $\mathrm{MeMgBr}$ in $\mathrm{Et}_{2} \mathrm{O}\left(3.0 \mathrm{M} \mathrm{in} \mathrm{Et}_{2} \mathrm{O}, 29.0 \mathrm{~mL}, 86.7 \mathrm{mmol}\right)$ was added dropwise to a solution of N-Boc-L-Ser-OMe (8) $(4.80 \mathrm{~g}$, $21.7 \mathrm{mmol})$ in $\mathrm{Et}_{2} \mathrm{O}(108 \mathrm{~mL})$ at $-78^{\circ} \mathrm{C}$. The mixture was allowed to reach room temperature and was stirred for $1 \mathrm{~h}$. After being cooled to $0{ }^{\circ} \mathrm{C}$, the reaction was quenched with saturated aqueous $\mathrm{NH}_{4} \mathrm{Cl}$. The aqueous phase was extracted with diethyl ether $(3 \times 25 \mathrm{~mL})$, and the combined organic layers were washed with brine, dried over $\mathrm{MgSO}_{4}$, filtered, and concentrated. The residue was purified by flash chromatography on silica gel (hexanes/EtOAc, 1:3) to afford the title compound as a white solid $(4.33 \mathrm{~g}, 91 \%):[\alpha]_{\mathrm{D}}{ }^{20}=-23\left(\mathrm{c} 1.1, \mathrm{CHCl}_{3}\right) ; \mathrm{mp}=63-64^{\circ} \mathrm{C}$; ${ }^{1} \mathrm{H}$ NMR $\left(300 \mathrm{MHz}, \mathrm{CDCl}_{3}\right) \delta=5.45(\mathrm{~d}, J=9.0 \mathrm{~Hz}, 1 \mathrm{H}), 3.98(\mathrm{dt}, J=$ $11.3,3.6 \mathrm{~Hz}, 1 \mathrm{H}), 3.84-3.71(\mathrm{~m}, 1 \mathrm{H}), 3.52-3.38(\mathrm{~m}, 1 \mathrm{H}), 3.27-3.18$ $(\mathrm{m}, 1 \mathrm{H}), 3.16(\mathrm{~s}, 1 \mathrm{H}), 1.43(\mathrm{~s}, 9 \mathrm{H}), 1.33(\mathrm{~s}, 3 \mathrm{H}), 1.22$ (s, 3H) ppm; ${ }^{13} \mathrm{C} \mathrm{NMR}\left(75 \mathrm{MHz}, \mathrm{CDCl}_{3}\right) \delta=156.6,79.7,73.9,63.5,57.8,28.5,27.7$, 27.4 ppm; IR (film) $\nu=3350,2977,2934,1684,1505 \mathrm{~cm}^{-1}$; MS (EI) $m / z 242\left[\mathrm{M}+\mathrm{Na}^{+}\right]$; HRMS (ESI) $m / z$ calcd for $\mathrm{C}_{10} \mathrm{H}_{21} \mathrm{NO}_{4} \mathrm{Na}$ $\left[\mathrm{M}+\mathrm{Na}^{+}\right] 242.1363$, found 242.1362 .

N-Boc-L-Val-OH (S2). ${ }^{27}$ Phosphate buffer (pH 6.7, $30 \mathrm{~mL}$ ), $\mathrm{PhI}(\mathrm{OAc})_{2}$ $(290 \mathrm{mg}, 0.900 \mathrm{mmol})$, and TEMPO $(142 \mathrm{mg}, 0.909 \mathrm{mmol})$ were added to a solution of alcohol $9(2.80 \mathrm{~g}, 12.6 \mathrm{mmol})$ in $\mathrm{MeCN}(36 \mathrm{~mL})$. The mixture was cooled to $0^{\circ} \mathrm{C}$ before sodium chlorite $(1.3 \mathrm{~g}, 15 \mathrm{mmol})$ was added. Stirring was continued at $0{ }^{\circ} \mathrm{C}$ for $2 \mathrm{~h}$ and at room temperature for $16 \mathrm{~h}$. The reaction was quenched with saturated aqueous $\mathrm{NH}_{4} \mathrm{Cl}$, and the aqueous layer was acidified to $\mathrm{pH} 2$ and extracted with EtOAc $(3 \times 25 \mathrm{~mL})$. The combined extracts were washed with brine, dried over $\mathrm{MgSO}_{4}$, filtered, and concentrated. The residue was recrystallized from EtOAc/hexanes to afford the title compound in the form of white crystals $(2.58 \mathrm{~g}, 88 \%):[\alpha]_{\mathrm{D}}{ }^{20}=-3.0\left(c 0.9, \mathrm{CHCl}_{3}\right) ; \mathrm{mp}=$ $123-124{ }^{\circ} \mathrm{C} ;{ }^{1} \mathrm{H}$ NMR $\left(300 \mathrm{MHz}, \mathrm{CDCl}_{3}\right) \delta=5.44(\mathrm{~s}, 1 \mathrm{H}), 4.25(\mathrm{~d}, J=$ $8.5 \mathrm{~Hz}, 1 \mathrm{H}), 1.46(\mathrm{~s}, 9 \mathrm{H}), 1.38(\mathrm{~s}, 3 \mathrm{H}), 1.29(\mathrm{~s}, 3 \mathrm{H}) \mathrm{ppm} ;{ }^{13} \mathrm{C}$ NMR $\left(126 \mathrm{MHz}, \mathrm{CDCl}_{3}\right) \delta=173.9,156.4,80.9,72.6,61.2,28.4,27.3,25.9$ ppm; IR (film) $\nu=3337,2979,2936,2583,1694,1508 \mathrm{~cm}^{-1}$; MS (ESI) $m / z 256\left[\mathrm{M}+\mathrm{Na}^{+}\right]$; HRMS (ESI) $m / z$ calcd for $\mathrm{C}_{10} \mathrm{H}_{19} \mathrm{NO}_{5} \mathrm{Na}$ $\left[\mathrm{M}+\mathrm{Na}^{+}\right] 256.1155$, found 256.1155.

$N$-Boc-L-Val-OTBS (10). $\mathrm{Et}_{3} \mathrm{~N}(1.40 \mathrm{~mL}, 10.0 \mathrm{mmol}), \mathrm{TBSCl}(1.10 \mathrm{~g}$, $7.30 \mathrm{mmol})$, and Verkade's base $11(146 \mathrm{mg}, 0.675 \mathrm{mmol})$ were added to a stirred solution of $\mathbf{S 2}(785 \mathrm{mg}, 3.37 \mathrm{mmol})$ in DMF $(3.0 \mathrm{~mL})$, and the resulting mixture was stirred at $80{ }^{\circ} \mathrm{C}$ for $48 \mathrm{~h}$. The reaction was quenched with $\mathrm{HCl}(2 \mathrm{M}, 10 \mathrm{~mL})$, and the aqueous layer was extracted with $\mathrm{EtOAc}(3 \times 5 \mathrm{~mL})$; the combined extracts were washed with brine $(1 \mathrm{~mL})$ and dried over $\mathrm{Na}_{2} \mathrm{SO}_{4}$. The solvent was evaporated, and the residue was purified by flash chromatography on silica gel (hexanes/ EtOAc, 5:1 to 3:1) to afford the title compound as a white solid $(830 \mathrm{mg}$, 71\%): $[\alpha]_{\mathrm{D}}{ }^{20}=+31\left(\mathrm{c} 1.5, \mathrm{CHCl}_{3}\right) ; \mathrm{mp}=93.6-94.9{ }^{\circ} \mathrm{C} ;{ }^{1} \mathrm{H}$ NMR $\left(400 \mathrm{MHz}, \mathrm{CDCl}_{3}\right) \delta=5.26(\mathrm{~d}, J=9.0 \mathrm{~Hz}, 1 \mathrm{H}), 4.18(\mathrm{~d}, J=9.0 \mathrm{~Hz}, 1 \mathrm{H})$, $1.44(\mathrm{~s}, 9 \mathrm{H}), 1.41(\mathrm{~s}, 3 \mathrm{H}), 1.28(\mathrm{~s}, 3 \mathrm{H}), 0.86(\mathrm{~s}, 9 \mathrm{H}), 0.13(\mathrm{~s}, 3 \mathrm{H}), 0.12$ $(\mathrm{s}, 3 \mathrm{H}) \mathrm{ppm} ;{ }^{13} \mathrm{C} \mathrm{NMR}\left(101 \mathrm{MHz}, \mathrm{CDCl}_{3}\right) \delta=174.8,156.0,80.2,76.2$, 62.5, 28.4, 27.7, 26.8, 25.8, 18.1, $-2.1,-2.2$ ppm; IR (film) $\nu=3453$, $3091,2928,2856,1717,1501,1473,1463 \mathrm{~cm}^{-1}$; MS (EI) $\mathrm{m} / z$ (\%) 173 (100), 190 (28), 234 (26); HRMS (ESI) $m / z$ calcd for $\mathrm{C}_{16} \mathrm{H}_{33} \mathrm{NO}_{5} \mathrm{SiNa}$ $\left[\mathrm{M}+\mathrm{Na}^{+}\right] 370.2020$, found 370.2023 .

1-(Trimethylsilyl)hex-5-en-1-yn-3-ol (13). ${ }^{29}$ A solution of allylmagnesium chloride ( $2 \mathrm{M}$ in THF, $27.4 \mathrm{~mL}, 54.8 \mathrm{mmol}$ ) was added over $30 \mathrm{~min}$ to a solution of $\mathbf{1 2}(6.02 \mathrm{~g}, 47.7 \mathrm{mmol})$ in THF $(95 \mathrm{~mL})$ at $0{ }^{\circ} \mathrm{C}$. After the addition was complete, the mixture was allowed to reach ambient temperature. After being stirred for another $2 \mathrm{~h}$, the reaction was quenched with saturated aqueous $\mathrm{NH}_{4} \mathrm{Cl}$. The aqueous layer was extracted with tert-butyl methyl ether $(3 \times 50 \mathrm{~mL})$, and the combined organic phases were washed with brine $(5 \mathrm{~mL})$, dried over $\mathrm{MgSO}_{4}$, filtered, and concentrated. The residue was purified by flash chromatography on silica gel (hexanes/tert-butyl methyl ether, 5:1) to afford the title compound as a colorless oil $(7.9 \mathrm{~g}, 98 \%):{ }^{1} \mathrm{H}$ NMR $(400 \mathrm{MHz}$, $\left.\mathrm{CDCl}_{3}\right) \delta=5.96-5.80(\mathrm{~m}, 1 \mathrm{H}), 5.24-5.17(\mathrm{~m}, 1 \mathrm{H}), 5.17(\mathrm{t}, J=1.2 \mathrm{~Hz}$, $1 \mathrm{H}), 4.41(\mathrm{q}, J=6.1 \mathrm{~Hz}, 1 \mathrm{H}), 2.47(\mathrm{ddq}, J=7.1,5.9,1.2 \mathrm{~Hz}, 2 \mathrm{H}), 1.91$ (dd, $J=6.1,1.2 \mathrm{~Hz}, 1 \mathrm{H}), 0.17(\mathrm{~s}, 9 \mathrm{H}) \mathrm{ppm} ;{ }^{13} \mathrm{C}$ NMR $(101 \mathrm{MHz}$, $\mathrm{CDCl}_{3}$ ) $\delta=133.1,119.2,106.0,90.0,62.1,42.2,0.0$ ppm; IR (film) $\nu=$ 3330, 3080, 2960, 2175, $1643 \mathrm{~cm}^{-1}$; MS (EI) $\mathrm{m} / z$ (\%) 75 (32), 83 (9), 99 (100), 127 (64); HRMS (ESI) $\mathrm{m} / z$ calcd for $\mathrm{C}_{9} \mathrm{H}_{16} \mathrm{OSiNa}\left[\mathrm{M}+\mathrm{Na}^{+}\right]$ 191.0863 , found 191.0863 .

(R)-1-(Trimethylsilyl)hex-5-en-1-yn-3-yl acetate (14) ${ }^{29}$. Method A: Molecular sieves (4 ̊̊, $500 \mathrm{mg}$ ), Amano lipase PS (395 mg), and vinyl acetate $(15.0 \mathrm{~mL}, 164 \mathrm{mmol})$ were added to a solution of compound 13 $(7.90 \mathrm{~g}, 47.0 \mathrm{mmol})$ in pentane $(313 \mathrm{~mL})$. The suspension was gently stirred for $56 \mathrm{~h}$ before it was filtered through a pad of Celite. The filtrate was evaporated, and the residue was purified by flash chromatography on silica gel (hexanes/ $\left.\mathrm{Et}_{2} \mathrm{O}, 10: 1\right)$ to afford the title compound as a colorless oil ( $4.65 \mathrm{~g}, 47 \%$, 99\% ee). [Conditions for GC analysis:

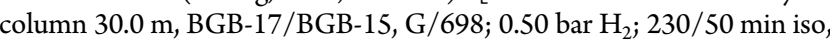
$804 / \mathrm{min} 220,5 / \mathrm{min}$ iso $350, t$ (minor) $=30.75 \mathrm{~min}, t$ (major) $=32.67 \mathrm{~min}$. $]$ Method B: Acetic acid $(1.9 \mathrm{~mL}, 32.6 \mathrm{mmol})$ and triphenylphosphine $(8.54 \mathrm{~g}, 32.6 \mathrm{mmol})$ were added to a solution of $(S)-13(3.73 \mathrm{~g}$, $21.7 \mathrm{mmol})$ in $\mathrm{Et}_{2} \mathrm{O}(109 \mathrm{~mL})$ at $0{ }^{\circ} \mathrm{C}$. After being stirred for 5 min at $0{ }^{\circ} \mathrm{C}$, diisopropylazodicarboxylate $(6.4 \mathrm{~mL}, 32.6 \mathrm{mmol})$ was added dropwise, and stirring was continued for $1.5 \mathrm{~h}$ at this temperature. The reaction was quenched with saturated aqueous $\mathrm{NaHCO}_{3}$, and the aqueous layer was extracted with tert-butyl methyl ether; the combined extracts were washed with brine, dried over $\mathrm{MgSO}_{4}$, and evaporated. The residue was purified by flash chromatography on silica gel (hexanes/ tert-butyl methyl ether, 20:1) to give the title compound as colorless oil (4.13 g, 91\%): $[\alpha]_{\mathrm{D}}{ }^{20}=+100\left(c 1.3, \mathrm{CHCl}_{3}\right) ;{ }^{1} \mathrm{H}$ NMR $(400 \mathrm{MHz}$, $\left.\mathrm{CDCl}_{3}\right) \delta=5.81(\mathrm{ddt}, J=17.3,10.3,7.0 \mathrm{~Hz}, 1 \mathrm{H}), 5.43(\mathrm{t}, J=6.5 \mathrm{~Hz}$, $1 \mathrm{H}), 5.18-5.14(\mathrm{~m}, 1 \mathrm{H}), 5.14-5.11(\mathrm{~m}, 1 \mathrm{H}), 2.51(\mathrm{td}, J=6.5,1.2 \mathrm{~Hz}$, $2 \mathrm{H}), 2.08(\mathrm{~s}, 3 \mathrm{H}), 0.17(\mathrm{~s}, 9 \mathrm{H}) \mathrm{ppm} ;{ }^{13} \mathrm{C} \mathrm{NMR}\left(101 \mathrm{MHz}, \mathrm{CDCl}_{3}\right) \delta=$ 170.0, 132.3, 118.9, 102.1, 91.0, 63.7, 39.5, 21.2, -0.1 ppm; IR (film) $\nu=$ 2961, $1746 \mathrm{~cm}^{-1}$; MS (EI) m/z (\%) 43 (100), 75 (45), 99 (20), 117 (17), 127 (11), 135 (16), 169 (35); HRMS (ESI) $\mathrm{m} / z$ calcd for $\mathrm{C}_{11} \mathrm{H}_{18} \mathrm{O}_{2} \mathrm{SiNa}\left[\mathrm{M}+\mathrm{Na}^{+}\right]$233.0968, found 233.0970.

(S)-1-(Trimethylsilyl)hex-5-en-1-yn-3-ol ((S)-13)). ${ }^{29}$ The compound was obtained as the second fraction from the enzymatic resolution described above: colorless oil (3.73 g, 47\%, 99\% ee). [Conditions for GC analysis: column $24.5 \mathrm{~m}$, hydrodex-beta-TBDAC; G/589; $0.80 \mathrm{bar} \mathrm{H}_{2} ; 220 / 10 \mathrm{~min}$ iso, $1056 / \mathrm{min} 220,5 \mathrm{~min}$ iso $/ 350, t$ (minor) $=$ $3.57 \mathrm{~min}, t$ (major) $=3.73 \mathrm{~min}]:[\alpha]_{\mathrm{D}}{ }^{20}=-29\left(c 1.1, \mathrm{CHCl}_{3}\right) ;{ }^{1} \mathrm{H} \mathrm{NMR}$ $\left(400 \mathrm{MHz}, \mathrm{CDCl}_{3}\right) \delta=5.96-5.80(\mathrm{~m}, 1 \mathrm{H}), 5.24-5.17(\mathrm{~m}, 1 \mathrm{H}), 5.17(\mathrm{t}$, $J=1.2 \mathrm{~Hz}, 1 \mathrm{H}), 4.41(\mathrm{q}, J=6.1 \mathrm{~Hz}, 1 \mathrm{H}), 2.47(\mathrm{ddq}, J=7.1,5.9,1.2 \mathrm{~Hz}$, $2 \mathrm{H}), 1.91(\mathrm{dd}, J=6.1,1.2 \mathrm{~Hz}, 1 \mathrm{H}), 0.17(\mathrm{~s}, 9 \mathrm{H}) \mathrm{ppm} ;{ }^{13} \mathrm{C}$ NMR $\left(101 \mathrm{MHz}, \mathrm{CDCl}_{3}\right) \delta=133.1,119.2,106.0,90.0,62.1,42.2,0.0$ ppm; IR (film) $\nu=3330,3080,2960,2175,1643, \mathrm{~cm}^{-1}$; MS (EI) $\mathrm{m} / z$ (\%) 75 (32), 99 (100), 127 (64); HRMS (ESI) $m / z$ calcd for $\mathrm{C}_{9} \mathrm{H}_{16} \mathrm{OSiNa}$ $\left[\mathrm{M}+\mathrm{Na}^{+}\right]$191.0863, found 191.0863.

Ethyl $(R, E)$-5-Acetoxy-2-methyl-7-(trimethylsilyl)hept-2-en-6ynoate (15). A solution of $14(2.0 \mathrm{~g}, 9.5 \mathrm{mmol})$ and Sudan red III $(5.0 \mathrm{mg}, 14 \mu \mathrm{mol})$ in $\mathrm{CH}_{2} \mathrm{Cl}_{2}(38 \mathrm{~mL})$ was cooled to $-78^{\circ} \mathrm{C}$. Ozone gas was bubbled through the red solution at $-78{ }^{\circ} \mathrm{C}$ until the color faded away. At this point, excess ozone was removed by bubbling argon 
through the solution for $15 \mathrm{~min}$. Triphenylphosphine $(2.90 \mathrm{~g}, 11.4 \mathrm{mmol})$ was then added. After being stirred at $-78{ }^{\circ} \mathrm{C}$ for $5 \mathrm{~min}$, the mixture was warmed to room temperature and stirring was continued for $3 \mathrm{~h}$. The mixture was then cooled to $0{ }^{\circ} \mathrm{C}$ before a solution of (1-ethoxycarbonylethylidene)triphenylphosphorane $(4.82 \mathrm{~g}, 13.3 \mathrm{mmol})$ in $\mathrm{CH}_{2} \mathrm{Cl}_{2}(19 \mathrm{~mL})$ was added over $30 \mathrm{~min}$. After being stirred for $3 \mathrm{~h}$ at ambient temperature, the solvent was evaporated and the residue was purified by flash chromatography on silica gel (hexanes/EtOAc, 10:1) to afford the title compound as a colorless oil (2.01 g, E:Z > 95:5, 71\%): $[\alpha]_{\mathrm{D}}{ }^{20}=+53\left(c 1.1, \mathrm{CHCl}_{3}\right) ;{ }^{1} \mathrm{H} \mathrm{NMR}\left(400 \mathrm{MHz}, \mathrm{CDCl}_{3}\right) \delta=6.78(\mathrm{tq}$, $J=7.3,1.4 \mathrm{~Hz}, 1 \mathrm{H}), 5.47(\mathrm{t}, J=6.3 \mathrm{~Hz}, 1 \mathrm{H}), 4.20(\mathrm{q}, J=7.3 \mathrm{~Hz}, 2 \mathrm{H})$, $2.65(\mathrm{ddt}, J=7.3,6.3,0.9 \mathrm{~Hz}, 2 \mathrm{H}), 2.09(\mathrm{~s}, 3 \mathrm{H}), 1.87(\mathrm{dq}, J=1.6,0.9 \mathrm{~Hz}$, $3 \mathrm{H}), 1.30(\mathrm{t}, J=7.3 \mathrm{~Hz}, 3 \mathrm{H}), 0.17(\mathrm{~s}, 9 \mathrm{H}) \mathrm{ppm} ;{ }^{13} \mathrm{C}$ NMR $(101 \mathrm{MHz}$, $\left.\mathrm{CDCl}_{3}\right) \delta=169.9,167.8,134.9,131.3,101.7,91.6,63.1,60.8,34.3,21.2$, 14.4, 12.9, -0.2 ppm; IR (film) $\nu=2962,1748,1713 \mathrm{~cm}^{-1}$; MS (EI) $\mathrm{m} / z$ (\%) 43 (100), 73 (61), 75 (59), 100 (26), 117 (12); HRMS (ESI) $m / z$ calcd for $\mathrm{C}_{15} \mathrm{H}_{24} \mathrm{O}_{4} \mathrm{SiNa}\left[\mathrm{M}+\mathrm{Na}^{+}\right]$319.1336, found 319.1335.

$(R, E)$-5-Hydroxy-2-methylhept-2-en-6-ynoic Acid (S3).

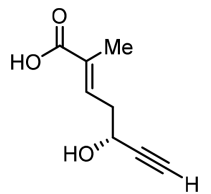

Lithium hydroxide $(477 \mathrm{mg}, 19.9 \mathrm{mmol})$ was added in portions to a solution of compound $15(1.97 \mathrm{~g}, 6.6 \mathrm{mmol})$ in $\mathrm{THF} / \mathrm{H}_{2} \mathrm{O}(66 \mathrm{~mL}$, $1: 1$ ). The mixture was stirred for $16 \mathrm{~h}$ before it was acidified to $\mathrm{pH} 2$ by addition of $\mathrm{HCl}(2 \mathrm{M})$. The aqueous layers were extracted with EtOAc $(3 \times 25 \mathrm{~mL})$, and the combined extracts were washed with brine $(60 \mathrm{~mL})$, dried over $\mathrm{MgSO}_{4}$, filtered, and concentrated. The crude material was purified by flash chromatography on silica gel (hexanes/ EtOAc, 1:1) to afford the title compound as a colorless oil (1.01 g, 99\%): $[\alpha]_{\mathrm{D}}{ }^{20}=+19\left(\mathrm{c} 1.4, \mathrm{CHCl}_{3}\right) ;{ }^{1} \mathrm{H} \mathrm{NMR}\left(400 \mathrm{MHz}, \mathrm{CDCl}_{3}\right) \delta=10.18$ $(\mathrm{br}, 1 \mathrm{H}), 7.00(\mathrm{td}, J=7.3,1.5 \mathrm{~Hz}, 1 \mathrm{H}), 4.54(\mathrm{td}, J=6.3,2.1 \mathrm{~Hz}, 1 \mathrm{H}), 2.66$ (ddt, $J=7.3,6.3,1.0 \mathrm{~Hz}, 2 \mathrm{H}), 2.52(\mathrm{~d}, J=2.1 \mathrm{~Hz}, 1 \mathrm{H}), 1.88(\mathrm{q}, J=$ $1.0 \mathrm{~Hz}, 3 \mathrm{H}) \mathrm{ppm} ;{ }^{13} \mathrm{C}$ NMR $\left(101 \mathrm{MHz}, \mathrm{CDCl}_{3}\right) \delta=173.1,138.6,130.3$, 83.8, 74.0, 61.1, 37.1, 12.6 ppm; IR (film) $\nu=3293,1688,1646$, $1421 \mathrm{~cm}^{-1}$; MS (ESI) $\mathrm{m} / z 153\left[\mathrm{M}-\mathrm{H}^{+}\right]$; HRMS $\left(\mathrm{ESI}^{-}\right) \mathrm{m} / z$ calcd for $\mathrm{C}_{8} \mathrm{H}_{9} \mathrm{O}_{3}\left[\mathrm{M}-\mathrm{H}^{-}\right]$153.0557, found 153.0558.

$(R, E)$-5-((tert-Butyldimethylsilyl)oxy)-2-methylhept-2-en-6ynoic Acid (16). Imidazole (1.47 g, $21.6 \mathrm{mmol})$ and tertbutyldimethylsilyl chloride $(3.12 \mathrm{~g}, 20.7 \mathrm{mmol})$ were added to a solution of S3 (1.45 g, $9.4 \mathrm{mmol})$ in DMF $(38 \mathrm{~mL})$. The mixture was stirred for $8 \mathrm{~h}$ before it was partitioned between water $(50 \mathrm{~mL})$ and EtOAc $(20 \mathrm{~mL})$. The aqueous layer was extracted with EtOAc $(3 \times$ $15 \mathrm{~mL}$ ), and the combined organic phases were washed with brine $(60 \mathrm{~mL})$, dried over $\mathrm{Na}_{2} \mathrm{SO}_{4}$, filtered, and concentrated.

The residue was dissolved in $\mathrm{THF} / \mathrm{MeOH} / \mathrm{H}_{2} \mathrm{O}(117 \mathrm{~mL}, 2: 2: 1)$ and the solution cooled to $0{ }^{\circ} \mathrm{C}$. Potassium carbonate $(1.95 \mathrm{~g}, 14.1 \mathrm{mmol})$ was added and the mixture stirred at $0{ }^{\circ} \mathrm{C}$ for $10 \mathrm{~min}$ and for $20 \mathrm{~min}$ at room temperature. The mixture was partitioned between water $(50 \mathrm{~mL})$ and $\mathrm{CH}_{2} \mathrm{Cl}_{2}(50 \mathrm{~mL})$. The aqueous layer was extracted with $\mathrm{CH}_{2} \mathrm{Cl}_{2}$ $(3 \times 50 \mathrm{~mL})$, and the combined organic phases were washed with brine $(100 \mathrm{~mL})$, dried over $\mathrm{Na}_{2} \mathrm{SO}_{4}$, filtered, and concentrated. The crude material was purified by flash chromatography on silica gel (hexanes/ EtOAc, 5:1) to afford the title compound as a colorless oil (2.18 g, 87\%): $[\alpha]_{\mathrm{D}}{ }^{20}=+36\left(c 1.07, \mathrm{CHCl}_{3}\right) ;{ }^{1} \mathrm{H}$ NMR $\left(400 \mathrm{MHz}, \mathrm{CDCl}_{3}\right) \delta=10.92$ $(\mathrm{br}, 1 \mathrm{H}), 6.97(\mathrm{td}, J=7.4,1.5 \mathrm{~Hz}, 1 \mathrm{H}), 4.47(\mathrm{td}, J=6.3,2.1 \mathrm{~Hz}, 1 \mathrm{H}), 2.60$ (dddd, $J=7.4,6.3,2.4,1.1 \mathrm{~Hz}, 2 \mathrm{H}), 2.42(\mathrm{~d}, J=2.1 \mathrm{~Hz}, 1 \mathrm{H}), 1.87(\mathrm{q}, J=$ $1.1 \mathrm{~Hz}, 3 \mathrm{H}), 0.90(\mathrm{~s}, 9 \mathrm{H}), 0.14(\mathrm{~s}, 3 \mathrm{H}), 0.11(\mathrm{~s}, 3 \mathrm{H}) \mathrm{ppm} ;{ }^{13} \mathrm{C}$ NMR $\left(101 \mathrm{MHz}, \mathrm{CDCl}_{3}\right) \delta=173.5,139.7,129.5,84.7,72.9,61.7,38.3,25.8$, $18.3,12.5,-4.5,-5.0 \mathrm{ppm}$; IR (film) $\nu=3309,2930,2956,2858,2887$, 2663, 1690, $1648 \mathrm{~cm}^{-1}$; MS (EI) $\mathrm{m} / z$ (\%) 75 (100), 83 (13), 91 (11), 129 (47); HRMS $\left(\mathrm{ESI}^{-}\right) \mathrm{m} / z$ calcd for $\mathrm{C}_{14} \mathrm{H}_{23} \mathrm{O}_{3} \mathrm{Si}\left[\mathrm{M}-\mathrm{H}^{-}\right]$267.1422, found 267.1424 .

3,5-Dichloro-L-tyrosine Methyl Ester Hydrochloride $(19 \cdot \mathrm{HCl})^{34,35}$. Sulfuryl chloride $(38.0 \mathrm{~mL}, 380 \mathrm{mmol})$ was added to a suspension of D-tyrosine $(2.75 \mathrm{~g}, 15.2 \mathrm{mmol})$ in glacial acetic acid $(15.2 \mathrm{~mL}$, $15.2 \mathrm{mmol}$ ) at room temperature. The resulting suspension was stirred for $24 \mathrm{~h}$ before the mixture was concentrated to afford 3,5-dichloro-DTyr-OH hydrochloride salt as a white solid.

Hydrochloric acid ( $36 \% w / w, 3.8 \mathrm{~mL}, 45.5 \mathrm{mmol})$ was added dropwise to a suspension of this salt in 2,2-dimethoxypropane $(43.0 \mathrm{~mL}$, $104 \mathrm{mmol}$ ) at room temperature. The resulting dark brown solution was stirred for 3 days. The mixture was then concentrated to dryness, and the residue was dissolved in a minimum amount of $\mathrm{MeOH}$ and crystallized from diethyl ether to afford the title compound as a light pink solid $(3.40 \mathrm{~g}, 75 \%):[\alpha]_{\mathrm{D}}{ }^{20}=-9.0(c 1.25, \mathrm{MeOH}) ; \mathrm{mp}=137-138{ }^{\circ} \mathrm{C}$; ${ }^{1} \mathrm{H}$ NMR $\left(300 \mathrm{MHz}, \mathrm{MeOH}-d_{4}\right) \delta=7.21(\mathrm{~s}, 2 \mathrm{H}), 4.30(\mathrm{dd}, J=7.6$, $6.0 \mathrm{~Hz}, 2 \mathrm{H}), 3.83(\mathrm{~s}, 3 \mathrm{H}), 3.18(\mathrm{dd}, J=14.6,6.0 \mathrm{~Hz}, 1 \mathrm{H}), 3.04(\mathrm{dd}, J=$ 14.6, 7.6 Hz, 1H) ppm; ${ }^{13} \mathrm{C}$ NMR $\left(126 \mathrm{MHz}, \mathrm{MeOH}-d_{4}\right) \delta=170.2$, $150.5,130.5,127.8,123.8,54.9,53.7,35.9$ ppm; IR (film) $\nu=3190$, $2956,1744,1570,1489,1444,1417 \mathrm{~cm}^{-1}$; MS (ESI) $m / z 264\left[\mathrm{M}+\mathrm{H}^{+}\right]$; HRMS (ESI) $m / z$ calcd for $\mathrm{C}_{10} \mathrm{H}_{12} \mathrm{NO}_{3} \mathrm{Cl}_{2}[\mathrm{M}]^{+}$264.0189, found 264.0189.

$\mathrm{N}$-Boc-Ile-3,5-dichloro-Tyr-OMe (21). $\mathrm{Et}_{3} \mathrm{~N}$ (1.3 mL, $\left.9.8 \mathrm{mmol}\right)$ and $\mathrm{N}$-hydroxybenzotriazole $(1.40 \mathrm{~g}, 10.6 \mathrm{mmol})$ were added to a solution of $20(2.0 \mathrm{~g}, 8.2 \mathrm{mmol})$ and $19 \cdot \mathrm{HCl}(2.7 \mathrm{~g}, 9.0 \mathrm{mmol})$ in THF $(45 \mathrm{~mL})$ at $0{ }^{\circ} \mathrm{C}$. After being stirred for $5 \mathrm{~min}$ at $0{ }^{\circ} \mathrm{C}, N, N^{\prime}$-dicyclohexylcarbodiimide $(2.20 \mathrm{~g}, 10.6 \mathrm{mmol})$ was introduced and the resulting mixture stirred for $1 \mathrm{~h} \mathrm{at} 0{ }^{\circ} \mathrm{C}$ and for $3 \mathrm{~h}$ at room temperature. The mixture was diluted with ethyl acetate, and the precipitated dicyclohexylurea was filtered off. The filtrate was washed with saturated aqueous $\mathrm{NaHCO}_{3}(30 \mathrm{~mL})$, water $(30 \mathrm{~mL})$, and brine $(30 \mathrm{~mL})$ before it was dried over $\mathrm{MgSO}_{4}$, filtered, and concentrated. The residue was purified by flash chromatography on silica gel (hexane/EtOAc, 3:1) to afford the title compound as a white solid $(3.14 \mathrm{~g}, 78 \%):[\alpha]_{\mathrm{D}}{ }^{20}=-84$ $\left(c 1.03, \mathrm{CHCl}_{3}\right) ; \mathrm{mp}=120-121{ }^{\circ} \mathrm{C} ;{ }^{1} \mathrm{H} \mathrm{NMR}\left(400 \mathrm{MHz}, \mathrm{CDCl}_{3}\right) \delta=$ $7.02(\mathrm{~s}, 2 \mathrm{H}), 6.81(\mathrm{~d}, J=8.2 \mathrm{~Hz}, 1 \mathrm{H}), 6.25(\mathrm{~s}, 1 \mathrm{H}), 4.74(\mathrm{q}, J=7.0 \mathrm{~Hz}$, $1 \mathrm{H}), 4.11(\mathrm{~d}, J=11.3 \mathrm{~Hz}, 1 \mathrm{H}), 3.69(\mathrm{~s}, 3 \mathrm{H}), 3.04(\mathrm{dd}, J=14.0,5.3 \mathrm{~Hz}$, $1 \mathrm{H}), 2.90(\mathrm{dd}, J=14.0,7.4 \mathrm{~Hz}, 1 \mathrm{H}), 2.72(\mathrm{~s}, 3 \mathrm{H}), 2.11-1.95(\mathrm{~m}, 1 \mathrm{H})$ $1.42(\mathrm{~s}, 9 \mathrm{H}), 1.44-1.33(\mathrm{~m}, 1 \mathrm{H}), 1.08-0.94(\mathrm{~m}, 1 \mathrm{H}), 0.86(\mathrm{t}, J=7.4 \mathrm{~Hz}$, $3 \mathrm{H}), 0.81(\mathrm{~d}, J=6.5 \mathrm{~Hz}, 3 \mathrm{H}) \mathrm{ppm} ;{ }^{13} \mathrm{C}$ NMR $\left(101 \mathrm{MHz}, \mathrm{CDCl}_{3}\right) \delta=$ $171.2,170.7,157.3,147.2,129.7,129.1,121.3,80.6,63.0,53.0,52.5$, $36.8,31.5,30.4,28.4,28.4,24.6,15.8,10.6$ ppm; IR (film) $\nu=3342$, 2966, 2933, 2877, 1743, $1666 \mathrm{~cm}^{-1}$; MS (EI) $\mathrm{m} / z 491\left[\mathrm{M}+\mathrm{H}^{+}\right] ; 513$ $\left[\mathrm{M}+\mathrm{Na}^{+}\right]$; HRMS (ESI) $m / z$ calcd for $\mathrm{C}_{22} \mathrm{H}_{32} \mathrm{~N}_{2} \mathrm{O}_{6} \mathrm{Cl}_{2} \mathrm{Na}\left[\mathrm{M}+\mathrm{Na}^{+}\right]$ 513.1530 , found 513.1536 .

(R)-2-((2S,3S)-2-((tert-Butoxycarbonyl)(methyl)amino)-3methylpentanamido $)-3-(3,5-d i c h l o r o-4-(2-0 \times 0-2-$ phenylethoxy)phenyl)propanoic Acid (S4).

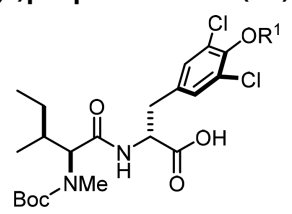

To a stirred solution of compound 21 (4.02 g, $8.19 \mathrm{mmol})$ and $\alpha$-bromoacetophenone $(3.26 \mathrm{~g}, 16.4 \mathrm{mmol})$ in acetone $(16.4 \mathrm{~mL})$ were added $\mathrm{KI}(2.72 \mathrm{~g}, 16.4 \mathrm{mmol})$ and $\mathrm{K}_{2} \mathrm{CO}_{3}(2.26 \mathrm{~g}, 16.4 \mathrm{mmol})$. The mixture was stirred at $40{ }^{\circ} \mathrm{C}$ for $12 \mathrm{~h}$. After ambient temperature was reached, the mixture was diluted with water, the aqueous layer was extracted with EtOAc $(3 \times 50 \mathrm{~mL})$, and the combined organic phases were washed with brine $(5 \mathrm{~mL})$ and dried over $\mathrm{Na}_{2} \mathrm{SO}_{4}$. The solvent was evaporated, and the residue was purified by flash chromatography on silica gel (EtOAc/hexanes, 3:1 to 1:1) to provide the desired compound 22 as a yellow solid.

The product was dissolved in THF $(40 \mathrm{~mL})$ and $\mathrm{H}_{2} \mathrm{O}(40 \mathrm{~mL})$. $\mathrm{LiOH}$ (391 mg, $16.4 \mathrm{mmol}$ ) was added at $0{ }^{\circ} \mathrm{C}$, and the solution was stirred at ambient temperature for $24 \mathrm{~h}$. The mixture was acidified to $\mathrm{pH} 2$ by addition of $\mathrm{HCl}(2 \mathrm{M})$. The aqueous layer was extracted with EtOAc $(3 \times 100 \mathrm{~mL})$, and the combined organic phases were washed with brine $(10 \mathrm{~mL})$, dried over $\mathrm{MgSO}_{4}$, filtered, and concentrated. The residue was purified by flash chromatography on silica gel (hexanes/EtOAc, 2:1 to $1: 1)$ to afford the title compound as a yellow oil $(2.82 \mathrm{~g}, 58 \%):[\alpha]_{\mathrm{D}}{ }^{20}=$ -25.8 (c 1.0, MeOH); ${ }^{1} \mathrm{H}$ NMR $\left(400 \mathrm{MHz}, \mathrm{MeOH}-d_{4}\right) \delta=8.04-7.98$ $(\mathrm{m}, 2 \mathrm{H}), 7.69-7.63(\mathrm{~m}, 1 \mathrm{H}), 7.56-7.50(\mathrm{~m}, 2 \mathrm{H}), 7.32(\mathrm{~s}, 2 \mathrm{H}), 5.32(\mathrm{~d}$, $J=2.9 \mathrm{~Hz}, 2 \mathrm{H}), 4.69(\mathrm{~s}, 1 \mathrm{H}), 4.19-4.04(\mathrm{~m}, 1 \mathrm{H}), 3.24(\mathrm{dd}, J=14.0,4.6$ $\mathrm{Hz}, 1 \mathrm{H}), 3.02-2.88(\mathrm{~m}, 1 \mathrm{H}), 2.77(\mathrm{~s}, 3 \mathrm{H}), 1.99-1.88(\mathrm{~m}, 1 \mathrm{H}), 1.46$ 
(s, 9H), 1.40-1.30 (m, 2H), 1.08-0.95 (m, 1H), $0.88(\mathrm{t}, J=7.4 \mathrm{~Hz}$, $3 \mathrm{H}), 0.69(\mathrm{~d}, J=6.5 \mathrm{~Hz}, 3 \mathrm{H}) \mathrm{ppm} ;{ }^{13} \mathrm{C} \mathrm{NMR}\left(101 \mathrm{MHz}, \mathrm{MeOH}-d_{4}\right) \delta=$ $195.2,172.2$, 150.7, 137.6, 135.7, 135.1, 131.2, 130.0, 130.0, 129.2, 81.6, 75.9, 63.6, 37.1, 33.2, 30.5, 28.6, 25.6, 15.9, 10.7 ppm; IR (film) $\nu=3066$, 2968, 2932, 2878, 1449, $1446 \mathrm{~cm}^{-1}$; MS (ESI) $\mathrm{m} / z 593\left[\mathrm{M}-\mathrm{H}^{-}\right]$; HRMS (ESI) $m / z$ calcd for $\mathrm{C}_{29} \mathrm{H}_{35} \mathrm{~N}_{2} \mathrm{O}_{7} \mathrm{Cl}_{2} \mathrm{Na}\left[\mathrm{M}-\mathrm{H}^{-}\right]$593.1827, found 593.1828 .

Compound 23. $N$-Hydroxybenzotriazole $(236 \mathrm{mg}, 1.75 \mathrm{mmol})$ was added to a solution of amine $7(500 \mathrm{mg}, 1.16 \mathrm{mmol})$ and acid S4 ( $830 \mathrm{mg}, 1.40 \mathrm{mmol})$ in $\mathrm{CH}_{2} \mathrm{Cl}_{2}(5.8 \mathrm{~mL})$ at $0{ }^{\circ} \mathrm{C}$. After being stirred for $5 \mathrm{~min}$ at $0^{\circ} \mathrm{C}, \mathrm{N}, \mathrm{N}^{\prime}$-dicyclohexylcarbodiimide $(360 \mathrm{mg}, 1.75 \mathrm{mmol})$ was introduced. The mixture was stirred for $1 \mathrm{~h}$ at $0{ }^{\circ} \mathrm{C}$ and for $2 \mathrm{~h}$ at ambient temperature before ethyl acetate $(100 \mathrm{~mL})$ was added. The precipitate was filtered off, and the filtrate was washed with saturated aqueous $\mathrm{NaHCO}_{3}(10 \mathrm{~mL})$, water $(10 \mathrm{~mL})$, and brine $(10 \mathrm{~mL})$, dried over $\mathrm{MgSO}_{4}$, filtered, and concentrated. The crude product was purified by flash chromatography on silica gel (hexanes/EtOAc, 5:1) to afford the title compound as a white solid $(945 \mathrm{mg}, 81 \%):[\alpha]_{\mathrm{D}}{ }^{20}=-50.8(c 0.8$, $\left.\mathrm{CHCl}_{3}\right) ; \mathrm{mp}=60.9-61.5{ }^{\circ} \mathrm{C}$; ${ }^{1} \mathrm{H}$ NMR $\left(400 \mathrm{MHz}, \mathrm{MeOH}-d_{4}\right) \delta=$ 8.03-7.99 (m, 2H), 7.68-7.63 (m, 1H), 7.55-7.50 (m, 2H), $7.36(\mathrm{~s}$, $2 \mathrm{H}), 7.34-7.25(\mathrm{~m}, 5 \mathrm{H}), 5.69(\mathrm{dd}, J=15.9,7.9 \mathrm{~Hz}, 1 \mathrm{H}), 5.56(\mathrm{~d}, J=$ $8.0 \mathrm{~Hz}, 1 \mathrm{H}), 5.35-5.26(\mathrm{~m}, 3 \mathrm{H}), 4.81-4.74(\mathrm{~m}, 1 \mathrm{H}), 4.44(\mathrm{~s}, 1 \mathrm{H})$, 4.24-4.09 (m, 1H), $3.14(\mathrm{dd}, J=13.9,5.9 \mathrm{~Hz}, 1 \mathrm{H}), 2.92-2.79(\mathrm{~m}, 2 \mathrm{H})$, $2.81(\mathrm{~s}, 3 \mathrm{H}), 2.02-1.90(\mathrm{~m}, 1 \mathrm{H}), 1.82(\mathrm{~d}, J=2.2 \mathrm{~Hz}, 3 \mathrm{H}), 1.48(\mathrm{~s}, 9 \mathrm{H})$, $1.37-1.28(\mathrm{~m}, 1 \mathrm{H}), 1.18(\mathrm{~s}, 6 \mathrm{H}), 1.04(\mathrm{~d}, J=6.7 \mathrm{~Hz}, 3 \mathrm{H}), 0.92-0.82$ $(\mathrm{m}, 4 \mathrm{H}), 0.74(\mathrm{~s}, 9 \mathrm{H}), 0.70-0.61(\mathrm{~m}, 3 \mathrm{H}), 0.01(\mathrm{~s}, 3 \mathrm{H}),-0.07(\mathrm{~s}, 3 \mathrm{H})$ ppm; ${ }^{13} \mathrm{C}$ NMR $\left(101 \mathrm{MHz}, \mathrm{MeOH}-d_{4}\right) \delta=195.0,172.5,172.3,170.2$, $158.1,150.8,143.1,139.2,137.5,135.7,135.1,131.3,130.1,130.0,129.3$, $129.2,129.2,129.1,113.0,86.0,81.5,78.8,75.9,63.4,62.9,55.2,43.3$, 37.3, 33.7, 30.7, 28.8, 28.2, 28.1, 27.2, 26.4, 25.5, 18.8, 16.8, 15.9, 10.8, $3.8,-1.9,-2.0 \mathrm{ppm}$; IR (film) $\nu=2965,2931,2857,1745,1680 \mathrm{~cm}^{-1}$; MS (ESI) $m / z 1006\left[\mathrm{M}+\mathrm{H}^{+}\right], 1023\left[\mathrm{M}+\mathrm{Na}^{+}\right]$; HRMS (ESI) $m / z$ calcd for $\mathrm{C}_{54} \mathrm{H}_{73} \mathrm{~N}_{3} \mathrm{O}_{9} \mathrm{Cl}_{2} \mathrm{SiNa}\left[\mathrm{M}+\mathrm{Na}^{+}\right]$1028.4385, found 1028.4392 . Compound S5.

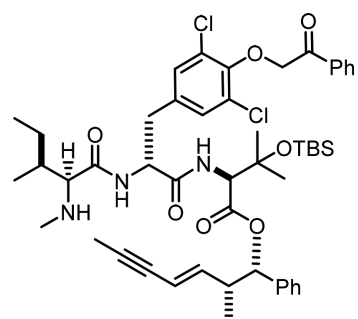

TBSOTf (1.3 mL, $5.69 \mathrm{mmol})$ was added dropwise to a stirred solution of $23(603 \mathrm{mg}, 0.599 \mathrm{mmol})$ and 2,6-lutidine $(700 \mu \mathrm{L}, 6.00 \mathrm{mmol})$ in $\mathrm{CH}_{2} \mathrm{Cl}_{2}(6.0 \mathrm{~mL})$ at $0{ }^{\circ} \mathrm{C}$. The resulting mixture was stirred for $5 \mathrm{~h}$ at room temperature before the reaction was quenched with saturated aqueous $\mathrm{NH}_{4} \mathrm{Cl}(5 \mathrm{~mL})$. The aqueous layer was extracted with EtOAc $(3 \times 50 \mathrm{~mL})$, and the combined extracts were washed with brine $(20 \mathrm{~mL})$, dried over $\mathrm{MgSO}_{4}$, filtered and concentrated.

A solution of tetrabutylammonium fluoride $(1 \mathrm{M}$ in THF, $1.1 \mathrm{~mL}$, $1.1 \mathrm{mmol})$ was added to a solution of the residue in THF $(28 \mathrm{~mL})$ at $0{ }^{\circ} \mathrm{C}$. The mixture was stirred for 5 min before saturated aqueous $\mathrm{NaHCO}_{3}$ $(5 \mathrm{~mL})$ was introduced. The aqueous layer was extracted with EtOAc $(3 \times 50 \mathrm{~mL})$, and the combined organic phases were washed with brine $(10 \mathrm{~mL})$, dried over $\mathrm{MgSO}_{4}$, filtered, and concentrated. The crude material was purified by flash chromatography on silica gel $\left(\mathrm{CH}_{2} \mathrm{Cl}_{2} /\right.$ tert-butyl methyl ether, 10:1 to 4:1) to afford the title compound as a colorless oil (543 mg, quant.): $[\alpha]_{\mathrm{D}}{ }^{20}=-3.4(c 1.2, \mathrm{MeOH}) ;{ }^{1} \mathrm{H} \mathrm{NMR}$ $\left(400 \mathrm{MHz}, \mathrm{MeOH}-d_{4}\right) \delta=8.03-7.98(\mathrm{~m}, 2 \mathrm{H}), 7.69-7.63(\mathrm{~m}, 1 \mathrm{H})$, 7.57-7.50 (m, 2H), 7.39 (s, 2H), 7.35-7.23 (m, 5H), 5.73-5.65 $(\mathrm{m}, 1 \mathrm{H}), 5.58(\mathrm{~d}, J=7.7 \mathrm{~Hz}, 1 \mathrm{H}), 5.35-5.27(\mathrm{~m}, 3 \mathrm{H}), 4.86-4.83(\mathrm{~m}$, $1 \mathrm{H}), 4.45(\mathrm{~s}, 1 \mathrm{H}), 3.14(\mathrm{dd}, J=14.0,6.0 \mathrm{~Hz}, 1 \mathrm{H}), 2.91(\mathrm{dd}, J=14.0$, $9.5 \mathrm{~Hz}, 1 \mathrm{H}), 2.84-2.76(\mathrm{~m}, 2 \mathrm{H}), 2.23(\mathrm{~s}, 3 \mathrm{H}), 1.83(\mathrm{~d}, J=2.3 \mathrm{~Hz}, 3 \mathrm{H})$, $1.60-1.53(\mathrm{~m}, 1 \mathrm{H}), 1.48-1.40(\mathrm{~m}, 1 \mathrm{H}), 1.19(\mathrm{~s}, 6 \mathrm{H}), 1.07-1.01(\mathrm{~m}$, $1 \mathrm{H}), 1.04(\mathrm{~d}, J=6.7 \mathrm{~Hz}, 3 \mathrm{H}), 1.02-0.96(\mathrm{~m}, 1 \mathrm{H}), 0.85(\mathrm{t}, J=7.4 \mathrm{~Hz}$, $3 \mathrm{H}), 0.78-0.76(\mathrm{~m}, 3 \mathrm{H}), 0.75(\mathrm{~s}, 9 \mathrm{H}), 0.01(\mathrm{~s}, 3 \mathrm{H}),-0.06(\mathrm{~s}, 3 \mathrm{H}) \mathrm{ppm}$; ${ }^{13} \mathrm{C} \mathrm{NMR}\left(126 \mathrm{MHz}, \mathrm{MeOH}-d_{4}\right) \delta=195.1,176.2,172.6,170.4,150.8$, 143.1, 139.1, 137.4, 137.4, 135.7, 135.1, 131.3, 130.1, 130.0, 129.3, 129.2,
129.2, 129.2, 129.1, 112.9, 85.9, 81.5, 78.8, 76.0, 76.0, 70.1, 63.1, 55.0, 43.4, 39.3, 37.5, 35.5, 28.2, 28.1, 26.5, 26.3, 18.9, 16.8, 15.8, 12.0, 3.7, $-2.0,-2.0 \mathrm{ppm}$; IR (film) $\nu=3322,2961,2931,2856,1737,1683 \mathrm{~cm}^{-1}$; MS (ESI) $m / z 908\left[\mathrm{M}+\mathrm{H}^{+}\right], 930\left[\mathrm{M}+\mathrm{Na}^{+}\right]$; HRMS (ESI) $m / z$ calcd for $\mathrm{C}_{49} \mathrm{H}_{66} \mathrm{~N}_{3} \mathrm{O}_{9} \mathrm{Cl}_{2} \mathrm{Si}\left[\mathrm{M}+\mathrm{H}^{+}\right]$906:4042, found 906.4051 .

Compound 24. Ghosez's reagent ( $199 \mathrm{mg}, 197 \mu \mathrm{L}, 1.49 \mathrm{mmol})$ was added to a solution of the carboxylic acid $16(333 \mathrm{mg}, 1.24 \mathrm{mmol})$ in $\mathrm{CH}_{2} \mathrm{Cl}_{2}(2.5 \mathrm{~mL})$ at $0{ }^{\circ} \mathrm{C}$. After $10 \mathrm{~min}$ at $0{ }^{\circ} \mathrm{C}$, the mixture was stirred at ambient temperature for another $2 \mathrm{~h}$.

A solution of the crude acid chloride $\mathbf{1 7}$ thus formed was added dropwise to a solution of amine $\mathbf{S 5}(750 \mathrm{mg}, 0.827 \mathrm{mmol})$ and $\mathrm{Et}_{3} \mathrm{~N}$ $(230 \mu \mathrm{L}, 1.65 \mathrm{mmol})$ in $\mathrm{CH}_{2} \mathrm{Cl}_{2}(2.5 \mathrm{~mL})$ at $0{ }^{\circ} \mathrm{C}$. The mixture was stirred for $1 \mathrm{~h}$ at this temperature. The reaction was quenched with water $(5 \mathrm{~mL})$, and the aqueous layer was extracted with EtOAc $(3 \times 10 \mathrm{~mL})$; the combined extracts were washed with brine $(5 \mathrm{~mL})$, dried over $\mathrm{Na}_{2} \mathrm{SO}_{4}$, filtered, and concentrated. The residue was purified by flash chromatography on silica gel (hexanes/EtOAc, 4:1) to afford the title compound as a colorless solid (730 mg, 76\%): $[\alpha]_{\mathrm{D}}{ }^{20}=-80.5(c$ 1.0, $\left.\mathrm{CHCl}_{3}\right) ; \mathrm{mp}=74.2-75.7{ }^{\circ} \mathrm{C} ;{ }^{1} \mathrm{H}$ NMR $\left(500 \mathrm{MHz}, \mathrm{MeOH}-d_{4}\right) \delta=$ $8.05-7.99(\mathrm{~m}, 2 \mathrm{H}), 7.66(\mathrm{td}, J=7.3,1.3 \mathrm{~Hz}, 1 \mathrm{H}), 7.54(\mathrm{t}, J=7.9 \mathrm{~Hz}$, $2 \mathrm{H}), 7.38(\mathrm{~s}, 2 \mathrm{H}), 7.34-7.26(\mathrm{~m}, 5 \mathrm{H}), 5.75-5.65(\mathrm{~m}, 2 \mathrm{H}), 5.56(\mathrm{~d}, J=$ $7.9 \mathrm{~Hz}, 1 \mathrm{H}), 5.38-5.26(\mathrm{~m}, 3 \mathrm{H}), 4.86-4.78(\mathrm{~m}, 1 \mathrm{H}), 4.61(\mathrm{~d}, J=19.1 \mathrm{~Hz}$, $2 \mathrm{H}), 4.43(\mathrm{~s}, 1 \mathrm{H}), 3.16(\mathrm{~d}, J=12.1 \mathrm{~Hz}, 1 \mathrm{H}), 3.00(\mathrm{~s}, 3 \mathrm{H}), 2.97-2.79(\mathrm{~m}$, $3 \mathrm{H}), 2.61-2.46(\mathrm{~m}, 2 \mathrm{H}), 2.05-2.01(\mathrm{~m}, 1 \mathrm{H}), 1.88(\mathrm{~s}, 3 \mathrm{H}), 1.84-1.82$ $(\mathrm{m}, 4 \mathrm{H}), 1.20(\mathrm{~s}, 3 \mathrm{H}), 1.19(\mathrm{~s}, 3 \mathrm{H}), 1.04(\mathrm{~d}, J=6.7 \mathrm{~Hz}, 3 \mathrm{H}), 0.92(\mathrm{~s}$, $9 \mathrm{H}), 0.91-0.87(\mathrm{~m}, 6 \mathrm{H}), 0.74(\mathrm{~s}, 9 \mathrm{H}), 0.66(\mathrm{~d}, J=6.5 \mathrm{~Hz}, 3 \mathrm{H}), 0.16(\mathrm{~s}$, $3 \mathrm{H}), 0.14(\mathrm{~s}, 3 \mathrm{H}), 0.01(\mathrm{~s}, 3 \mathrm{H}),-0.07(\mathrm{~s}, 3 \mathrm{H}) \mathrm{ppm} ;{ }^{13} \mathrm{C}$ NMR $(126$ $\left.\mathrm{MHz}, \mathrm{MeOH}-d_{4}\right) \delta=195.1,176.6,172.2,171.9,170.3,150.8,143.1$, $139.1,137.6,135.7,135.2,135.1,131.3,130.1,130.0,129.3,129.3,129.2$, 129.1, 128.0, 113.0, 86.0, 85.8, 81.5, 78.8, 76.0, 74.6, 63.2, 63.0, 61.7, $55.1,43.4,37.8,37.2,33.9,33.2,28.2,26.4,26.3,25.6,19.0,18.9,16.9$, 15.8, 14.9, 10.7, 3.8, -2.0, -4.3, -4.8 ppm; IR (film) $\nu=3300,3271$, 2958, 2929, 1744, 1607, $1471 \mathrm{~cm}^{-1}$; MS (ESI) $\mathrm{m} / z 1156\left[\mathrm{M}+\mathrm{H}^{+}\right]$, $1173\left[\mathrm{M}+\mathrm{NH}_{4}^{+}\right], 1178\left[\mathrm{M}+\mathrm{Na}^{+}\right], 1194\left[\mathrm{M}+\mathrm{K}^{+}\right]$; HRMS (ESI) $m / z$ calcd for $\mathrm{C}_{63} \mathrm{H}_{87} \mathrm{~N}_{3} \mathrm{O}_{9} \mathrm{Cl}_{2} \mathrm{Si}_{2} \mathrm{Na}\left[\mathrm{M}+\mathrm{Na}^{+}\right] 1178.5250$, found 1178.5261 .

Compound S6a $\left(\mathbf{R}^{1}=\right.$ Phenacyl).

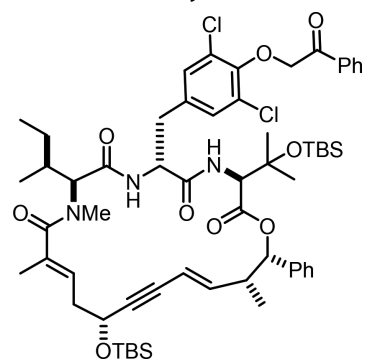

A flame-dried Schlenk flask was charged with powdered 4 Å molecular sieves (1.8 g) and $5 \AA$ molecular sieves ( $3.5 \mathrm{~g}$ ). The flask was evacuated, and the molecular sieves were flame-dried. After ambient temperature was reached, a solution of diyne $24(132 \mathrm{mg}, 0.114 \mathrm{mmol})$ in dry toluene $(56 \mathrm{~mL})$ was added and the resulting suspension was stirred for $45 \mathrm{~min}$. In a separate flame-dried Schlenk flask, a solution of complex $25(35.6 \mathrm{mg}$, $34.2 \mu \mathrm{mol})$ in toluene $(0.6 \mathrm{~mL})$ was prepared. This solution was added to the flask containing the diyne, and the resulting mixture was stirred at room temperature for $15 \mathrm{~min}$. The suspension was filtered through a short pad of Celite. The filtrate was evaporated, and the crude product was purified by flash chromatography on silica gel (hexanes/EtOAc, 9:1 to $4: 1)$ to afford the title compound as a white solid ( $84.5 \mathrm{mg}, 66 \%)$ : $[\alpha]_{\mathrm{D}}{ }^{20}=-93.2\left(\mathrm{c} 1.0, \mathrm{CHCl}_{3}\right) ; \mathrm{mp}=103-103.9^{\circ} \mathrm{C} ;{ }^{1} \mathrm{H} \mathrm{NMR}(400 \mathrm{MHz}$, $\left.\mathrm{CDCl}_{3}\right) \delta=8.01-7.97(\mathrm{~m}, 2 \mathrm{H}), 7.63-7.56(\mathrm{~m}, 1 \mathrm{H}), 7.50-7.43(\mathrm{~m}$, $2 \mathrm{H}), 7.32-7.23(\mathrm{~m}, 5 \mathrm{H}), 7.22(\mathrm{~s}, 2 \mathrm{H}), 6.93(\mathrm{~d}, J=8.9 \mathrm{~Hz}, 1 \mathrm{H}), 6.68(\mathrm{~d}$, $J=9.3 \mathrm{~Hz}, 1 \mathrm{H}), 5.99(\mathrm{dd}, J=15.9,8.0 \mathrm{~Hz}, 1 \mathrm{H}), 5.72(\mathrm{~d}, J=2.6 \mathrm{~Hz}, 1 \mathrm{H})$, $5.51-5.40(\mathrm{~m}, 2 \mathrm{H}), 5.19(\mathrm{~s}, 2 \mathrm{H}), 4.69(\mathrm{~d}, J=11.4 \mathrm{~Hz}, 1 \mathrm{H}), 4.60-4.49$ $(\mathrm{m}, 2 \mathrm{H}), 4.43(\mathrm{~d}, J=9.1 \mathrm{~Hz}, 1 \mathrm{H}), 3.09(\mathrm{dd}, J=13.5,9.0 \mathrm{~Hz}, 1 \mathrm{H}), 2.84-2.78$ $(\mathrm{m}, 1 \mathrm{H}), 2.77(\mathrm{~s}, 3 \mathrm{H}), 2.74-2.61(\mathrm{~m}, 2 \mathrm{H}), 2.45-2.36(\mathrm{~m}, 1 \mathrm{H}), 2.20-2.12$ $(\mathrm{m}, 1 \mathrm{H}), 1.96(\mathrm{~s}, 3 \mathrm{H}), 1.41-1.34(\mathrm{~m}, 1 \mathrm{H}), 1.32(\mathrm{~s}, 3 \mathrm{H}), 1.12-1.03(\mathrm{~m}$, $1 \mathrm{H}), 1.00(\mathrm{~d}, J=6.9 \mathrm{~Hz}, 3 \mathrm{H}), 0.93(\mathrm{~d}, J=1.2 \mathrm{~Hz}, 6 \mathrm{H}), 0.91(\mathrm{~s}, 9 \mathrm{H}), 0.88$ $(\mathrm{d}, J=7.9 \mathrm{~Hz}, 3 \mathrm{H}), 0.67(\mathrm{~s}, 9 \mathrm{H}), 0.14(\mathrm{~s}, 3 \mathrm{H}), 0.13(\mathrm{~s}, 3 \mathrm{H}),-0.10$ (s, 3H), -0.17 (s, 3H) ppm; ${ }^{13} \mathrm{C}$ NMR (101 MHz, $\left.\mathrm{CDCl}_{3}\right) \delta=192.9$, 
$175.9,170.2,169.5,169.2,149.8,144.8,137.5,135.0,135.0,134.6,133.9$, $130.1,129.3,128.9,128.3,128.2,128.2,128.1,128.1,127.3,125.2,110.4$ 90.5, 83.0, 80.3, 75.3, 74.8, 74.8, 63.0, 60.9, 59.9, 54.4, 42.6, 37.5, 36.6, $32.1,30.3,28.1,28.0,25.9,25.8,25.8,25.7,24.5,18.4,18.0,16.1,14.7$, 13.2, 10.5, -2.1, -2.4, -4.4, -4.8 ppm; IR (film) $\nu=3552,3287,2957$, 2929, $1683,1511 \mathrm{~cm}^{-1}$; MS (ESI) $\mathrm{m} / z 1133\left[\mathrm{M}+\mathrm{NH}_{4}^{+}\right], 1138$ $\left[\mathrm{M}+\mathrm{Na}^{+}\right]$; HRMS (ESI) $m / z$ calcd for $\mathrm{C}_{60} \mathrm{H}_{83} \mathrm{~N}_{3} \mathrm{O}_{9} \mathrm{Cl}_{2} \mathrm{Si}_{2} \mathrm{Na}\left[\mathrm{M}+\mathrm{Na}^{+}\right]$ 1138.4937, found 1138.4954 .

Compound S6b $\left(R^{1}=A c\right)$.

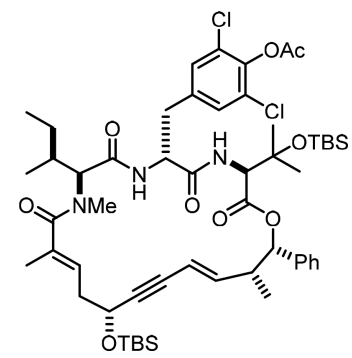

The compound was prepared analogously as colorless oil (9.8 $\mathrm{mg}, 83 \%)$ : ${ }^{1} \mathrm{H} \mathrm{NMR}\left(400 \mathrm{MHz}, \mathrm{CDCl}_{3}\right) \delta=7.30(\mathrm{dd}, J=7.2,1.7 \mathrm{~Hz}, 2 \mathrm{H}), 7.26$ $(\mathrm{s}, 3 \mathrm{H}), 7.25(\mathrm{~d}, J=5.5 \mathrm{~Hz}, 2 \mathrm{H}), 6.94(\mathrm{~d}, J=9.0 \mathrm{~Hz}, 1 \mathrm{H}), 6.66(\mathrm{~d}, J=$ $9.2 \mathrm{~Hz}, 1 \mathrm{H}), 5.99(\mathrm{dd}, J=15.9,8.0 \mathrm{~Hz}, 1 \mathrm{H}), 5.72(\mathrm{~d}, J=2.5 \mathrm{~Hz}, 1 \mathrm{H})$, $5.49(\mathrm{dt}, J=15.9,1.5 \mathrm{~Hz}, 1 \mathrm{H}), 5.43(\mathrm{ddd}, J=10.6,5.1,1.7 \mathrm{~Hz}, 1 \mathrm{H}), 4.69$ $(\mathrm{d}, J=11.5 \mathrm{~Hz}, 1 \mathrm{H}), 4.56(\mathrm{td}, J=9.5,6.3 \mathrm{~Hz}, 1 \mathrm{H}), 4.55-4.50(\mathrm{~m}, 1 \mathrm{H})$, $4.41(\mathrm{~d}, J=9.2 \mathrm{~Hz}, 1 \mathrm{H}), 3.10(\mathrm{dd}, J=13.4,9.6 \mathrm{~Hz}, 1 \mathrm{H}), 2.84(\mathrm{dd}, J=$ $13.4,6.0 \mathrm{~Hz}, 1 \mathrm{H}), 2.77(\mathrm{~s}, 3 \mathrm{H}), 2.72(\mathrm{dt}, J=13.0,10.7 \mathrm{~Hz}, 1 \mathrm{H}), 2.68-$ $2.60(\mathrm{~m}, 1 \mathrm{H}), 2.44-2.37(\mathrm{~m}, 1 \mathrm{H}), 2.36(\mathrm{~s}, 3 \mathrm{H}), 2.17(\mathrm{td}, J=11.3,9.2$, $4.6 \mathrm{~Hz}, 1 \mathrm{H}), 1.97(\mathrm{~s}, 3 \mathrm{H}), 1.38$ (ddd, $J=13.6,7.8,2.7 \mathrm{~Hz}, 1 \mathrm{H}), 1.32(\mathrm{~s}$, $3 \mathrm{H}), 1.09-1.00(\mathrm{~m}, 1 \mathrm{H}), 1.01(\mathrm{~d}, J=6.9 \mathrm{~Hz}, 3 \mathrm{H}), 0.93(\mathrm{~d}, J=6.5 \mathrm{~Hz}$, $3 \mathrm{H}), 0.92(\mathrm{~s}, 9 \mathrm{H}), 0.90(\mathrm{t}, J=7.1 \mathrm{~Hz}, 3 \mathrm{H}), 0.87(\mathrm{~s}, 3 \mathrm{H}), 0.66(\mathrm{~s}, 9 \mathrm{H})$, $0.15(\mathrm{~s}, 3 \mathrm{H}), 0.14(\mathrm{~s}, 3 \mathrm{H}),-0.12(\mathrm{~s}, 3 \mathrm{H}),-0.17(\mathrm{~s}, 3 \mathrm{H}) \mathrm{ppm} ;{ }^{13} \mathrm{C}$ NMR $\left(101 \mathrm{MHz} \mathrm{CDCl}_{3}\right) \delta=175.8,170.1,169.3,169.1,167.0,144.9,143.0$, 137.6, 136.3, 135.0, 129.6, 128.8, 128.1, 127.9, 127.2, 124.9, 110.2, 90.4, $82.8,80.1,75.2,62.9,60.8,59.7,54.5,42.6,37.4,36.5,32.0,30.1,28.0$, $27.7,25.8,25.6,24.4,20.2,18.3,17.9,15.9,14.6,13.0,10.4,-2.4,-2.6$, $-4.5,-4.9$ ppm; MS (ESI) $m / z$ (\%) 1057 (23), 1062 (100), 1078 (17); HRMS (ESI) $m / z$ calcd for $\mathrm{C}_{54} \mathrm{H}_{79} \mathrm{~N}_{3} \mathrm{O}_{9} \mathrm{Cl}_{2} \mathrm{Si}_{2} \mathrm{Na}[\mathrm{M}+\mathrm{Na}]^{+}$ 1062.4624 , found 1062.4624 .

Compound 26a $\left(\mathbf{R}^{1}=\right.$ Phenacyl). HF.py $(600 \mu \mathrm{L})$ was added at $0{ }^{\circ} \mathrm{C}$ to a stirred solution of $\mathbf{S} 6 \mathrm{a}\left(\mathrm{R}^{1}=\right.$ phenacyl, $\left.94.5 \mathrm{mg}, 95.8 \mu \mathrm{mol}\right)$ in THF $(600 \mu \mathrm{L})$. The mixture was stirred for $15 \mathrm{~min}$ at $0{ }^{\circ} \mathrm{C}$ and for $1 \mathrm{~h}$ at ambient temperature before aqueous $\mathrm{NaHCO}_{3}$ was introduced at $0{ }^{\circ} \mathrm{C}$. The aqueous layer was extracted with EtOAc $(3 \times 30 \mathrm{~mL})$. The combined extracts were washed with brine $(2 \mathrm{~mL})$, dried over $\mathrm{Na}_{2} \mathrm{SO}_{4}$, and filtered. The filtrate was evaporated and the residue purified by flash chromatography on silica gel $\left(\mathrm{CH}_{2} \mathrm{Cl}_{2} /\right.$ tert-butyl methyl ether, $6: 1$ to $5: 2)$ to afford the title compound as a white solid $(60.8 \mathrm{mg}, 71 \%)$ : $[\alpha]_{\mathrm{D}}{ }^{20}=-63.4(c 0.8, \mathrm{MeOH}) ; \mathrm{mp}=128-130.3^{\circ} \mathrm{C} ;{ }^{1} \mathrm{H} \mathrm{NMR}(400 \mathrm{MHz}$, $\mathrm{MeOH}-d_{4}$, mixture of rotamers ca. 2.3:1) $\delta=8.05-7.95(\mathrm{~m}, 2 \mathrm{H})$, $7.69-7.64(\mathrm{~m}, 1 \mathrm{H}), 7.55-7.52(\mathrm{~m}, 2 \mathrm{H}), 7.41(\mathrm{~s}, 2 \mathrm{H}), 7.39-7.37(\mathrm{~m}$, $2 \mathrm{H}), 7.35-7.31(\mathrm{~m}, 2 \mathrm{H}), 7.29-7.25(\mathrm{~m}, 1 \mathrm{H}), 6.35(\mathrm{dd}, J=16.2,5.8 \mathrm{~Hz}$, $0.3 \mathrm{H}$, minor $), 6.18-6.08(\mathrm{~m}, 1 \mathrm{H}), 5.91-5.84(\mathrm{~m}, 0.3 \mathrm{H}$, minor $), 5.75(\mathrm{~d}$, $J=3.0 \mathrm{~Hz}, 0.7 \mathrm{H}$, major $), 5.67-5.63(\mathrm{~m}, 0.7 \mathrm{H}$, major $), 5.58-5.49(\mathrm{~m}$, $1 \mathrm{H}), 5.35-5.27(\mathrm{~m}, 2 \mathrm{H}), 4.85-4.77(\mathrm{~m}, 1.3 \mathrm{H}), 4.68-4.65(\mathrm{~m}, 1.4 \mathrm{H})$, $4.55-4.47(\mathrm{~m}, 1 \mathrm{H}), 4.14(\mathrm{~d}, J=10.9 \mathrm{~Hz}, 0.3 \mathrm{H}, \mathrm{mionr}), 3.40-3.33(\mathrm{~m}$, $0.3 \mathrm{H}$, minor), 3.12 (dd, $J=13.9,5.7 \mathrm{~Hz}, 0.7 \mathrm{H}$, major), 3.07 (d, $J=$ $11.9 \mathrm{~Hz}, 0.3 \mathrm{H}$, minor), 3.02 (s, $0.9 \mathrm{H}$, minor), 2.88 (s, $2.1 \mathrm{H}$, major), $2.86-2.83(\mathrm{~m}, 1 \mathrm{H}), 2.80-2.70(\mathrm{~m}, 1 \mathrm{H}), 2.60-2.50(\mathrm{~m}, 1.4 \mathrm{H}), 2.43(\mathrm{~d}$, $J=15.0 \mathrm{~Hz}, 0.3 \mathrm{H}$, minor $), 2.07-1.98(\mathrm{~m}, 0.7 \mathrm{H}$, major $), 1.96-1.92(\mathrm{~m}$, $0.3 \mathrm{H}$, minor), 1.94 (s, $2.1 \mathrm{H}$, major), $1.84(\mathrm{~s}, 0.9 \mathrm{H}$, minor $), 1.43-1.28$ $(\mathrm{m}, 1 \mathrm{H}), 1.25(\mathrm{~s}, 0.9 \mathrm{H}$, minor $), 1.22(\mathrm{~s}, 0.9 \mathrm{H}$, minor $), 1.18(\mathrm{~s}, 2.1 \mathrm{H}$, major), $1.12(\mathrm{~s}, 2.1 \mathrm{H}$, major $), 1.08-1.01(\mathrm{~m}, 1 \mathrm{H}), 0.94-0.87(\mathrm{~m}, 6 \mathrm{H})$, 0.73 (d, $J=6.5 \mathrm{~Hz}, 2.1 \mathrm{H}$, major), 0.45 (d, $J=6.5 \mathrm{~Hz}, 0.9 \mathrm{H}$, minor) ppm; ${ }^{13} \mathrm{C}$ NMR $\left(151 \mathrm{MHz}, \mathrm{MeOH}-d_{4}\right) \delta=195.2,177.1,176.9,172.6,172.4$, 171.4, 171.4, 171.2, 150.8, 148.6, 145.8, 139.7, 138.9, 137.3, 135.7, 135.7, 135.1, 131.3, 131.0, 130.1, 130.0, 130.0, 129.3, 129.2, 129.0, 128.8, 128.6, 128.4, 128.1, 127.1, 111.5, 110.3, 90.8, 89.4, 85.4, 84.1, 81.2, 77.8, 75.9, $72.8,72.1,68.4,62.5,62.1,61.9,61.6,61.5,55.9,54.7,43.9,43.3,38.2$,
$37.3,37.2,35.4,35.1,33.1,32.4,29.2,28.0,27.3,26.5,26.4,25.9,25.4$ 16.0, 15.5, 15.4, 14.7, 13.8, 11.7, 10.7, 10.0 ppm; IR (film) $\nu=3340$, $2971,2928,2857,1678,1602,1469 \mathrm{~cm}^{-1}$; MS (ESI) $m / z 888\left[\mathrm{M}+\mathrm{H}^{+}\right]$, $905\left[\mathrm{M}+\mathrm{NH}_{4}^{+}\right], 910\left[\mathrm{M}+\mathrm{Na}^{+}\right]$; HRMS (ESI) $\mathrm{m} / z$ calcd for $\mathrm{C}_{48} \mathrm{H}_{56} \mathrm{~N}_{3} \mathrm{O}_{9} \mathrm{Cl}_{2}\left[\mathrm{M}+\mathrm{H}^{+}\right]$888.3388, found 888.3404.

Compound $26 \mathrm{~b}\left(\mathbf{R}^{1}=\mathbf{A c}\right)$. A solution of TBAF ( $1 \mathrm{M}$ in THF, $94 \mu \mathrm{L}, 94 \mu \mathrm{mol})$ was added to a solution of compound $\mathbf{S 6} \mathbf{b}(46.5 \mathrm{mg}$, $45 \mu \mathrm{mol})$ in THF $(0.45 \mathrm{~mL})$ at $0{ }^{\circ} \mathrm{C}$. After $10 \mathrm{~min}$ at $0{ }^{\circ} \mathrm{C}$, stirring was continued at ambient temperature for $2 \mathrm{~h}$. The reaction was quenched with saturated aqueous $\mathrm{NH}_{4} \mathrm{Cl}$, and the aqueous layer was extracted with EtOAc $(3 \times 10 \mathrm{~mL})$; the combined extracts were washed with brine $(15 \mathrm{~mL})$, dried over $\mathrm{Na}_{2} \mathrm{SO}_{4}$, filtered, and concentrated. The crude material was purified by flash chromatography on silica gel (hexanes/ EtOAc, 1:1) to afford the title compound as a colorless oil $(24 \mathrm{mg}, 66 \%)$ : ${ }^{1} \mathrm{H}$ NMR $\left(400 \mathrm{MHz}, \mathrm{CDCl}_{3}\right) \delta=7.32-7.29(\mathrm{dd}, J=5.1,1.9 \mathrm{~Hz}, 3 \mathrm{H})$, $7.25-7.23(\mathrm{~m}, 2 \mathrm{H}), 7.10(\mathrm{~s}, 2 \mathrm{H}), 7.08(\mathrm{~d}, J=9.1 \mathrm{~Hz}, 1 \mathrm{H}), 6.64(\mathrm{~d}, J=$ $8.6 \mathrm{~Hz}, 1 \mathrm{H}), 6.19(\mathrm{dd}, J=16.0,7.3 \mathrm{~Hz}, 1 \mathrm{H}), 5.76(\mathrm{~d}, J=3.1 \mathrm{~Hz}, 1 \mathrm{H})$, $5.58(\mathrm{td}, J=6.8,3.3 \mathrm{~Hz}, 1 \mathrm{H}), 5.52(\mathrm{ddd}, J=9.4,4.4,1.4 \mathrm{~Hz}, 1 \mathrm{H}), 5.44$ $(\mathrm{dt}, J=16.1,1.5 \mathrm{~Hz}, 1 \mathrm{H}), 4.65(\mathrm{q}, J=7.7 \mathrm{~Hz}, 1 \mathrm{H}), 4.58(\mathrm{~d}, J=9.0 \mathrm{~Hz}$, $1 \mathrm{H}), 4.48(\mathrm{~d}, J=11.4 \mathrm{~Hz}, 1 \mathrm{H}), 2.99(\mathrm{dd}, J=14.0,7.7 \mathrm{~Hz}, 1 \mathrm{H}), 2.89(\mathrm{~s}$, $3 \mathrm{H}), 2.88-2.83(\mathrm{~m}, 1 \mathrm{H}), 2.78-2.71(\mathrm{~m}, 1 \mathrm{H}), 2.71-2.63(\mathrm{~m}, 1 \mathrm{H}), 2.55$ $(\mathrm{dt}, J=12.9,5.6 \mathrm{~Hz}, 1 \mathrm{H}), 2.16-2.10(\mathrm{~m}, 1 \mathrm{H}), 2.10(\mathrm{~s}, 3 \mathrm{H}), 2.00-1.94$ $(\mathrm{m}, 3 \mathrm{H}), 1.75-1.54(\mathrm{~m}, 2 \mathrm{H}), 1.48-1.36(\mathrm{~m}, 1 \mathrm{H}), 1.14(\mathrm{~s}, 3 \mathrm{H}), 1.12-$ $1.06(\mathrm{~m}, 1 \mathrm{H}), 1.04(\mathrm{~s}, 3 \mathrm{H}), 0.99-0.87(\mathrm{~m}, 9 \mathrm{H}) \mathrm{ppm} ;{ }^{13} \mathrm{C} \mathrm{NMR}$ $\left(101 \mathrm{MHz}, \mathrm{CDCl}_{3}\right) \delta=176.0,170.6,170.5,170.0,169.9,147.0,145.9$, $136.9,135.8,129.7,129.1,128.3,128.2,127.2,125.0,121.2,110.1,85.7$, 84.7, 80.2, 72.4, 63.5, 61.2, 60.4, 53.9, 42.1, 36.5, 33.2, 32.8, 31.0, 27.1, $26.5,25.2,21.2,16.1,14.7,13.5,10.7 \mathrm{ppm}$; MS (ESI) $\mathrm{m} / z(\%) 834$ (100), 1645 (10); HRMS (ESI) $m / z$ calcd for $\mathrm{C}_{42} \mathrm{H}_{51} \mathrm{~N}_{3} \mathrm{O}_{9} \mathrm{Cl}_{2} \mathrm{Na}$ $[\mathrm{M}+\mathrm{Na}]^{+} 834.2895$, found 834.2895.

Compound $27 \mathrm{a}\left(\mathbf{R}^{1}=\right.$ Phenacyl). A solution of tributyltin hydride $(21.8 \mu \mathrm{L}, 81.0 \mu \mathrm{mol})$ in $\mathrm{CH}_{2} \mathrm{Cl}_{2}(1.1 \mathrm{~mL})$ was added dropwise over $20 \mathrm{~min}$ to a stirred solution of $\left[\mathrm{Cp}^{*} \mathrm{RuCl}\right]_{4}(8.1 \mathrm{mg}, 7.5 \mu \mathrm{mol})$ and substrate $26(60.0 \mathrm{mg}, 67.5 \mu \mathrm{mol})$ in $\mathrm{CH}_{2} \mathrm{Cl}_{2}(0.5 \mathrm{~mL})$. After the addition was complete, all volatile materials were evaporated. The residue was quickly purified by flash chromatography on silica gel $\left(\mathrm{CH}_{2} \mathrm{Cl}_{2} /\right.$ tertbutyl methyl ether, 4:1 to 5:2) to afford the title compound as a yellow oil (64.0 mg, 80\%): $[\alpha]_{\mathrm{D}}{ }^{20}=-34.8$ (c 0.88, $\left.\mathrm{CHCl}_{3}\right) ;{ }^{1} \mathrm{H}$ NMR $\left(400 \mathrm{MHz}, \mathrm{CDCl}_{3}\right) \delta=8.01-7.96(\mathrm{~m}, 2 \mathrm{H}), 7.64-7.58(\mathrm{~m}, 1 \mathrm{H}), 7.49$ $(\mathrm{dd}, J=8.4,7.1 \mathrm{~Hz}, 2 \mathrm{H}), 7.36-7.27(\mathrm{~m}, 5 \mathrm{H}), 7.18(\mathrm{~s}, 2 \mathrm{H}), 7.03(\mathrm{~d}, J=$ $8.6 \mathrm{~Hz}, 1 \mathrm{H}), 6.78(\mathrm{~d}, J=8.5 \mathrm{~Hz}, 1 \mathrm{H}), 6.65(\mathrm{~d}, J=10.4 \mathrm{~Hz}, 1 \mathrm{H}), 6.07$ $(\mathrm{ddd}, J=15.0,10.5,1.4 \mathrm{~Hz}, 1 \mathrm{H}), 5.86(\mathrm{~d}, J=2.5 \mathrm{~Hz}, 1 \mathrm{H}), 5.76(\mathrm{dd}, J=$ $15.0,6.5 \mathrm{~Hz}, 1 \mathrm{H}), 5.54-5.48(\mathrm{~m}, 1 \mathrm{H}), 5.20(\mathrm{~s}, 2 \mathrm{H}), 4.60(\mathrm{dd}, J=8.6$, $6.4 \mathrm{~Hz}, 1 \mathrm{H}), 4.50(\mathrm{dd}, J=19.7,9.9 \mathrm{~Hz}, 2 \mathrm{H}), 4.42(\mathrm{~d}, J=8.9 \mathrm{~Hz}, 1 \mathrm{H})$, 3.08 (dd, $J=13.8,8.5 \mathrm{~Hz}, 1 \mathrm{H}), 2.80(\mathrm{dd}, J=13.8,6.3 \mathrm{~Hz}, 1 \mathrm{H}), 2.72(\mathrm{~s}$, $3 \mathrm{H}), 2.67(\mathrm{t}, J=6.9 \mathrm{~Hz}, 1 \mathrm{H}), 2.56(\mathrm{dt}, J=14.3,9.0 \mathrm{~Hz}, 1 \mathrm{H}), 2.45-2.42$ $(\mathrm{m}, 2 \mathrm{H}), 2.17-2.09(\mathrm{~m}, 1 \mathrm{H}), 1.85(\mathrm{~m}, 3 \mathrm{H}), 1.55-1.46(\mathrm{~m}, 6 \mathrm{H}), 1.34(\mathrm{~h}$, $J=7.3 \mathrm{~Hz}, 6 \mathrm{H}), 1.13(\mathrm{~s}, 3 \mathrm{H}), 1.11-1.00(\mathrm{~m}, 10 \mathrm{H}), 1.00(\mathrm{~d}, J=2.6 \mathrm{~Hz}$, $3 \mathrm{H}), 0.92-0.88(\mathrm{~m}, 15 \mathrm{H}) \mathrm{ppm} ;{ }^{13} \mathrm{C}$ NMR $\left(101 \mathrm{MHz}, \mathrm{CDCl}_{3}\right) \delta=$ 192.9, 175.9, 170.7, 170.3, 169.8, 151.2, 149.7, 139.3, 137.9, 137.2, 134.9, $134.5,133.9,132.9,131.2,129.9,129.2,128.8,128.2,128.0,128.0,126.9$, 80.6, 74.7, 72.4, 60.7, 60.4, 54.1, 41.9, 36.1, 35.4, 32.7, 30.9, 29.4, 29.3, $27.9,27.5,27.0,26.9,26.5,24.8,17.6,16.0,14.8,13.7,13.7,12.2,11.2$, $10.5 \mathrm{ppm} ;{ }^{119} \mathrm{Sn} \mathrm{NMR}\left(149 \mathrm{MHz}, \mathrm{CDCl}_{3}\right) \delta=-51.9 \mathrm{ppm}$; IR (film) $\nu=$ 3349, 2957, 2926, 2854, 1677, 1600, $1468 \mathrm{~cm}^{-1}$; MS (ESI) $\mathrm{m} / z 1202$ $\left[\mathrm{M}+\mathrm{Na}^{+}\right]$; HRMS (ESI) $m / z$ calcd for $\mathrm{C}_{60} \mathrm{H}_{83} \mathrm{~N}_{3} \mathrm{O}_{9} \mathrm{Cl}_{2} \mathrm{SnNa}$ $\left[\mathrm{M}+\mathrm{Na}^{+}\right]$1202.4420, found 1202.4435 .

Compound $27 \mathrm{~b}\left(\mathbf{R}^{1}=\mathbf{A c}\right)$. The compound was prepared analogously in the form of a white solid $(13.8 \mathrm{mg}, 56 \%):[\alpha]_{\mathrm{D}}{ }^{20}=-72.5$ $\left(c 0.4, \mathrm{CHCl}_{3}\right) ;{ }^{1} \mathrm{H}$ NMR $\left(400 \mathrm{MHz}, \mathrm{CDCl}_{3}\right) \delta=7.35-7.26(\mathrm{~m}, 5 \mathrm{H})$, $7.11(\mathrm{~s}, 2 \mathrm{H}), 6.99(\mathrm{~d}, J=8.7 \mathrm{~Hz}, 1 \mathrm{H}), 6.73(\mathrm{~d}, J=8.9 \mathrm{~Hz}, 1 \mathrm{H}), 6.64(\mathrm{~d}$, $J=10.5 \mathrm{~Hz}, 1 \mathrm{H}), 6.06(\mathrm{ddd}, J=15.0,10.6,1.6 \mathrm{~Hz}, 1 \mathrm{H}), 5.88(\mathrm{~d}, J=2.4 \mathrm{~Hz}$, $1 \mathrm{H}), 5.87(\mathrm{~d}, J=3.2 \mathrm{~Hz}, 1 \mathrm{H}), 5.78(\mathrm{dd}, J=15.0,6.1 \mathrm{~Hz}, 1 \mathrm{H}), 5.50(\mathrm{ddd}$, $J=8.6,6.6,1.7 \mathrm{~Hz}, 1 \mathrm{H}), 5.41(\mathrm{dd}, J=9.4,3.0 \mathrm{~Hz}, 1 \mathrm{H}), 4.55(\mathrm{td}, J=8.8$, $6.2 \mathrm{~Hz}, 1 \mathrm{H}), 4.51(\mathrm{~d}, J=11.3 \mathrm{~Hz}, 1 \mathrm{H}), 4.47(\mathrm{~d}, J=8.5 \mathrm{~Hz}, 1 \mathrm{H}), 3.01(\mathrm{dd}$ $J=13.9,8.8 \mathrm{~Hz}, 1 \mathrm{H}), 2.80(\mathrm{dd}, J=13.8,6.1,1 \mathrm{H}), 2.73(\mathrm{~s}, 3 \mathrm{H})$, $2.71-2.63(\mathrm{~m}, 1 \mathrm{H}), 2.56-2.50(\mathrm{~m}, 1 \mathrm{H}), 2.50-2.43(\mathrm{~m}, 1 \mathrm{H}), 2.14(\mathrm{tq}$, $J=9.2,2.8 \mathrm{~Hz}, 1 \mathrm{H}), 2.06(\mathrm{~s}, 3 \mathrm{H}), 1.84(\mathrm{~s}, 3 \mathrm{H}), 1.51(\mathrm{ddt}, J=10.5,8.0$, $6.1 \mathrm{~Hz}, 6 \mathrm{H}), 1.43-1.39(\mathrm{~m}, 1 \mathrm{H}), 1.38-1.30(\mathrm{~m}, 6 \mathrm{H}), 1.10(\mathrm{~s}, 3 \mathrm{H})$, $1.08-1.05(\mathrm{~m}, 1 \mathrm{H}), 1.04-1.02(\mathrm{~m}, 9 \mathrm{H}), 1.01(\mathrm{~s}, 3 \mathrm{H}), 0.93-0.88$ 
$(\mathrm{m}, 15 \mathrm{H}) \mathrm{ppm} ;{ }^{13} \mathrm{C} \mathrm{NMR}\left(151 \mathrm{MHz}, \mathrm{CDCl}_{3}\right) \delta=175.8,170.8,170.4$, $170.1,169.8,146.9,146.4,141.5,138.1,138.0,133.9,130.9,129.9,129.2$, $128.3,128.1,127.1,126.9,121.2,80.5,79.9,72.7,60.8,60.4,54.4,41.9$, 35.8 , 33.2, 32.7, 30.9, 29.3, 29.2, 27.5, 27.0, 26.4, 24.9, 21.6, 16.1, 14.9, $13.8,11.8,11.3,10.6 \mathrm{ppm} ;{ }^{119} \mathrm{Sn}$ NMR $\left(300 \mathrm{MHz}, \mathrm{CDCl}_{3}\right) \delta=-50.4$ ppm; IR (film) $\nu=3351,2957,2926,2855,1605,1489 \mathrm{~cm}^{-1}$; MS (ESI) $m / z 1126$ (100) $\left[\mathrm{M}+\mathrm{Na}^{+}\right]$; HRMS (ESI) $m / z$ calcd for $\mathrm{C}_{54} \mathrm{H}_{79} \mathrm{~N}_{3} \mathrm{O}_{9} \mathrm{Cl}_{2} \mathrm{SnNa}$ 1126.4107, found 1126.4111 .

Compound 30. MeI $(13 \mu \mathrm{L}, 0.209 \mathrm{mmol})$ was added to a solution stannane $27 \mathrm{a}(41.1 \mathrm{mg}, 34.8 \mu \mathrm{mol})$ and flame-dried $\left[\mathrm{Ph}_{2} \mathrm{PO}_{2}\right]\left[\mathrm{NBu}_{4}\right]$ $(32.0 \mathrm{mg}, 69.7 \mu \mathrm{mol})$ in DMSO $(230 \mu \mathrm{L})$. The mixture was stirred for $1 \mathrm{~min}$ before CuTC $(13.2 \mathrm{mg}, 69.2 \mu \mathrm{mol})$ was introduced. Stirring was continued for $2 \mathrm{~h}$ at room temperature. The mixture was diluted with EtOAc before water was added. The aqueous layer was extracted with EtOAc $(3 \times 3 \mathrm{~mL})$, and the combined organic phases were dried over $\mathrm{Na}_{2} \mathrm{SO}_{4}$, filtered, and concentrated. The residue was purified by flash chromatography on silica gel $\left(\mathrm{CH}_{2} \mathrm{Cl}_{2} /\right.$ tert-butyl methyl ether, 5:1 to $3: 1)$ to afford the title compound $(22.1 \mathrm{mg}, 70 \%)$; a second fraction contained recovered starting material $(3.6 \mathrm{mg}, 9 \%):[\alpha]_{\mathrm{D}}{ }^{20}=-11.8$ $(c 1.0, \mathrm{MeOH}) ;{ }^{1} \mathrm{H}$ NMR $\left(600 \mathrm{MHz}, \mathrm{MeOH}-d_{4}\right) \delta=8.01(\mathrm{~d}, J=7.8 \mathrm{~Hz}$, $2 \mathrm{H}), 7.66(\mathrm{t}, J=7.4 \mathrm{~Hz}, 1 \mathrm{H}), 7.54(\mathrm{t}, J=7.6 \mathrm{~Hz}, 2 \mathrm{H}), 7.43(\mathrm{~d}, J=7.3 \mathrm{~Hz}$, $2 \mathrm{H}), 7.38(\mathrm{~s}, 2 \mathrm{H}), 7.32(\mathrm{t}, J=7.5 \mathrm{~Hz}, 2 \mathrm{H}), 7.26(\mathrm{t}, J=7.3 \mathrm{~Hz}, 1 \mathrm{H}), 6.39$ $(\mathrm{dd}, J=15.4,10.6 \mathrm{~Hz}, 1 \mathrm{H}), 6.03(\mathrm{~d}, J=10.9 \mathrm{~Hz}, 1 \mathrm{H}), 5.88(\mathrm{dd}, J=15.3$, $6.4 \mathrm{~Hz}, 1 \mathrm{H}), 5.81(\mathrm{~s}, 1 \mathrm{H}), 5.48(\mathrm{t}, J=7.5 \mathrm{~Hz}, 1 \mathrm{H}), 5.32(\mathrm{~d}, J=3.5 \mathrm{~Hz}$, $2 \mathrm{H}), 4.77(\mathrm{t}, J=7.8 \mathrm{~Hz}, 1 \mathrm{H}), 4.63(\mathrm{~d}, J=11.1 \mathrm{~Hz}, 1 \mathrm{H}), 4.59(\mathrm{~s}, 1 \mathrm{H}), 4.12$ $(\mathrm{d}, J=8.8 \mathrm{~Hz}, 1 \mathrm{H}), 3.05$ (dd, $J=13.8,6.5 \mathrm{~Hz}, 1 \mathrm{H}), 2.84$ (dd, $J=13.8$, $8.9 \mathrm{~Hz}, 1 \mathrm{H}), 2.77(\mathrm{~s}, 3 \mathrm{H}), 2.71-2.65(\mathrm{~m}, 1 \mathrm{H}), 2.54(\mathrm{dt}, J=16.2,8.3 \mathrm{~Hz}$, $1 \mathrm{H}), 2.49(\mathrm{~d}, J=7.5 \mathrm{~Hz}, 1 \mathrm{H}), 2.06-1.97(\mathrm{~m}, 1 \mathrm{H}), 1.86(\mathrm{~s}, 3 \mathrm{H}), 1.79(\mathrm{~s}$, $3 \mathrm{H}), 1.36(\mathrm{p}, J=7.2 \mathrm{~Hz}, 1 \mathrm{H}), 1.18(\mathrm{~s}, 3 \mathrm{H}), 1.08(\mathrm{~s}, 3 \mathrm{H}), 1.07-1.01(\mathrm{~m}$, $1 \mathrm{H}), 0.99(\mathrm{~d}, J=6.9 \mathrm{~Hz}, 3 \mathrm{H}), 0.88(\mathrm{t}, J=7.5 \mathrm{~Hz}, 3 \mathrm{H}), 0.73(\mathrm{~d}, J=6.4 \mathrm{~Hz}$, $3 \mathrm{H}) \mathrm{ppm} ;{ }^{13} \mathrm{C}$ NMR $\left(151 \mathrm{MHz}, \mathrm{MeOH}-d_{4}\right) \delta=195.2,177.0,172.3$, 171.6, 171.5, 150.8, 140.4, 138.2, 137.3, 137.1, 135.7, 135.2, 134.2, 131.3, 130.0, 130.0, 129.2, 129.2, 129.0, 128.6, 128.5, 127.7, 127.4, 127.2, 81.8, 76.4, 75.9, 72.9, 61.5, 61.4, 55.1, 43.4, 37.8, 33.8, 33.1, 32.6, 28.3, 25.7, 25.4, 16.0, 14.6, 13.1, 12.2, 10.6 ppm; IR (film) $\nu=3316,2958,2924$, 1599, $1494 \mathrm{~cm}^{-1}$; MS (ESI) $m / z 904\left[\mathrm{M}+\mathrm{H}^{+}\right], 921\left[\mathrm{M}+\mathrm{NH}_{4}^{+}\right], 926$ $\left[\mathrm{M}+\mathrm{Na}^{+}\right]$; HRMS (ESI) $m / z$ calcd for $\mathrm{C}_{49} \mathrm{H}_{59} \mathrm{~N}_{3} \mathrm{O}_{9} \mathrm{Cl}_{2} \mathrm{Na}\left[\mathrm{M}+\mathrm{Na}^{+}\right]$ 926.3521, found 926.3525 .

Nannocystin Ax (1).

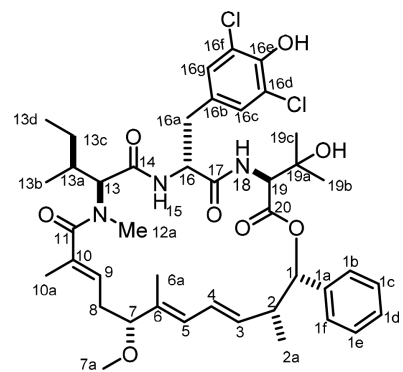

$\mathrm{Ph}_{3} \mathrm{PAuCl}(8.7 \mathrm{mg}, 17.6 \mu \mathrm{mol})$ and $\operatorname{AgOTf}(4.5 \mathrm{mg}, 17.5 \mu \mathrm{mol})$ were successively added to a solution of $30(4.0 \mathrm{mg}, 4.4 \mu \mathrm{mol})$ and 32 $(9.6 \mathrm{mg}, 44.4 \mu \mathrm{mol})^{57}$ in benzene $(0.4 \mathrm{~mL})$ at ambient temperature. After the mixture had been stirred for $15 \mathrm{~min}$, the suspension was filtered through a short pad of silica. The filtrate was evaporated and the residue purified by preparative TLC (tert-butyl methyl ether $/ \mathrm{CH}_{2} \mathrm{Cl}_{2}, 3: 1$ ).

$\mathrm{Zn}$ powder $(11.5 \mathrm{mg}, 0.176 \mathrm{mmol})$ was added to a stirred solution of the resulting product 31 in HOAc $(90 \mu \mathrm{L})$ and THF $(90 \mu \mathrm{L})$. The mixture was stirred for $7 \mathrm{~h}$ before the suspension was filtered through a short pad of Celite. The filtrate was neutralized with saturated aqueous $\mathrm{NaHCO}_{3}(1 \mathrm{~mL})$, and the aqueous layer was extracted with EtOAc $(3 \times 3 \mathrm{~mL})$; the combined organic phases were washed with brine $(1 \mathrm{~mL})$, dried over $\mathrm{Na}_{2} \mathrm{SO}_{4}$, filtered, and concentrated. The residue was purified by preparative LC ( $150 \mathrm{~mm}$ Kromasil 5-C18, $5 \mu \mathrm{m}, \varnothing 30 \mathrm{~mm}, \mathrm{MeOH} / \mathrm{H}_{2} \mathrm{O}=75: 25,35 \mathrm{~mL} / \mathrm{min}, 6.4 \mathrm{MPa}, 308 \mathrm{~K}, \mathrm{UV}$, $240 \mathrm{~nm})$ to afford the title compound $(1.5 \mathrm{mg}, 44 \%)$ as a white solid: $[\alpha]_{\mathrm{D}}{ }^{20}=-55.4($ c $0.26, \mathrm{MeOH})$; for a tabular comparison of the ${ }^{1} \mathrm{H}$ NMR and ${ }^{13} \mathrm{C}$ NMR data with those of the natural product published in the literature, see the Supporting Information; IR (film) $\nu=2853,1456$,
$1379 \mathrm{~cm}^{-1}$; MS (ESI) $m / z 798\left[\mathrm{M}-\mathrm{H}^{-}\right.$]; HRMS (ESI) $m / z$ calcd for $\mathrm{C}_{42} \mathrm{H}_{54} \mathrm{~N}_{3} \mathrm{O}_{8} \mathrm{Cl}_{2}\left[\mathrm{M}-\mathrm{H}^{-}\right]$798.3294, found 798.3296.

\section{Analogues.}

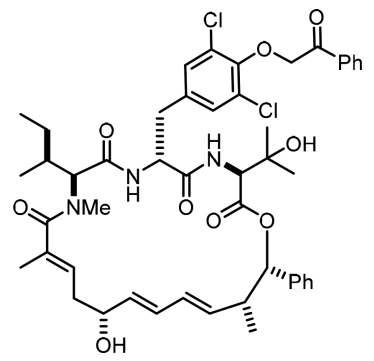

Compound S7. CuTC $(4.7 \mathrm{mg}, 24.6 \mu \mathrm{mol})$ was added at room temperature to a stirred solution of $27(26.7 \mathrm{mg}, 22.6 \mu \mathrm{mol})$ and $\left[\mathrm{Ph}_{2} \mathrm{PO}_{2}\right]\left[\mathrm{NBu}_{4}\right](12.5 \mathrm{mg}, 27.2 \mu \mathrm{mol})$ in DMF $(230 \mu \mathrm{L})$. The mixture was stirred for $1 \mathrm{~h}$ before it was diluted with EtOAc and water. The aqueous layer was extracted with EtOAc $(3 \times 3 \mathrm{~mL})$, and the combined organic phases were dried over $\mathrm{MgSO}_{4}$; the drying agent was filtered off, and the filtrate was concentrated. The residue was purified by flash chromatography $\left(\mathrm{CH}_{2} \mathrm{Cl}_{2} /\right.$ tert-butyl methyl ether, 5:1 to 2:1) to afford the title compound as a white solid $(17.3 \mathrm{mg}, 86 \%):[\alpha]_{\mathrm{D}}{ }^{20}=-74.7$ $(c 0.15, \mathrm{MeOH}) ;{ }^{1} \mathrm{H}$ NMR $\left(600 \mathrm{MHz}, \mathrm{MeOH}-d_{4}\right.$, mixture of rotamers, ca. $3.5: 1) \delta=8.01-8.00(\mathrm{~m}, 2 \mathrm{H}), 7.68-7.65(\mathrm{~m}, 1 \mathrm{H}), 7.55-7.53(\mathrm{~m}$, $2 \mathrm{H}), 7.43-7.37(\mathrm{~m}, 2 \mathrm{H}), 7.40(\mathrm{~s}, 2 \mathrm{H}), 7.34(\mathrm{t}, J=7.6 \mathrm{~Hz}, 2 \mathrm{H}), 7.30-$ $7.25(\mathrm{~m}, 1 \mathrm{H}), 6.25-6.11(\mathrm{~m}, 2 \mathrm{H}), 5.99(\mathrm{~s}, 0.22 \mathrm{H}$, minor $), 5.95(\mathrm{dd}, J=$ $15.3,7.3 \mathrm{~Hz}, 0.22 \mathrm{H}$, minor), $5.84-5.81$ (m, $1.56 \mathrm{H}$, major), 5.75 (dd, $J=$ $15.3,5.4 \mathrm{~Hz}, 0.22 \mathrm{H}$, minor), 5.65 (dd, $J=14.9,6.6 \mathrm{~Hz}, 0.78 \mathrm{H}$, major), 5.57-5.54 (m, $1 \mathrm{H}), 4.90-4.87(\mathrm{~m}, 0.44 \mathrm{H}, \mathrm{minor}), 4.86-4.82(\mathrm{~m}$, $1.56 \mathrm{H}$, major), $4.64(\mathrm{~d}, J=11.2 \mathrm{~Hz}, 0.78 \mathrm{H}$, major), $4.63(\mathrm{~s}, 0.78 \mathrm{H}$, major), 4.57 (s, $0.22 \mathrm{H}$, minor), $4.40-4.38(\mathrm{~m}, 0.22 \mathrm{H}$, minor $), 4.19-4.16$ (m, $0.78 \mathrm{H}$, major), 4.08 (d, $J=10.8 \mathrm{~Hz}, 0.22 \mathrm{H}$, minor), 3.23 (dd, $J=$ $14.3,4.4 \mathrm{~Hz}, 0.22 \mathrm{H}$, minor), 3.09 (dd, $J=13.8,5.8 \mathrm{~Hz}, 0.78 \mathrm{H}$, major), $2.97(\mathrm{~s}, 0.66 \mathrm{H}$, minor $), 2.83-2.77(\mathrm{~m}, 0.78 \mathrm{H}$, major $), 2.80(\mathrm{~s}, 2.34 \mathrm{H}$, major), $2.69-2.64(\mathrm{~m}, 1.22 \mathrm{H}), 2.59-2.52(\mathrm{~m}, 1 \mathrm{H}), 2.42-2.35(\mathrm{~m}, 1 \mathrm{H})$, 2.03-1.99 (m, 1H), 1.91-1.87 (m, 2.34H, major), $1.85(\mathrm{~s}, 0.66 \mathrm{H}$, minor), $1.67-1.61(\mathrm{~m}, 1 \mathrm{H}), 1.41-1.36(\mathrm{~m}, 1 \mathrm{H}), 1.37-1.34(\mathrm{~m}, 1 \mathrm{H})$, $1.26(\mathrm{~s}, 0.66 \mathrm{H}, \mathrm{minor}), 1.22(\mathrm{~s}, 0.66 \mathrm{H}$, minor $), 1.19(\mathrm{~s}, 2.34 \mathrm{H}$, major $)$, $1.10(\mathrm{~s}, 2.34 \mathrm{H}$, major $), 1.06-1.01(\mathrm{~m}, 1 \mathrm{H}), 0.98-0.95(\mathrm{~m}, 3 \mathrm{H}), 0.95-$ $0.93(\mathrm{~m}, 3 \mathrm{H}), 0.90-0.86(\mathrm{~m}, J=7.3 \mathrm{~Hz}, 3 \mathrm{H}), 0.70(\mathrm{~d}, J=6.5 \mathrm{~Hz}, 2.34 \mathrm{H}$, major), 0.46 (d, $J=6.6 \mathrm{~Hz}, 0.66 \mathrm{H}$, minor) ppm; ${ }^{13} \mathrm{C}$ NMR $(151 \mathrm{MHz}$, $\left.\mathrm{MeOH}-d_{4}\right) \delta=195.2,195.2,177.3,176.8,172.2,172.1,171.4,171.3$, $150.8,140.3,140.2$, 137.9, 137.3, 137.0, 135.7, 135.7, 135.1, 134.5, 134.1, $133.5,132.1,131.4,131.4,131.3,131.1,130.1,130.0,130.0,129.5,129.2$, $129.2,129.0,128.5,128.4,127.7,127.3,81.4,79.3,73.1,72.3,72.2,71.3$, $68.4,62.2,61.5,61.4,55.2,54.7,43.0,42.9,38.3,36.7,36.2,35.1,34.7$, $33.1,32.5,29.4,29.2,28.3,28.2,27.5,26.7,26.4,25.9,25.4,16.0,15.5$, 15.1, 14.5, 14.0, 12.2, 12.0, 11.6, 10.7 ppm; IR (film) $\nu=3350,2964$, 2929, 2874, 1662, 1598, $1465 \mathrm{~cm}^{-1}$; MS (ESI) $\mathrm{m} / z 890\left[\mathrm{M}+\mathrm{H}^{+}\right], 907$ $\left[\mathrm{M}+\mathrm{NH}_{4}^{+}\right], 912\left[\mathrm{M}+\mathrm{Na}^{+}\right]$; HRMS (ESI) $m / z$ calcd for $\mathrm{C}_{48} \mathrm{H}_{57} \mathrm{~N}_{3} \mathrm{O}_{9} \mathrm{Cl}_{2} \mathrm{Na}\left[\mathrm{M}+\mathrm{Na}^{+}\right]$912.3364, found 912.3372.<smiles>CCC(C)C(C(=O)N[C@@H](Cc1cc(Cl)c(OCC(=O)c2ccccc2)c(Cl)c1)C(=O)NC(C(=O)OC1NC(=O)/C(C)=C/C[C@@H](O)/C(F)=C/C=C/[C@H](C)[C@H]1C)C(C)(O)Cl)c1ccccc1</smiles>

Compound S8. In a flame-dried Schlenk tube under argon, solid $\mathrm{AgOP}(\mathrm{O}) \mathrm{Ph}_{2}(13.6 \mathrm{mg}, 41.7 \mu \mathrm{mol})$ and F-TEDA-PF 6 (32.7 mg, $69.5 \mu \mathrm{mol}$ ) were stirred for ca. $10 \mathrm{~min}$ until a homogeneous gray powder was obtained. Dry acetone $(500 \mu \mathrm{L})$ was added, and the resulting gray suspension was stirred vigorously. Meanwhile, in a separate flask, the vinyl stannane $27(16.3 \mathrm{mg}, 13.8 \mu \mathrm{mol})$ was dissolved in acetone $(200 \mu \mathrm{L})$, 
and the obtained solution was slowly added to the suspension over $60 \mathrm{~min}$ via a syringe pump. Once the addition was complete, the mixture was diluted with EtOAc/tert-butyl methyl ether $(1: 1,10 \mathrm{~mL})$ and poured into saturated aqueous $\mathrm{NH}_{4} \mathrm{Cl}(10 \mathrm{~mL})$. The aqueous phase was extracted with a EtOAc/tert-butyl methyl ether $(1: 1,2 \times 30 \mathrm{~mL})$, and the combined extracts were dried over $\mathrm{Na}_{2} \mathrm{SO}_{4}$, filtered, and concentrated under reduced pressure. The residue was purified by flash chromatography on silica gel $\left(\mathrm{CH}_{2} \mathrm{Cl}_{2} /\right.$ tert-butyl methyl ether, $6: 1$ to $\left.2: 1\right)$ to afford the title compound as a white solid $(6.8 \mathrm{mg}, 54 \%):[\alpha]_{\mathrm{D}}{ }^{20}=-72.2$ $\left(c 0.4, \mathrm{CHCl}_{3}\right) ;{ }^{1} \mathrm{H}$ NMR $\left(400 \mathrm{MHz}, \mathrm{MeOH}-d_{4}\right) \delta=8.05-7.99(\mathrm{~m}$, $2 \mathrm{H}), 7.69-7.64(\mathrm{~m}, 1 \mathrm{H}), 7.54(\mathrm{dd}, J=8.4,7.1 \mathrm{~Hz}, 2 \mathrm{H}), 7.43(\mathrm{dd}, J=7.1$, $1.8 \mathrm{~Hz}, 2 \mathrm{H}), 7.39(\mathrm{~s}, 2 \mathrm{H}), 7.36-7.29(\mathrm{~m}, 2 \mathrm{H}), 7.29-7.22(\mathrm{~m}, 1 \mathrm{H}), 6.36$ (ddd, $J=15.6,10.7,1.5 \mathrm{~Hz}, 1 \mathrm{H}), 5.92(\mathrm{dd}, J=15.6,6.7 \mathrm{~Hz}, 1 \mathrm{H}), 5.80(\mathrm{~d}$, $J=2.5 \mathrm{~Hz}, 1 \mathrm{H}), 5.63-5.54(\mathrm{~m}, 1 \mathrm{H}), 5.59-5.52(\mathrm{~m}, 1 \mathrm{H}), 5.32(\mathrm{~d}, J=$ $2.2 \mathrm{~Hz}, 2 \mathrm{H}), 4.83-4.76(\mathrm{~m}, 1 \mathrm{H}), 4.65(\mathrm{~d}, J=11.2 \mathrm{~Hz}, 1 \mathrm{H}), 4.61(\mathrm{~s}, 1 \mathrm{H})$, 4.21 (ddd, $J=14.0,9.4,3.8 \mathrm{~Hz}, 1 \mathrm{H}), 3.07$ (dd, $J=13.8,6.2 \mathrm{~Hz}, 1 \mathrm{H}), 2.83$ (dd, $J=13.8,9.2 \mathrm{~Hz}, 1 \mathrm{H}), 2.77(\mathrm{~s}, 3 \mathrm{H}), 2.71-2.64(\mathrm{~m}, 1 \mathrm{H}), 2.61-2.56$ (m, 1H), 2.52-2.48 (m, 1H), 2.05-1.98 (m, 1H), $1.87(\mathrm{~s}, 3 \mathrm{H}), 1.39-$ $1.33(\mathrm{~m}, 1 \mathrm{H}), 1.19(\mathrm{~s}, 3 \mathrm{H}), 1.09(\mathrm{~s}, 3 \mathrm{H}), 1.07-1.02(\mathrm{~m}, 1 \mathrm{H}), 0.98(\mathrm{~d}, J=$ $6.9 \mathrm{~Hz}, 3 \mathrm{H}), 0.88(\mathrm{t}, J=7.3 \mathrm{~Hz}, 3 \mathrm{H}), 0.72(\mathrm{~d}, J=6.5 \mathrm{~Hz}, 3 \mathrm{H}) \mathrm{ppm} ;{ }^{13} \mathrm{C}$ NMR $\left(126 \mathrm{MHz}, \mathrm{MeOH}-d_{4}\right) \delta=195.2,176.7,172.3,171.5,171.4$, $160.9,158.8,150.8,140.3,137.5,137.2,135.7,135.2,135.1,131.3,130.0$, 129.1, 129.0, 128.5, 127.6, 127.3, 122.4, 122.3, 109.0, 108.9, 81.6, 75.9, 72.9, 70.2, 69.9, 61.4, 61.4, 54.9, 43.6, 38.0, 33.1, 32.6, 28.3, 25.7, 25.4, $16.0,14.5,12.2,10.7 \mathrm{ppm} ;{ }^{19} \mathrm{~F}$ NMR $\left(282 \mathrm{MHz}, \mathrm{MeOH}-d_{4}\right) \delta=-120.5$, -121.9 ppm; IR (film) $\nu=2958,2924,2855,1684,1601,1469 \mathrm{~cm}^{-1}$; MS (ESI) $m / z 907\left[\mathrm{M}+\mathrm{Na}^{+}\right]$; HRMS (ESI) $m / z$ calcd for $\mathrm{C}_{48} \mathrm{H}_{56} \mathrm{Cl}_{2} \mathrm{FN}_{3} \mathrm{O}_{9} \mathrm{Na}\left[\mathrm{M}+\mathrm{Na}^{+}\right]$930.3270, found 930.3272 .

Compound 37. $\mathrm{Ph}_{3} \mathrm{PAuCl}(12.9 \mathrm{mg}, 26.1 \mu \mathrm{mol}$ ) and AgOTf $(6.7 \mathrm{mg}, 26.1 \mu \mathrm{mol})$ were successively added to a stirred solution of $\mathbf{S} 7$ (5.8 $\mathrm{mg}, 6.5 \mu \mathrm{mol})$ and $32(14.0 \mathrm{mg}, 67.4 \mu \mathrm{mol})$ in benzene $(650 \mu \mathrm{L})$. After the reaction mixture had been stirred for $15 \mathrm{~min}$, saturated aqueous $\mathrm{NaHCO}_{3}$ was added. The aqueous layer was extracted with EtOAc $(3 \times 3 \mathrm{~mL})$, and the combined organic phases were washed with brine $(1 \mathrm{~mL})$, dried over $\mathrm{Na}_{2} \mathrm{SO}_{4}$, and evaporated. The crude product was purified by preparative TLC (tert-butyl methyl ether/ $\mathrm{CH}_{2} \mathrm{Cl}_{2}, 3: 1$ ).

The resulting product was dissolved in HOAc $(130 \mu \mathrm{L})$ and THF $(130 \mu \mathrm{L}) . \mathrm{Zn}$ powder $(17.1 \mathrm{mg}, 0.262 \mathrm{mmol})$ was added and the resulting mixture was stirred for $7 \mathrm{~h}$. The suspension was filtered and the filtrate neutralized with saturated aqueous $\mathrm{NaHCO}_{3}(1 \mathrm{~mL})$. The aqueous layer was extracted with EtOAc $(3 \times 3 \mathrm{~mL})$, and the combined extracts were washed with brine $(1 \mathrm{~mL})$, dried over $\mathrm{MgSO}_{4}$, filtered, and concentrated. The residue was purified by preparative HPLC $(150 \mathrm{~mm}$ Kromasil 5-C18, $5 \mu \mathrm{m}, \varnothing 30 \mathrm{~mm}, \mathrm{MeOH} / \mathrm{H}_{2} \mathrm{O}=75: 25,35 \mathrm{~mL} / \mathrm{min}$, 6.4 MPa, $308 \mathrm{~K}, \mathrm{UV}, 230 \mathrm{~nm}$ ) to afford the title compound as a white solid (1.9 mg, 37\%): $[\alpha]_{\mathrm{D}}{ }^{20}=-71.8$ (c 0.11, acetone); ${ }^{1} \mathrm{H}$ NMR $\left(600 \mathrm{MHz}\right.$, acetone- $d_{6}$, mixture of rotamers, ca. $\left.4: 1\right) \delta=7.72(\mathrm{~d}, J=$ $8.9 \mathrm{~Hz}, 0.2 \mathrm{H}$, minor), $7.68(\mathrm{~d}, J=9.5 \mathrm{~Hz}, 0.8 \mathrm{H}$, major $), 7.55-7.50(\mathrm{~m}$, $1.6 \mathrm{H}$, major), $7.46(\mathrm{~d}, J=7.0 \mathrm{~Hz}, 0.4 \mathrm{H}$, minor $), 7.37-7.29(\mathrm{~m}, 4 \mathrm{H})$, $7.28-7.23(\mathrm{~m}, 1.2 \mathrm{H}), 7.12(\mathrm{~d}, J=9.3 \mathrm{~Hz}, 0.8 \mathrm{H}), 6.27(\mathrm{dd}, J=15.7$, $10.1 \mathrm{~Hz}, 0.2 \mathrm{H}$, minor), $6.23-6.13(\mathrm{~m}, 2 \mathrm{H}), 6.01(\mathrm{dd}, J=15.7,6.9 \mathrm{~Hz}$, $0.2 \mathrm{H}$, minor), $5.96(\mathrm{~s}, 0.2 \mathrm{H}$, minor), $5.91-5.85(\mathrm{~m}, 1.6 \mathrm{H}$, major), 5.78 $(\mathrm{dd}, J=15.6,5.3 \mathrm{~Hz}, 0.2 \mathrm{H}$, minor), 5.56-5.48 $(\mathrm{m}, 1.8 \mathrm{H}), 5.00-4.96(\mathrm{~m}$, $0.2 \mathrm{H}$, minor $), 4.87-4.83(\mathrm{~m}, 0.8 \mathrm{H}$, major $), 4.72-4.65(\mathrm{~m}, 1 \mathrm{H}), 4.57(\mathrm{~d}$, $J=11.3 \mathrm{~Hz}, 0.8 \mathrm{H}$, major), 4.20 (s, $0.6 \mathrm{H}$, major), $4.11-4.04(\mathrm{~m}, 0.4 \mathrm{H}$, minor), $3.86-3.84(\mathrm{~m}, 0.2 \mathrm{H}$, minor), $3.73-3.69(\mathrm{~m}, 0.8 \mathrm{H}$, major), 3.31 (s, $0.6 \mathrm{H}$, minor), 3.23 (s, $2.4 \mathrm{H}$, major), $3.08(\mathrm{dd}, J=13.9,5.7 \mathrm{~Hz}, 1 \mathrm{H})$, $2.81-2.75(\mathrm{~m}, 1 \mathrm{H}), 2.70(\mathrm{~s}, 2.4 \mathrm{H}$, major), $2.71-2.66(\mathrm{~m}, 1.6 \mathrm{H})$ $2.50-2.46(\mathrm{~m}, 1 \mathrm{H}), 2.36(\mathrm{dt}, J=13.8,9.5 \mathrm{~Hz}, 1 \mathrm{H}), 2.02-1.97(\mathrm{~m}, 1 \mathrm{H})$, 1.84 (s, 2.4H, major), 1.81 (d, $J=6.2 \mathrm{~Hz}, 0.6 \mathrm{H}$, minor), $1.40-1.34(\mathrm{~m}$, $1 \mathrm{H}), 1.29$ (s, $0.6 \mathrm{H}$, minor), 1.23 (s, $0.6 \mathrm{H}$, minor), 1.22 (s, $2.4 \mathrm{H}$, major), $1.08(\mathrm{~s}, 2.4 \mathrm{H}$, major $), 1.03-0.99(\mathrm{~m}, 1 \mathrm{H}), 0.97(\mathrm{~d}, J=6.9 \mathrm{~Hz}, 3 \mathrm{H}), 0.83$ $(\mathrm{t}, J=7.4 \mathrm{~Hz}, 3 \mathrm{H}), 0.73(\mathrm{~d}, J=6.5 \mathrm{~Hz}, 2.4 \mathrm{H}$, major $), 0.47(\mathrm{~d}, J=6.5 \mathrm{~Hz}$, $0.6 \mathrm{H}$, minor) ppm; ${ }^{13} \mathrm{C}$ NMR $\left(151 \mathrm{MHz}\right.$, acetone- $\left.d_{6}\right) \delta=175.3,171.4$, $171.1,170.5,148.6,140.5,137.1,134.7,133.9,133.4,133.1,132.3,131.6$ $130.7,130.4,130.4,130.3,128.9,128.7,128.0,127.3,127.2,126.9,122.4$, $122.3,86.2,81.7,81.1,80.1,78.3,72.9,67.4,61.5,60.7,60.5,56.1,56.0$, 54.2 , 42.5, 42.0, 37.8, 37.3, 34.4, 34.1, 32.6, 31.6, 31.5, 28.5, 28.5, 25.6, 25.6, 25.0, 16.0, 15.0, 14.6, 12.1, 11.5, 11.2, 10.6 ppm; IR (film) $\nu=3338$,
2972, 2932, 1665, 1606, $1490 \mathrm{~cm}^{-1}$; MS (ESI) $\mathrm{m} / z 808\left[\mathrm{M}+\mathrm{Na}^{+}\right]$; HRMS (ESI) $m / z$ calcd for $\mathrm{C}_{41} \mathrm{H}_{53} \mathrm{~N}_{3} \mathrm{O}_{8} \mathrm{Cl}_{2} \mathrm{Na}\left[\mathrm{M}+\mathrm{Na}^{+}\right]$808.3102, found 808.3112 .

Compounds 39 and $40 . \mathrm{K}_{2} \mathrm{CO}_{3}(13.7 \mathrm{mg}, 99.1 \mu \mathrm{mol})$ and methyl$p$-toluenesulfonate $(36.9 \mathrm{mg}, 0.198 \mathrm{mmol})$ were added to a solution of S8 $(3.0 \mathrm{mg}, 3.3 \mu \mathrm{mol})$ in acetone $(10 \mu \mathrm{L})$. After being stirred at $50{ }^{\circ} \mathrm{C}$ for $24 \mathrm{~h}$, TLC analysis indicated that the starting material had been fully consumed. The material obtained after preparative TLC (tert-butyl methyl ether $/ \mathrm{CH}_{2} \mathrm{Cl}_{2}, 3: 1$ ) was used in the next step without further characterization.

Zn powder $(8.7 \mathrm{mg}, 0.113 \mathrm{mmol})$ was added to a stirred solution of the compound in HOAc $(70 \mu \mathrm{L})$ and THF $(70 \mu \mathrm{L})$. The resulting mixture was stirred for $7 \mathrm{~h}$ before the suspension was filtered and the filtrate neutralized with saturated aqueous $\mathrm{NaHCO}_{3}$. The aqueous were extracted with EtOAc $(3 \times 3 \mathrm{~mL})$, and the combined organic phases were washed with brine $(1 \mathrm{~mL})$, dried over $\mathrm{MgSO}_{4}$, filtered, and concentrated. The residue was purified by preparative HPLC $(150 \mathrm{~mm}$ Kromasil 5-C18, $5 \mu \mathrm{m}, \varnothing 30 \mathrm{~mm}, \mathrm{CH}_{3} \mathrm{CN} / \mathrm{H}_{2} \mathrm{O}=65: 35,35 \mathrm{~mL} / \mathrm{min}$, $4.2 \mathrm{MPa}, 308 \mathrm{~K}, \mathrm{UV}, 227 \mathrm{~nm})$ to afford compound $39(0.9 \mathrm{mg}, 34 \%)$ and compound $40(0.7 \mathrm{mg}, 28 \%)$ as a white solid each.

Analytical Data of Compound 39: $[\alpha]_{\mathrm{D}}{ }^{20}=-75.0$ (c 0.08 , acetone); ${ }^{1} \mathrm{H}$ NMR $\left(600 \mathrm{MHz}\right.$, acetone- $\left.d_{6}\right) \delta=7.63(\mathrm{~d}, J=9.5 \mathrm{~Hz}, 1 \mathrm{H})$, $7.58-7.50(\mathrm{~m}, 2 \mathrm{H}), 7.34-7.31(\mathrm{~d}, J=8.6 \mathrm{~Hz}, 4 \mathrm{H}), 7.27-7.22(\mathrm{~m}, 1 \mathrm{H})$, $7.04(\mathrm{~d}, J=9.4 \mathrm{~Hz}, 1 \mathrm{H}), 6.37(\mathrm{ddd}, J=15.6,10.7,1.7 \mathrm{~Hz}, 1 \mathrm{H}), 5.98(\mathrm{dd}$, $J=15.6,5.9 \mathrm{~Hz}, 1 \mathrm{H}), 5.85(\mathrm{~d}, J=2.2 \mathrm{~Hz}, 1 \mathrm{H}), 5.64(\mathrm{dd}, J=36.1,10.7 \mathrm{~Hz}$, $1 \mathrm{H}), 5.50(\mathrm{ddd}, J=8.8,6.9,1.7 \mathrm{~Hz}, 1 \mathrm{H}), 4.83(\mathrm{td}, J=9.2,5.8 \mathrm{~Hz}, 1 \mathrm{H})$, $4.72-4.68(\mathrm{~m}, 1 \mathrm{H}), 4.57(\mathrm{~d}, J=11.3 \mathrm{~Hz}, 1 \mathrm{H}), 4.16(\mathrm{~s}, 1 \mathrm{H}), 3.84$ (ddd, $J=20.7,10.5,3.4 \mathrm{~Hz}, 1 \mathrm{H}), 3.30(\mathrm{~s}, 3 \mathrm{H}), 3.06(\mathrm{dd}, J=13.9,5.8 \mathrm{~Hz}, 1 \mathrm{H})$, $2.72-2.61(\mathrm{~m}, 2 \mathrm{H}), 2.68(\mathrm{~s}, 3 \mathrm{H}), 2.44(\mathrm{ddd}, J=13.8,7.2,3.4 \mathrm{~Hz}, 1 \mathrm{H})$, $2.01-1.96(\mathrm{dtt}, J=9.3,6.7,3.3 \mathrm{~Hz}, 1 \mathrm{H}), 1.87(\mathrm{~s}, 3 \mathrm{H}), 1.41-1.35(\mathrm{~m}$, $1 \mathrm{H}), 1.22(\mathrm{~s}, 3 \mathrm{H}), 1.07(\mathrm{~s}, 3 \mathrm{H}), 1.05-1.00(\mathrm{~m}, 1 \mathrm{H}), 0.99(\mathrm{~d}, J=6.9 \mathrm{~Hz}$, $3 \mathrm{H}), 0.83(\mathrm{t}, J=7.4 \mathrm{~Hz}, 3 \mathrm{H}), 0.75(\mathrm{~d}, J=6.5 \mathrm{~Hz}, 3 \mathrm{H}) \mathrm{ppm} ;{ }^{13} \mathrm{C} \mathrm{NMR}$ $\left(151 \mathrm{MHz}\right.$, acetone- $\left.d_{6}\right) \delta=175.2,171.4,171.1,170.6,157.3,155.5$, $148.6,140.6,137.9,135.7,131.6,130.4,128.7,128.0,127.3,126.0,122.2$, $121.5,121.5,111.4,111.4,80.1,79.5,79.3,72.9,72.8,60.7,60.5,56.4$, $54.2,54.2,43.0,37.7,32.6,31.5,30.9,28.6,25.5,25.1,16.0,14.4,11.2$, $10.5 \mathrm{ppm} ;{ }^{19} \mathrm{~F}$ NMR $\left(470 \mathrm{MHz}\right.$, acetone- $\left.d_{6}\right) \delta=-119.9,-123.7 \mathrm{ppm}$; IR (film) $\nu=2967,2932,1735,1665,1606,1490 \mathrm{~cm}^{-1}$; MS (ESI) $\mathrm{m} / z$ $804\left[\mathrm{M}+\mathrm{H}^{+}\right], 821\left[\mathrm{M}+\mathrm{NH}_{4}^{+}\right]$; HRMS (ESI) $\mathrm{m} / z$ calcd for $\mathrm{C}_{41} \mathrm{H}_{52} \mathrm{~N}_{3} \mathrm{O}_{8} \mathrm{Cl}_{2} \mathrm{FNa}\left[\mathrm{M}+\mathrm{Na}^{+}\right]$826.3008, found 826.3012.

Analytical Data of Compound 40: $[\alpha]_{\mathrm{D}}{ }^{20}=-26.7$ (c 0.06 , acetone); ${ }^{1} \mathrm{H}$ NMR $\left(600 \mathrm{MHz}\right.$, acetone- $\left.d_{6}\right) \delta=8.65(\mathrm{~s}, 1 \mathrm{H}), 7.46(\mathrm{~s}$, $1 \mathrm{H}), 7.42-7.36(\mathrm{~m}, 4 \mathrm{H}), 7.34(\mathrm{~d}, J=9.4 \mathrm{~Hz}, 1 \mathrm{H}), 7.29(\mathrm{~s}, 3 \mathrm{H}), 6.37$ $(\mathrm{ddd}, J=15.7,10.7,1.8 \mathrm{~Hz}, 1 \mathrm{H}), 6.23(\mathrm{~d}, J=2.2 \mathrm{~Hz}, 1 \mathrm{H}), 6.01(\mathrm{dd}, J=$ 15.7, $5.3 \mathrm{~Hz}, 1 \mathrm{H}), 5.67(\mathrm{dd}, J=35.7,10.7 \mathrm{~Hz}, 1 \mathrm{H}), 5.56(\mathrm{t}, J=7.4 \mathrm{~Hz}$, $1 \mathrm{H}), 4.73(\mathrm{td}, J=9.4,5.2 \mathrm{~Hz}, 1 \mathrm{H}), 4.41(\mathrm{~d}, J=11.3 \mathrm{~Hz}, 1 \mathrm{H}), 4.04(\mathrm{t}, J=$ $5.3 \mathrm{~Hz}, 2 \mathrm{H}), 3.81$ (ddd, $J=23.7,11.0,3.5 \mathrm{~Hz}, 1 \mathrm{H}), 3.29$ (s, $3 \mathrm{H}), 3.11$ $(\mathrm{dd}, J=14.3,5.3 \mathrm{~Hz}, 1 \mathrm{H}), 2.81-2.79(\mathrm{~m}, 5 \mathrm{H}), 2.62(\mathrm{ddd}, J=14.2,10.9$, $8.2 \mathrm{~Hz}, 1 \mathrm{H}), 2.50-2.40(\mathrm{~m}, 1 \mathrm{H}), 2.10-2.06(\mathrm{~m}, 1 \mathrm{H}), 1.81(\mathrm{~s}, 3 \mathrm{H})$, $1.45-1.40(\mathrm{~m}, 1 \mathrm{H}), 1.06-0.99(\mathrm{~m}, 1 \mathrm{H}), 0.94(\mathrm{~d}, J=7.0 \mathrm{~Hz}, 3 \mathrm{H}), 0.85$ $(\mathrm{t}, J=7.4 \mathrm{~Hz}, 3 \mathrm{H}), 0.75(\mathrm{~d}, J=6.5 \mathrm{~Hz}, 3 \mathrm{H}) \mathrm{ppm} ;{ }^{13} \mathrm{C} \mathrm{NMR}(151 \mathrm{MHz}$, acetone- $\left.d_{6}\right) \delta=175.7,171.9,171.4,169.4,156.8,155.0,148.5,140.2$, 138.1, 135.6, 132.0, 130.2, 129.1, 128.2, 126.9, 126.5, 122.3, 121.1, 121.1, $112.1,112.0,79.6,79.4,77.1,61.5,56.3,54.2,54.1,54.1,42.7,41.6,41.5$, 36.1, 33.0, 31.9, 31.0, 25.5, 15.9, 14.5, 10.6, $10.2 \mathrm{ppm} ;{ }^{19} \mathrm{~F}$ NMR (470 MHz, acetone- $d_{6}$ ) $\delta=-125.5 \mathrm{ppm}$; IR (film) $\nu=2967,2932,1751,1677$, $1605,1490 \mathrm{~cm}^{-1}$; MS (ESI) $\mathrm{m} / z 746\left[\mathrm{M}+\mathrm{H}^{+}\right], 763\left[\mathrm{M}+\mathrm{NH}_{4}^{+}\right], 768$ $\left[\mathrm{M}+\mathrm{Na}^{+}\right]$; HRMS (ESI) $m / z$ calcd for $\mathrm{C}_{38} \mathrm{H}_{46} \mathrm{~N}_{3} \mathrm{O}_{7} \mathrm{Cl}_{2} \mathrm{FNa}\left[\mathrm{M}+\mathrm{Na}^{+}\right]$ 768.2589, found 768.2594 .

Compound 42. The compound was prepared analogously as a white solid $(1.8 \mathrm{mg}, 45 \%):[\alpha]_{\mathrm{D}}{ }^{20}=-91.2\left(c \quad 0.16\right.$, acetone); ${ }^{1} \mathrm{H}$ NMR $\left(600 \mathrm{MHz}, \mathrm{MeOH}-d_{4}\right.$, mixture of rotamers, ca. 4:1) $\delta=7.40-7.37$ (m, $2 \mathrm{H}), 7.36-7.30(\mathrm{~m}, 2 \mathrm{H}), 7.29-7.25(\mathrm{~m}, 1 \mathrm{H}), 7.23(\mathrm{~s}, 2 \mathrm{H}), 6.34(\mathrm{dd}, J=$ $16.1,6.3 \mathrm{~Hz}, 0.2 \mathrm{H}$, minor), 6.17 (dd, $J=16.0,7.6 \mathrm{~Hz}, 0.8 \mathrm{H}$, major), 6.04 (s, $0.2 \mathrm{H}$, minor), $5.75-5.72(\mathrm{~m}, 1 \mathrm{H}), 5.63(\mathrm{td}, J=7.2,4.0 \mathrm{~Hz}, 0.8 \mathrm{H}$, minor), $5.61-5.55(\mathrm{~m}, 1 \mathrm{H}), 4.77(\mathrm{dd}, J=9.4,6.1 \mathrm{~Hz}, 1 \mathrm{H}), 4.65(\mathrm{~d}, J=$ $11.3 \mathrm{~Hz}, 0.8 \mathrm{H}$, major), 4.64 (s, $0.8 \mathrm{H}$, major), 4.50 (s, $0.2 \mathrm{H}$, minor), 4.33 (d, $J=7.4 \mathrm{~Hz}, 0.2 \mathrm{H}$, minor), 4.19 (ddd, $J=9.2,5.1,1.6 \mathrm{~Hz}, 0.8 \mathrm{H}$, major) 4.03 (d, $J=10.9 \mathrm{~Hz}, 0.2 \mathrm{H}$, minor), 3.39 (s, $2.4 \mathrm{H}$, major), $3.33(\mathrm{~s}, 0.6 \mathrm{H}$, minor), $3.23-3.20$ (m, $0.2 \mathrm{H}$, minor), 3.02 (dd, $J=13.9,6.1 \mathrm{~Hz}, 0.8 \mathrm{H}$, 
major), 2.98 (s, 0.6H, minor), 2.96-2.91 (m, 0.4H, minor), 2.87 (s, $2.4 \mathrm{H}$, major), $2.80-2.71(\mathrm{~m}, 1.8 \mathrm{H}), 2.59-2.51(\mathrm{~m}, 1.6 \mathrm{H}$, major), $2.49-2.47(\mathrm{~m}, 0.2 \mathrm{H}$, minor), $2.06-1.98(\mathrm{~m}, 1 \mathrm{H}), 1.93(\mathrm{~d}, J=1.6 \mathrm{~Hz}$, $2.4 \mathrm{H}$, major), $1.86(\mathrm{~s}, 0.6 \mathrm{H}$, minor), $1.40-1.33(\mathrm{~m}, 1 \mathrm{H}), 1.29(\mathrm{~s}, 1 \mathrm{H})$, 1.23 (s, $0.6 \mathrm{H}$, minor), 1.18 (s, $0.6 \mathrm{H}$, minor), 1.15 (s, 2.4H, major), 1.08 (s, 2.4H, major), $1.06-1.00(\mathrm{~m}, 1 \mathrm{H}), 0.94(\mathrm{~d}, J=7.0 \mathrm{~Hz}, 2.4 \mathrm{H}$, major), $0.93-0.90(\mathrm{~m}, 1.2 \mathrm{H}$, minor), $0.88(\mathrm{t}, J=7.4 \mathrm{~Hz}, 2.4 \mathrm{H}$, major), 0.72 (d, $J=6.5 \mathrm{~Hz}, 2.4 \mathrm{H}$, major), 0.55 (d, $J=6.5 \mathrm{~Hz}, 0.6 \mathrm{H}$, minor) ppm; ${ }^{13} \mathrm{C} \mathrm{NMR}$ $\left(151 \mathrm{MHz}, \mathrm{MeOH}-d_{4}\right) \delta=176.8,172.7,171.4,171.4,150.0,148.7$, 146.4, 139.0, 135.8, 130.5, 130.4, 130.2, 129.2, 129.0, 128.8, 128.6, 128.0, $127.4,127.2,126.8,123.3,111.1,110.3,88.2,85.9,81.2,78.7,72.9,72.3$, 71.7, 68.3, 61.8, 61.5, 56.7, 55.4, 55.1, 43.7, 43.5, 37.8, 36.4, 35.1, 34.7, $33.7,33.1,32.4,29.4,28.0,27.6,26.5,26.3,25.7,25.4,15.8,15.6,15.3$, 14.6, 13.6, 11.7, 11.1, 10.7 ppm; IR (film) $\nu=2853,1732,1675,1608$, $1450 \mathrm{~cm}^{-1}$; MS (ESI) $\mathrm{m} / z 784\left[\mathrm{M}+\mathrm{H}^{+}\right], 784\left[\mathrm{M}+\mathrm{NH}_{4}^{+}\right], 806$ $\left[\mathrm{M}+\mathrm{Na}^{+}\right]$; HRMS (ESI) $m / z$ calcd for $\mathrm{C}_{41} \mathrm{H}_{51} \mathrm{~N}_{3} \mathrm{O}_{8} \mathrm{Cl}_{2} \mathrm{Na}\left[\mathrm{M}+\mathrm{Na}^{+}\right]$ 806.2945, found 806.2948.

Compound 41.

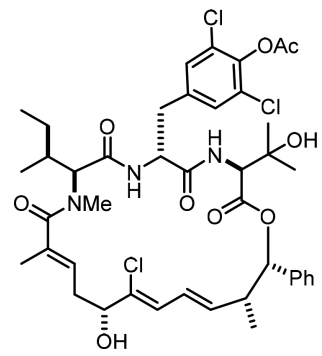

2,6-Lutidine (1.0 M in THF, $65 \mu \mathrm{L}, 65 \mu \mathrm{mol}$ ) and anhydrous $\mathrm{CuCl}_{2}$ $(17.2 \mathrm{mg}, 128 \mu \mathrm{mol})$ were consecutively added to a solution of stannane $27 \mathbf{b}(7.0 \mathrm{mg}, 6.3 \mu \mathrm{mol})$ in THF $(600 \mu \mathrm{L})$. The resulting green mixture was stirred at ambient temperature for $72 \mathrm{~h}$. The orange suspension was diluted with EtOAc $(30 \mathrm{~mL})$ and poured into aqueous saturated $\mathrm{NH}_{4} \mathrm{OH} / \mathrm{NH}_{4} \mathrm{Cl}$ solution $(1: 9,10 \mathrm{~mL})$. The phases were separated, and the aqueous phase was extracted with EtOAc $(2 \times 30 \mathrm{~mL})$. The combined extracts were dried over $\mathrm{Na}_{2} \mathrm{SO}_{4}$, filtered, and concentrated under reduced pressure. The residue was purified by flash chromatography on silica gel (EtOAc/hexanes, 1:1) to afford the title compound as a white solid $(4.4 \mathrm{mg}, 82 \%):[\alpha]_{\mathrm{D}}{ }^{20}=-74.5(c 0.4$, $\mathrm{MeOH}) ;{ }^{1} \mathrm{H} \mathrm{NMR}\left(400 \mathrm{MHz}, \mathrm{CDCl}_{3}\right) \delta=7.38-7.29(\mathrm{~m}, 5 \mathrm{H}), 7.06(\mathrm{~s}$, $3 \mathrm{H}), 6.54(\mathrm{~d}, J=8.4 \mathrm{~Hz}, 1 \mathrm{H}), 6.41(\mathrm{ddd}, J=15.3,10.2,1.3 \mathrm{~Hz}, 1 \mathrm{H}), 6.25$ $(\mathrm{d}, J=10.2 \mathrm{~Hz}, 1 \mathrm{H}), 5.92-5.87(\mathrm{~m}, 1 \mathrm{H}), 5.86(\mathrm{~d}, J=2.7 \mathrm{~Hz}, 1 \mathrm{H}), 5.79$ $(\mathrm{s}, 1 \mathrm{H}), 5.55(\mathrm{td}, J=7.7,1.7 \mathrm{~Hz}, 1 \mathrm{H}), 5.41(\mathrm{dd}, J=7.9,3.5 \mathrm{~Hz}, 1 \mathrm{H})$, $4.62-4.55(\mathrm{~m}, 1 \mathrm{H}), 4.51(\mathrm{~d}, J=8.8 \mathrm{~Hz}, 1 \mathrm{H}), 4.47(\mathrm{~d}, J=11.3 \mathrm{~Hz}, 2 \mathrm{H})$, 3.64-3.59 (m, 1H), $2.99(\mathrm{dd}, J=14.0,7.7 \mathrm{~Hz}, 1 \mathrm{H}), 2.77(\mathrm{~s}, 3 \mathrm{H})$, 2.74-2.64 (m, 2H), 2.61-2.57 (m, 1H), $2.12(\mathrm{~s}, 3 \mathrm{H}), 2.11-2.05(\mathrm{~m}$, $1 \mathrm{H}), 1.88(\mathrm{~d}, J=1.5 \mathrm{~Hz}, 3 \mathrm{H}), 1.45-1.32(\mathrm{~m}, 2 \mathrm{H}), 1.18(\mathrm{~s}, 3 \mathrm{H}), 1.05(\mathrm{~s}$, $3 \mathrm{H}), 1.03(\mathrm{~d}, J=7.0 \mathrm{~Hz}, 3 \mathrm{H}), 0.91(\mathrm{t}, J=7.4 \mathrm{~Hz}, 3 \mathrm{H}), 0.83(\mathrm{~d}, J=6.4 \mathrm{~Hz}$, $3 \mathrm{H}) \mathrm{ppm} ;{ }^{13} \mathrm{C}$ NMR $\left(101 \mathrm{MHz}, \mathrm{CDCl}_{3}\right) \delta=175.5,170.7,170.4,169.8$, $169.5,146.9,140.0,137.5,135.6,129.9,129.7,129.1,128.3,127.3,127.2$, $125.8,125.4,121.2,80.2,74.8,72.2,61.1,60.6,54.2,42.2,36.1,32.4$, $31.3,30.2,27.1,26.6,25.0,21.3,15.9,14.7,13.1,10.6$ ppm; IR (film) $\nu=$ $3361,2964,2929,1735,1663,1606,1489 \mathrm{~cm}^{-1}$; MS (ESI) $\mathrm{m} / z 870$ $\left[\mathrm{M}+\mathrm{Na}^{+}\right]$; HRMS (ESI) $m / z$ calcd for $\mathrm{C}_{42} \mathrm{H}_{52} \mathrm{Cl}_{3} \mathrm{~N}_{3} \mathrm{O}_{9} \mathrm{Na}\left[\mathrm{M}+\mathrm{Na}^{+}\right]$ 870.2261 , found 870.2269 .

Representative Procedure for Phenacyl Cleavage. Compound $35 . \mathrm{Zn}$ powder $(11.6 \mathrm{mg}, 0.177 \mathrm{mmol})$ was added to a stirred solution of $30(4.0 \mathrm{mg}, 4.4 \mu \mathrm{mol})$ in HOAc $(90 \mu \mathrm{L})$ and THF $(90 \mu \mathrm{L})$ at room temperature. The resulting mixture was stirred for $7 \mathrm{~h}$ before the suspension was filtered. The filtrate was neutralized with saturated aqueous $\mathrm{NaHCO}_{3}$, and the aqueous layer was extracted with EtOAc $(3 \times 3 \mathrm{~mL})$; the combined organic layers were washed with brine $(1 \mathrm{~mL})$, dried over $\mathrm{MgSO}_{4}$, filtered, and concentrated. The residue was purified by preparative HPLC (150 mm Kromasil 5-C18, $5 \mu \mathrm{m}, \varnothing$ $30 \mathrm{~mm}, \mathrm{MeOH} / \mathrm{H}_{2} \mathrm{O}=70: 30,35 \mathrm{~mL} / \mathrm{min}, 7.0 \mathrm{MPa}, 308 \mathrm{~K}, \mathrm{UV}$, $230 \mathrm{~nm})$ to afford the title compound as a white solid $(2.7 \mathrm{mg}, 78 \%)$ : $[\alpha]_{\mathrm{D}}{ }^{20}=-21.1$ (c 0.19, acetone); ${ }^{1} \mathrm{H}$ NMR $\left(600 \mathrm{MHz}, \mathrm{MeOH}-d_{4}\right.$, mixture of rotamers, ca. $4: 1) \delta=7.43-7.42(\mathrm{~m}, 1.6 \mathrm{H}$, major $), 7.40-7.38$ (m, 0.4H, minor), 7.34-7.30 (m, $2 \mathrm{H}), 7.26-7.22(\mathrm{~m}, 1.4 \mathrm{H}), 7.21$ (s, 1.6H), 6.46-6.41 (m, 0.2H, minor), $6.38(\mathrm{ddd}, J=15.2,10.7,1.5 \mathrm{~Hz}$, $0.8 \mathrm{H}$, major), $6.06-6.01(\mathrm{~m}, 1 \mathrm{H}), 5.97-5.92(\mathrm{~m}, 0.4 \mathrm{H}$, minor $), 5.87$ (dd, $J=15.3,6.4 \mathrm{~Hz}, 0.8 \mathrm{H}$, major), $5.80(\mathrm{~d}, J=2.5 \mathrm{~Hz}, 0.8 \mathrm{H}$, major), 5.48 (dd, $J=8.5,6.9 \mathrm{~Hz}, 1 \mathrm{H}), 4.70$ (dd, $J=8.6,6.9 \mathrm{~Hz}, 0.8 \mathrm{H}$, major), 4.62 (d, $J=11.1 \mathrm{~Hz}, 0.8 \mathrm{H}$, major), $4.58-4.57(\mathrm{~m}, 2.6 \mathrm{H}), 4.12(\mathrm{dd}, J=9.2,3.4 \mathrm{~Hz}$, $0.8 \mathrm{H}$, major), $2.98-2.93(\mathrm{~m}, 1.4 \mathrm{H}), 2.77-2.73(\mathrm{~m}, 1 \mathrm{H}), 2.76(\mathrm{~s}, 2.4 \mathrm{H}$, major), $2.67(\mathrm{t}, J=7.2 \mathrm{~Hz}, 1 \mathrm{H}), 2.56-2.51(\mathrm{~m}, 1.4 \mathrm{H}), 2.50-2.44(\mathrm{~m}$, $0.8 \mathrm{H}$, major), 2.05-1.97 (m, 1H), $1.85(\mathrm{~s}, 2.4 \mathrm{H}$, major), $1.82(\mathrm{~s}, 0.6 \mathrm{H}$, minor), 1.81 (s, $0.6 \mathrm{H}$, minor), 1.79 (s, $2.4 \mathrm{H}$, major), $1.37-1.33(\mathrm{~m}, 2 \mathrm{H})$, $1.25(\mathrm{~s}, 0.6 \mathrm{H}$, minor $), 1.20(\mathrm{~s}, 0.6 \mathrm{H}$, minor $), 1.14(\mathrm{~s}, 2.4 \mathrm{H}$, major $), 1.04$ (s, 2.4H, major), 0.99 (d, $J=6.9 \mathrm{~Hz}, 3 \mathrm{H}), 0.95-0.90(\mathrm{~m}, 1 \mathrm{H}), 0.88$ (d, $J=7.4 \mathrm{~Hz}, 3 \mathrm{H}), 0.72(\mathrm{~d}, J=6.5 \mathrm{~Hz}, 2.4 \mathrm{H}), 0.50(\mathrm{~d}, J=6.5 \mathrm{~Hz}, 0.6 \mathrm{H}) \mathrm{ppm}$; ${ }^{13} \mathrm{C}$ NMR $\left(151 \mathrm{MHz}, \mathrm{MeOH}-d_{4}\right) \delta=176.9,172.6,171.6,171.5,140.4$, 138.1, 137.3, 134.2, 130.4, 129.0, 128.5, 128.4, 127.7, 127.4, 127.1, 81.7, $76.4,72.9,61.4,55.4,43.5,37.5,33.8,33.1,32.6,28.3,25.5,25.5,15.9$, 14.6, 13.1, 12.2, 10.6 ppm; IR (film) $\nu=3349,2966,2929$, 1603, $1490 \mathrm{~cm}^{-1}$; MS (ESI) $m / z: 786\left[\mathrm{M}+\mathrm{H}^{+}\right], 803\left[\mathrm{M}+\mathrm{NH}_{4}^{+}\right], 808$ $\left[\mathrm{M}+\mathrm{Na}^{+}\right]$; HRMS (ESI) $m / z$ calcd for $\mathrm{C}_{41} \mathrm{H}_{53} \mathrm{~N}_{3} \mathrm{O}_{8} \mathrm{Cl}_{2} \mathrm{Na}\left[\mathrm{M}+\mathrm{Na}^{+}\right]$ 808.3102, found 808.3107.

Compound 38. The compound was prepared analogously from $\mathbf{S 8}$ $(4.9 \mathrm{mg}, 5.4 \mu \mathrm{mol})$ as a white solid $(3.7 \mathrm{mg}, 87 \%)$ : preparative HPLC ( $150 \mathrm{~mm}$ YMC ODS-A $5 \mu \mathrm{m}, \varnothing 20 \mathrm{~mm}, \mathrm{MeOH} / \mathrm{H}_{2} \mathrm{O}=75: 25,15 \mathrm{~mL} /$ min, $8.8 \mathrm{MPa}, 298 \mathrm{~K}, \mathrm{UV}, 220 \mathrm{~nm}) ;[\alpha]_{\mathrm{D}}{ }^{20}=-35.2$ (c 0.23, acetone); ${ }^{1} \mathrm{H}$ NMR $\left(600 \mathrm{MHz}, \mathrm{MeOH}-d_{4}\right.$, mixture of rotamers, ca. 5.7:1) $\delta=$ 7.44-7.40 (m, 1.7H, major), 7.39-7.38 (m, 0.3H, minor), 7.35-7.31 $(\mathrm{m}, 2 \mathrm{H}), 7.28-7.23(\mathrm{~m}, 1.3 \mathrm{H}), 7.21(\mathrm{~s}, 1.7 \mathrm{H}$, major $), 6.36$ (ddd, $J=$ $15.6,10.7,1.4 \mathrm{~Hz}, 1 \mathrm{H}), 6.05-6.01(\mathrm{~m}, 0.3 \mathrm{H}$, minor), 5.91 (dd, $J=15.5$, $6.8 \mathrm{~Hz}, 0.85 \mathrm{H}$, major $), 5.79(\mathrm{~d}, J=2.5 \mathrm{~Hz}, 0.85 \mathrm{H}$, major $), 5.68-5.54(\mathrm{~m}$ $2 \mathrm{H}), 4.72(\mathrm{dd}, J=8.9,6.6 \mathrm{~Hz}, 1 \mathrm{H}), 4.65(\mathrm{~d}, J=11.1 \mathrm{~Hz}, 0.85 \mathrm{H}$, major), $4.59(\mathrm{~s}, 0.85 \mathrm{H}$, major $), 4.49(\mathrm{~s}, 0.15 \mathrm{H}$, minor $), 4.39-4.36(\mathrm{~m}, 0.15 \mathrm{H}$, minor), $4.26-4.19$ (m, $0.85 \mathrm{H}$, major), $4.09(\mathrm{~d}, J=7.2 \mathrm{~Hz}, 0.15 \mathrm{H}$, minor), 3.13 (dd, $J=14.4,4.8 \mathrm{~Hz}, 0.15 \mathrm{H}$, minor), $3.00-2.92(\mathrm{~m}, 1.3 \mathrm{H})$, $2.840(\mathrm{dd}, J=14.3,10.6 \mathrm{~Hz}, 0.15 \mathrm{H}), 2.76$ (s, $2.55 \mathrm{H}$, major), $2.75-2.72$ (m, 0.85H, major), 2.69-2.63 (m, 1H), 2.63-2.56 (m, 1H), 2.54-2.47 $(\mathrm{m}, 1 \mathrm{H}), 2.05-1.96(\mathrm{~m}, 0.85 \mathrm{H}$, major $), 1.88-1.83(\mathrm{~m}, 3.15 \mathrm{H}), 1.39-$ $1.32(\mathrm{~m}, 1 \mathrm{H}), 1.26(\mathrm{~s}, 0.45 \mathrm{H}$, minor $), 1.23(\mathrm{~s}, 0.45 \mathrm{H}, \mathrm{minor}), 1.16(\mathrm{~s}$, $2.55 \mathrm{H}$, major), 1.05 (s, $2.55 \mathrm{H}$, major), $1.04-0.99(\mathrm{~m}, 1 \mathrm{H}), 0.97(\mathrm{~d}, J=$ $6.9 \mathrm{~Hz}, 2.55 \mathrm{H}$, major), $0.93(\mathrm{~d}, J=6.9 \mathrm{~Hz}, 0.45 \mathrm{H}$, minor), $0.87(\mathrm{t}, J=$ $7.4 \mathrm{~Hz}, 3 \mathrm{H}), 0.72(\mathrm{~d}, J=6.5 \mathrm{~Hz}, 2.55 \mathrm{H}$, major), $0.47(\mathrm{~d}, J=6.5 \mathrm{~Hz}$, $0.45 \mathrm{H}$, minor) $\mathrm{ppm} ;{ }^{13} \mathrm{C} \mathrm{NMR}\left(151 \mathrm{MHz}, \mathrm{MeOH}-d_{4}\right) \delta=176.8,172.8$, $171.6,171.5,160.9,159.1,150.2,140.4,137.7,135.4,130.6,129.2,128.6$, $127.8,127.4,123.5,122.5,122.5,109.1,109.0,81.7,73.1,70.3,70.1$, 61.6, 55.4, 43.8, 37.9, 33.2, 33.2, 32.8, 28.4, 25.7, 25.6, 16.0, 14.6, 12.4, $10.8 \mathrm{ppm} ;{ }^{19} \mathrm{~F}$ NMR $\left(282 \mathrm{MHz}, \mathrm{MeOH}-d_{4}\right) \delta=-120.4,-121.7 \mathrm{ppm}$; IR (film) $\nu=3331,2970,2931,2877,1664,1604,1522,1490 \mathrm{~cm}^{-1}$; MS (ESI) $m / z 812\left[\mathrm{M}+\mathrm{Na}^{+}\right]$; HRMS (ESI) $\mathrm{m} / z$ calcd for $\mathrm{C}_{40} \mathrm{H}_{50} \mathrm{~N}_{3} \mathrm{O}_{8} \mathrm{Cl}_{2} \mathrm{FNa}\left[\mathrm{M}+\mathrm{Na}^{+}\right]$812.2851, found 812.2856.

Compound 43. The compound was prepared analogously from 26 (6.6 $\mathrm{mg}, 7.4 \mu \mathrm{mol}$ ) as a white solid (4.6 $\mathrm{mg}, 80 \%)$ : purification by preparative HPLC (150 mm YMC Pack Pro C18, $5 \mu \mathrm{m}, \varnothing 10 \mathrm{~mm}$, $\mathrm{MeOH} / \mathrm{H}_{2} \mathrm{O}=80: 20,4.7 \mathrm{~mL} / \mathrm{min}, 9.6 \mathrm{MPa}, 308 \mathrm{~K}$, UV, $\left.220 \mathrm{~nm}\right)$; $[\alpha]_{\mathrm{D}}{ }^{20}=-106$ (c 0.1, acetone); ${ }^{1} \mathrm{H}$ NMR $\left(600 \mathrm{MHz}\right.$, acetone- $d_{6}$ mixture of rotamers, ca. $2.3: 1) \delta=8.65(\mathrm{~s}, 0.6 \mathrm{H}), 7.79-7.70(\mathrm{~m}, 0.9 \mathrm{H})$ $7.51(\mathrm{~d}, J=8.8 \mathrm{~Hz}, 0.2 \mathrm{H}), 7.48-7.44(\mathrm{~m}, 2.2 \mathrm{H}), 7.38-7.27(\mathrm{~m}, 4.5 \mathrm{H})$, $7.14(\mathrm{~d}, J=9.2 \mathrm{~Hz}, 0.6 \mathrm{H}), 6.38(\mathrm{dd}, J=16.2,5.9 \mathrm{~Hz}, 0.3 \mathrm{H}$, minor $)$, $6.21-6.09(\mathrm{~m}, 1 \mathrm{H}), 5.87(\mathrm{~d}, J=9.2 \mathrm{~Hz}, 0.3 \mathrm{H}$, minor $), 5.76(\mathrm{~d}, J=2.9 \mathrm{~Hz}$, $0.7 \mathrm{H}$, major $), 5.63-5.56(\mathrm{~m}, 1 \mathrm{H}), 5.56-5.48(\mathrm{~m}, 0.7 \mathrm{H}$, major $), 4.92(\mathrm{~s}$, $0.3 \mathrm{H}$, minor), $4.89-4.83(\mathrm{~m}, 0.7 \mathrm{H}$, major $), 4.78(\mathrm{~s}, 0.3 \mathrm{H}$, minor $), 4.72$ (d, $J=9.5 \mathrm{~Hz}, 0.7 \mathrm{H}$, major), $4.59-4.57(\mathrm{~m}, 1.3 \mathrm{H}), 4.56-4.51(\mathrm{~m}, 0.7 \mathrm{H}$, major), $4.20(\mathrm{~d}, J=10.9 \mathrm{~Hz}, 0.3 \mathrm{H}$, minor $), 4.14(\mathrm{~s}, 0.5 \mathrm{H}$, major $), 3.82(\mathrm{~s}$, $0.2 \mathrm{H}$, minor), $3.40-3.34(\mathrm{~m}, 0.3 \mathrm{H}$, minor), $3.12(\mathrm{dd}, J=14.0,5.5 \mathrm{~Hz}$, $0.7 \mathrm{H}$, major), 2.98 (d, $J=14.0 \mathrm{~Hz}, 0.3 \mathrm{H}$, minor), 2.95 (s, 0.9H, major), 2.81 (s, $4.4 \mathrm{H}$, major), $2.77-2.75(\mathrm{~m}, 0.7 \mathrm{H}$, major), 2.58 (dt, $J=13.0$, $9.6 \mathrm{~Hz}, 0.7 \mathrm{H}$, major), $2.49(\mathrm{dt}, J=12.5,5.3 \mathrm{~Hz}, 0.7 \mathrm{H}$, major), $2.42-2.37$ (m, $0.3 \mathrm{H}$, minor), $2.01-1.97(\mathrm{~m}, 0.7 \mathrm{H}$, major), $1.94(\mathrm{~s}, 2.1 \mathrm{H}$, major $)$, $1.90-1.88$ (s, $0.3 \mathrm{H}$, minor), $1.78(\mathrm{~s}, 0.9 \mathrm{H}$, minor), $1.42-1.37(\mathrm{~m}, 0.7 \mathrm{H}$, major), $1.33-1.25(\mathrm{~m}, 2.4 \mathrm{H}), 1.22(\mathrm{~s}, 3.1 \mathrm{H}), 1.12(\mathrm{~s}, 2.1 \mathrm{H}$, major $)$, $1.05-0.99(\mathrm{~m}, 0.7 \mathrm{H}$, major), $0.92-0.88(\mathrm{~m}, 3 \mathrm{H}), 0.88-0.83(\mathrm{~m}, 3 \mathrm{H})$, $0.76(\mathrm{~d}, J=6.5 \mathrm{~Hz}, 2.1 \mathrm{H}$, major $), 0.42(\mathrm{~d}, J=6.5 \mathrm{~Hz}, 0.9 \mathrm{H}$, minor) ppm; ${ }^{13} \mathrm{C}$ NMR $\left(151 \mathrm{MHz}\right.$, acetone- $\left.d_{6}\right) \delta=175.6,174.7,171.8,171.7,171.2$, 
171.1, 171.0, 170.6, 148.6, 148.0, 145.4, 139.8, 139.1, 135.6, 135.3, 132.7, $131.7,130.3,130.0,129.0,128.7,128.3,128.2,127.7,126.8,126.5,126.1$, $122.4,122.3,111.2,110.1,91.7,85.1,83.2,80.2,76.6,72.6,71.7,67.5$, $62.2,61.9,61.3,61.1,60.7,55.5,54.2,43.2,43.0,37.8,37.4,36.8,35.2$, 34.6, 32.7, 31.6, 28.4, 28.3, 27.8, 26.3, 26.0, 25.7, 25.2, 16.1, 15.5, 15.2, $14.8,14.4,13.5,11.7,10.6,10.1 \mathrm{ppm}$; IR (film) $\nu=3342,2970$, 2931, 2877, 1738, 1605, $1521 \mathrm{~cm}^{-1}$; MS (ESI) $\mathrm{m} / z 770\left[\mathrm{M}+\mathrm{H}^{+}\right]$, $787\left[\mathrm{M}+\mathrm{Na}^{+}\right], 792\left[\mathrm{M}+\mathrm{Na}^{+}\right]$; HRMS (ESI) $\mathrm{m} / z$ calcd for $\mathrm{C}_{40} \mathrm{H}_{49} \mathrm{~N}_{3} \mathrm{O}_{8} \mathrm{Cl}_{2} \mathrm{Na}\left[\mathrm{M}+\mathrm{Na}^{+}\right]$792.2789, found 792.2795.

Compound 36. The compound was prepared analogously from S7 ( $4.0 \mathrm{mg}, 4.5 \mu \mathrm{mol})$ as a white solid $(2.6 \mathrm{mg}, 75 \%)$ : preparative HPLC (150 mm YMC Pack Pro C18, $5 \mu \mathrm{m}, \varnothing 10 \mathrm{~mm}, \mathrm{MeOH} / \mathrm{H}_{2} \mathrm{O}=80: 20$, $4.7 \mathrm{~mL} / \mathrm{min}, 9.6 \mathrm{MPa}, 308 \mathrm{~K}, \mathrm{UV}, 220 \mathrm{~nm}) ;[\alpha]_{\mathrm{D}}{ }^{20}=-91.0(c 0.2$, acetone); ${ }^{1} \mathrm{H}$ NMR $\left(600 \mathrm{MHz}, \mathrm{MeOH}-d_{4}\right.$, mixture of rotamers, ca. $3.5: 1) \delta=7.42(\mathrm{~d}, J=7.4 \mathrm{~Hz}, 1.56 \mathrm{H}$, major $), 7.39(\mathrm{~d}, J=7.9 \mathrm{~Hz}, 0.44 \mathrm{H}$, minor), 7.35-7.30 (m, 2H), 7.27-7.24 (m, 1.44H), $7.22(\mathrm{~s}, 1.56 \mathrm{H})$, $6.24-6.09(\mathrm{~m}, 2 \mathrm{H}), 5.99(\mathrm{~s}, 0.22 \mathrm{H}$, minor $), 5.94(\mathrm{dd}, J=15.3,7.3 \mathrm{~Hz}$, $0.22 \mathrm{H}$, minor), $5.85-5.79(\mathrm{~m}, 1.56 \mathrm{H}$, major), $5.75(\mathrm{dd}, J=15.3,5.4 \mathrm{~Hz}$, $0.22 \mathrm{H}$, minor), 5.65 (dd, $J=14.8,6.6 \mathrm{~Hz}, 0.78 \mathrm{H}$, major), $5.55(\mathrm{td}, J=$ $6.8,6.1,3.4 \mathrm{~Hz}, 1 \mathrm{H}), 4.76(\mathrm{dd}, J=9.3,6.2 \mathrm{~Hz}, 1 \mathrm{H}), 4.63(\mathrm{~d}, J=11.2 \mathrm{~Hz}$, $0.78 \mathrm{H}$, major), $4.60(\mathrm{~s}, 0.78 \mathrm{H}$, major $), 4.56(\mathrm{~s}, 0.22 \mathrm{H}$, minor $)$, $4.41-4.32(\mathrm{~m}, 0.22 \mathrm{H}$, minor), $4.2-4.13(\mathrm{~m}, 0.78 \mathrm{H}$, major), 4.07 (d, $J=$ $10.8 \mathrm{~Hz}, 0.22 \mathrm{H}$, minor), 3.14 (dd, $J=14.3,4.6 \mathrm{~Hz}, 0.22 \mathrm{H}$, minor), 3.00 (dd, $J=13.8,6.2 \mathrm{~Hz}, 0.78 \mathrm{H}$, major), 2.96 (s, $0.66 \mathrm{H}$, minor), $2.92-2.84$ (m, $0.22 \mathrm{H}$, minor), $2.78(\mathrm{~s}, 2.34 \mathrm{H}$, major), $2.73(\mathrm{dd}, J=13.8,9.4 \mathrm{~Hz}$, $0.78 \mathrm{H}$, major), $2.69-2.62(\mathrm{~m}, 1.22 \mathrm{H}), 2.55-2.50(\mathrm{~m}, 1 \mathrm{H}), 2.41-2.35$ (m, $0.78 \mathrm{H}$, major), $2.04-1.95(\mathrm{~m}, 0.78 \mathrm{H}$, major), $1.87(\mathrm{~d}, J=1.5 \mathrm{~Hz}$, $2.34 \mathrm{H}$, major), $1.83(\mathrm{~s}, 0.88 \mathrm{H}), 1.39-1.31(\mathrm{~m}, 1 \mathrm{H}), 1.29(\mathrm{~s}, 1 \mathrm{H}), 1.24$ (s, $0.66 \mathrm{H}$, minor), $1.20(\mathrm{~s}, 0.66 \mathrm{H}$, minor), $1.16(\mathrm{~s}, 2.34 \mathrm{H}$, major $), 1.06$ (s, 2.34H, major), $1.06-1.00(\mathrm{~m}, 1 \mathrm{H}), 0.97(\mathrm{~d}, J=6.9 \mathrm{~Hz}, 2.34 \mathrm{H}$, major), 0.95 (d, $J=7.1 \mathrm{~Hz}, 0.66 \mathrm{H}$, minor), $0.87(\mathrm{t}, J=7.4 \mathrm{~Hz}, 3 \mathrm{H}), 0.69$ (d, $J=6.5 \mathrm{~Hz}, 2.34 \mathrm{H}$, major), 0.44 (d, $J=6.5 \mathrm{~Hz}, 0.66 \mathrm{H}$, minor) ppm; ${ }^{13} \mathrm{C}$ NMR $\left(151 \mathrm{MHz}, \mathrm{MeOH}-d_{4}\right) \delta=177.3,176.8,172.4,172.4,172.1$, 171.4, 171.3, 171.3, 149.7, 140.3, 140.2, 137.2, 137.0, 135.1, 134.5, 134.2, 133.4, 132.1, 132.1, 131.4, 131.3, 131.1, 130.8, 130.5, 130.4, 129.5, 129.2, 129.0, 128.5, 128.4, 128.4, 127.7, 127.3, 123.4, 123.3, 81.4, 79.3, 73.1, 72.3, 72.2, 71.3, 68.4, 62.1, 61.5, 61.3, 55.5, 55.0, 43.0, 42.8, 38.0, 36.5, $36.2,35.1,34.8,33.1,32.5,29.4,28.2,27.5,26.6,26.4,25.7,25.4,15.9$, $15.3,15.1,14.5,12.2,12.0,11.6,10.7 \mathrm{ppm}$; IR (film) $\nu=3369,2969$, $2929,2875,1735,1663,1604,1490 \mathrm{~cm}^{-1}$; MS (ESI) $m / z 772\left[\mathrm{M}+\mathrm{H}^{+}\right]$, $789\left[\mathrm{M}+\mathrm{NH}_{4}^{+}\right], 794\left[\mathrm{M}+\mathrm{Na}^{+}\right]$; HRMS (ESI) $m / z$ calcd for $\mathrm{C}_{40} \mathrm{H}_{51} \mathrm{~N}_{3} \mathrm{O}_{8} \mathrm{Cl}_{2} \mathrm{Na}\left[\mathrm{M}+\mathrm{Na}^{+}\right]$794.2945, found 794.2952.

Compound $44 . \mathrm{Zn}(\mathrm{Cu} / \mathrm{Ag})$ alloy $(20 \mathrm{mg})$ was added to a solution of $43(3.7 \mathrm{mg}, 4.8 \mu \mathrm{mol})$ in $\mathrm{MeOH} /$ dioxane $/ \mathrm{H}_{2} \mathrm{O}(300 \mu \mathrm{L}, 1: 1: 1)$, and the resulting suspension was stirred at $60{ }^{\circ} \mathrm{C}$ for $12 \mathrm{~h}$. All insoluble materials were filtered off through a pad of Celite. The filtrate was evaporated and the crude product purified by preparative HPLC (150 mm YMC ODS-A $5 \mu \mathrm{m}, \varnothing 20 \mathrm{~mm}, \mathrm{MeOH} / \mathrm{H}_{2} \mathrm{O}=75: 25$, $15 \mathrm{~mL} / \mathrm{min}, 10.8 \mathrm{MPa}, 298 \mathrm{~K}, \mathrm{UV}, 220 \mathrm{~nm})$ to afford the title compound as a white solid $(2.3 \mathrm{mg}, 62 \%):[\alpha]_{\mathrm{D}}{ }^{20}=-113.5$ (c 0.23 , acetone); ${ }^{1} \mathrm{H}$ NMR $\left(600 \mathrm{MHz}, \mathrm{MeOH}-d_{4}\right)$, mixture of rotamers, ca. 2.6:1) $\delta=$ $7.41-7.36(\mathrm{~m}, 2 \mathrm{H}), 7.35-7.31(\mathrm{q}, J=8.8,7.7 \mathrm{~Hz}, 2 \mathrm{H}), 7.29-7.25(\mathrm{~m}$, $1 \mathrm{H}), 7.24(\mathrm{~s}, 2 \mathrm{H}), 6.34(\mathrm{dd}, J=16.2,5.8 \mathrm{~Hz}, 0.28 \mathrm{H}$, minor $), 6.17-6.09$ $(\mathrm{m}, 1 \mathrm{H}), 5.91-5.85(\mathrm{~m}, 0.28 \mathrm{H}$, minor), $5.74(\mathrm{~s}, 0.72 \mathrm{H}$, major), $5.64(\mathrm{dt}$, $J=8.0,4.4 \mathrm{~Hz}, 0.72 \mathrm{H}$, major), $5.56(\mathrm{~d}, J=16.0 \mathrm{~Hz}, 0.72 \mathrm{H}$, major $), 5.51$ (d, $J=16.2 \mathrm{~Hz}, 0.28 \mathrm{H}$, minor), $4.85-4.81(\mathrm{~m}, 1 \mathrm{H}), 4.77(\mathrm{dd}, J=9.3$, $6.1 \mathrm{~Hz}, 1 \mathrm{H}), 4.72(\mathrm{dd}, J=11.2,3.8 \mathrm{~Hz}, 1 \mathrm{H}), 4.66(\mathrm{~d}, J=11.3 \mathrm{~Hz}, 0.72 \mathrm{H}$, major), 4.63 (s, $0.72 \mathrm{H}$, major), $4.53(\mathrm{~s}, 0.28 \mathrm{H}$, minor), $4.52-4.48(\mathrm{~m}$, $0.72 \mathrm{H}$, major), 4.14 (d, $J=10.8 \mathrm{~Hz}, 0.28 \mathrm{H}$, minor), $3.26(\mathrm{~d}, J=15.7 \mathrm{~Hz}$, $0.28 \mathrm{H}$, minor), $3.04-3.01(\mathrm{~m}, 0.72 \mathrm{H}$, major), 3.01 (s, $0.84 \mathrm{H}, \mathrm{minor}$ ), $2.96(\mathrm{dd}, J=14.6,11.4 \mathrm{~Hz}, 0.28 \mathrm{H}$, minor), 2.87 (s, $2.16 \mathrm{H}$, major), $2.79-2.72(\mathrm{~m}, 2 \mathrm{H}), 2.59-2.49(\mathrm{~m}, 1.44 \mathrm{H}$, major $), 2.43(\mathrm{~d}, J=15.0 \mathrm{~Hz}$, $0.28 \mathrm{H}$, minor), $2.06-1.97(\mathrm{~m}, 0.72 \mathrm{H}$, major), $1.94(\mathrm{~s}, 2.16 \mathrm{H}$, major), 1.87 (d, $J=27.2 \mathrm{~Hz}, 0.28 \mathrm{H}$, minor), 1.84 (s, $0.84 \mathrm{H}$, major), $1.40-1.33$ (m, $1 \mathrm{H}), 1.24$ (s, $0.84 \mathrm{H}$, minor), $1.20(\mathrm{~s}, 0.84 \mathrm{H}$, minor $), 1.15(\mathrm{~s}, 2.16 \mathrm{H}$, major), $1.08(\mathrm{~s}, 2.16 \mathrm{H}$, major), $1.07-0.97(\mathrm{~m}, 1 \mathrm{H}), 0.93(\mathrm{~d}, J=6.9 \mathrm{~Hz}$ $2.16 \mathrm{H}$, major), $0.91-0.86(\mathrm{~m}, 3.84 \mathrm{H}), 0.72(\mathrm{~d}, J=6.5 \mathrm{~Hz}, 2.16 \mathrm{H}$, major), 0.44 (d, $J=6.5 \mathrm{~Hz}, 0.84 \mathrm{H}$, minor) ppm; ${ }^{13} \mathrm{C}$ NMR $(151 \mathrm{MHz}$, $\left.\mathrm{MeOH}-d_{4}\right) \delta=177.1,176.9,172.6,172.6,172.2,171.4,171.3,171.2$, $149.9,148.5,145.9,139.7,139.0,135.7,134.8,130.7,130.4,130.1,129.3$,
$129.0,128.8,128.5,128.4,128.0,127.1,127.0,111.4,110.3,90.8,89.4$ 85.3, 84.1, 81.2, 77.8, 72.9, 72.2, 68.3, 62.5, 62.0, 61.8, 61.5, 61.5, 56.2, 55.1, 43.8, 43.4, 37.9, 37.2, 37.2, 35.2, 35.2, 33.1, 32.4, 29.2, 28.0, 27.4, 26.4, 26.4, 25.7, 25.4, 15.8, 15.4, 15.4, 14.6, 13.7, 11.7, 10.7, $10.1 \mathrm{ppm}$; IR (film) $\nu=2923,2853,1659,1604,1455 \mathrm{~cm}^{-1}$; MS (ESI) $\mathrm{m} / z 772$ $\left[\mathrm{M}+\mathrm{H}^{+}\right], 794\left[\mathrm{M}+\mathrm{Na}^{+}\right]$; HRMS (ESI) $m / z$ calcd for $\mathrm{C}_{40} \mathrm{H}_{51} \mathrm{~N}_{3} \mathrm{O}_{8} \mathrm{Cl}_{2} \mathrm{Na}$ $\left[\mathrm{M}+\mathrm{Na}^{+}\right]$794.2945, found 794.2945.

\section{ASSOCIATED CONTENT}

\section{S Supporting Information}

The Supporting Information is available free of charge on the ACS Publications website at DOI: 10.1021/acs.joc.7b02871. CCDC-1584397 contains the supplementary crystallographic data for this paper. These data can be obtained free of charge from the Cambridge Crystallographic Data Centre via the Internet at www.ccdc.ca.ac.uk/data_request/cif.

Crystallographic abstract, tabular comparison of the NMR data of synthetic nannocystin Ax with those of the natural product, copies of HPLC traces, and copies of spectra of new compounds (PDF)

$\mathrm{X}$-ray data for compound 26 (CIF)

\section{AUTHOR INFORMATION}

\section{Corresponding Author}

*E-mail: fuerstner@kofo.mpg.de.

ORCID $\odot$

Rolf Müller: 0000-0002-1042-5665

Alois Fürstner: 0000-0003-0098-3417

\section{Notes}

The authors declare no competing financial interest.

\section{ACKNOWLEDGMENTS}

Generous financial support by the Swiss National Science Foundation (fellowship to L.S.), the Alexander-von-Humboldt Foundation (fellowship to B.M.), and the MPG is gratefully acknowledged. We thank the analytical departments of our institute for expert support, especially Dr. R. Goddard for solving the X-ray structure. The crystallographic dataset was recorded at PETRA III at DESY, a member of the Helmholtz Association (HGF); we would like to thank Anja Burkhardt and Alke Meents for assistance in using the P11 beamline.

\section{REFERENCES}

(1) (a) Herrmann, J.; Abou Fayad, A.; Müller, R. Nat. Prod. Rep. 2017, 34, 135-160. (b) Weissman, K. J.; Müller, R. Nat. Prod. Rep. 2010, 27, 1276-1295. (c) Schäberle, T. F.; Lohr, F.; Schmitz, A.; König, G. M. Nat. Prod. Rep. 2014, 31, 953-972.

(2) Hoffmann, H.; Kogler, H.; Heyse, W.; Matter, H.; Caspers, M.; Schummer, D.; Klemke-Jahn, C.; Bauer, A.; Penarier, G.; Debussche, L.; Brönstrup, M. Angew. Chem., Int. Ed. 2015, 54, 10145-10148.

(3) Krastel, P.; Roggo, S.; Schirle, M.; Ross, N. T.; Perruccio, F.; Aspesi, P.; Aust, T.; Buntin, K.; Estoppey, D.; Liechty, B.; Mapa, F.; Memmert, K.; Miller, H.; Pan, X.; Riedl, R.; Thibaut, C.; Thomas, J.; Wagner, T.; Weber, E.; Xie, X.; Schmitt, E. K.; Hoepfner, D. Angew. Chem., Int. Ed. 2015, 54, 10149-10154.

(4) Although EF-1 is ubiquitous in mammalian cells, EF-1 levels and mutations are thought to play an important role in certain cancers; for a leading reference, see the following and literature cited therein: Lee, M.H.; Surh, Y.-J. Ann. N. Y. Acad. Sci. 2009, 1171, 87-93.

(5) Didemnin B, another potent inhibitor of EF-1, entered clinical phase II trials in the U.S.; for a review, see: Lee, J.; Currano, J. N.; Carroll, P. J.; Joullié, M. M. Nat. Prod. Rep. 2012, 29, 404-424.

(6) The binding site was shown to overlap with that of didemnin B; see ref 3. 
(7) Liao, L.; Zhou, J.; Xu, Z.; Ye, T. Angew. Chem., Int. Ed. 2016, 55, $13263-13266$.

(8) Huang, J.; Wang, Z. Org. Lett. 2016, 18, 4702-4705.

(9) Yang, Z.; Xu, X.; Yang, C.-H.; Tian, Y.; Chen, X.; Lian, L.; Pan, W.; $\mathrm{Su}, \mathrm{X}$.; Zhang, W.; Chen, Y. Org. Lett. 2016, 18, 5768-5770.

(10) Liu, Q.; Hu, P.; He, Y. J. Org. Chem. 2017, 82, 9217-9222.

(11) Zhang, Y.-H.; Liu, R.; Liu, B. Chem. Commun. 2017, 53, 55495552.

(12) Poock, C.; Kalesse, M. Org. Lett. 2017, 19, 4536-4539.

(13) For a discussion, see: Fürstner, A. Science 2013, 341, 1229713.

(14) Wilson, R. M.; Danishefsky, S. J. Angew. Chem., Int. Ed. 2010, 49, 6032-6056.

(15) (a) Szpilman, A. M.; Carreira, E. M. Angew. Chem., Int. Ed. 2010, 49, 9592-9628. (b) Fürstner, A. Isr. J. Chem. 2011, 51, 329-345.

(c) Wach, J.-Y.; Gademann, K. Synlett 2012, 2012, 163-170.

(16) Fürstner, A. Angew. Chem., Int. Ed. 2013, 52, 2794-2819.

(17) Trost, B. M.; Ball, Z. T. Synthesis 2005, 2005, 853-887.

(18) Frihed, T. G.; Fürstner, A. Bull. Chem. Soc. Jpn. 2016, 89, 135160.

(19) (a) Cromm, P. M.; Schaubach, S.; Spiegel, J.; Fürstner, A.; Grossmann, T. N.; Waldmann, H. Nat. Commun. 2016, 7, 11300. (b) Cromm, P. M.; Wallraven, K.; Glas, A.; Bier, D.; Fürstner, A.; Ottmann, C.; Grossmann, T. N. ChemBioChem 2016, 17, 1915-1919. (c) Ghalit, N.; Poot, A. J.; Fürstner, A.; Rijkers, D. T. S.; Liskamp, R. M. J. Org. Lett. 2005, 7, 2961-2964.

(20) Burnley, J.; Jackson, W. R.; Robinson, A. J. J. Org. Chem. 2015, 80, 9057-9063.

(21) (a) Rummelt, S. M.; Radkowski, K.; Roşca, D.-A.; Fürstner, A. J. Am. Chem. Soc. 2015, 137, 5506-5519. (b) Rummelt, S. M.; Fürstner, A. Angew. Chem., Int. Ed. 2014, 53, 3626-3630.

(22) Roşca, D.-A.; Radkowski, K.; Wolf, L. M.; Wagh, M.; Goddard, R.; Thiel, W.; Fürstner, A. J. Am. Chem. Soc. 2017, 139, 2443-2455.

(23) Amides and sulfonamides were previously shown to exert an appreciable steering effect; see ref 21.

(24) Yang, Y.; Perry, I. B.; Lu, G.; Liu, P.; Buchwald, S. L. Science 2016, 353, 144-150.

(25) Bartko, S. G.; Deng, J.; Danheiser, R. L. Org. Synth. 2016, 93, 245262.

(26) Denmark, S. E.; Jones, T. K. J. Org. Chem. 1982, 47, 4595-4597.

(27) Dettwiler, J. E.; Lubell, W. D. J. Org. Chem. 2003, 68, 177-179.

(28) Fürstner, A.; Schlecker, A. Chem. - Eur. J. 2008, 14, 9181-9191.

(29) (a) Burgess, K.; Jennings, L. D. J. Am. Chem. Soc. 1991, 113, 6129-6139. (b) Burova, S. A.; McDonald, F. E. J. Am. Chem. Soc. 2002, 124, 8188-8189. (c) Masuda, Y.; Mori, K. Eur. J. Org. Chem. 2005, 2005, 4789-4800. (d) Matsuda, M.; Yamazaki, T.; Fuhshuku, K.-i.; Sugai, T. Tetrahedron 2007, 63, 8752-8760.

(30) Hughes, D. L. Org. React. 1992, 42, 335-656.

(31) Maryanoff, B. E.; Reitz, A. B. Chem. Rev. 1989, 89, 863-927.

(32) (a) Devos, A.; Remion, J.; Frisque-Hesbain, A.-M.; Colens, A.; Ghosez, L. J. Chem. Soc., Chem. Commun. 1979, 1180-1181. (b) Munyemana, F.; George, I.; Devos, A.; Colens, A.; Badarau, E.; Frisque-Hesbain, A.-M.; Loudet, A.; Differding, E.; Damien, J.-M.; Rémion, J.; Van Uytbergen, J.; Ghosez, L. Tetrahedron 2016, 72, 420430.

(33) For an application where the use of this reagent had been critical, see: Fürstner, A.; Weintritt, H. J. Am. Chem. Soc. 1998, 120, 2817-2825.

(34) Golakoti, T.; Ogino, J.; Heltzel, C. E.; Le Husebo, T.; Jensen, C. M.; Larsen, L. K.; Patterson, G. M. L.; Moore, R. E.; Mooberry, S. L.; Corbett, T. H.; Valeriote, F. A. J. Am. Chem. Soc. 1995, 117, 1203012049.

(35) (a) Rachele, J. R. J. Org. Chem. 1963, 28, 2898. (b) Nishiyama, S.; Suzuki, Y.; Yamamura, S. Tetrahedron Lett. 1988, 29, 559-562.

(36) Hendrickson, J. B.; Kandall, C. Tetrahedron Lett. 1970, 11, 343344.

(37) Aurelio, L.; Brownlee, R. T. C.; Hughes, A. B. Chem. Rev. 2004, 104, 5823-5846.

(38) Haberlag, B.; Freytag, M.; Daniliuc, C. G.; Jones, P. G.; Tamm, M. Angew. Chem., Int. Ed. 2012, 51, 13019-13022.
(39) (a) Willwacher, J.; Fürstner, A. Angew. Chem., Int. Ed. 2014, 53, 4217-4221. (b) Ungeheuer, F.; Fürstner, A. Chem. - Eur. J. 2015, 21, 11387-11392.

(40) (a) Lhermet, R.; Fürstner, A. Chem. - Eur. J. 2014, 20, 1318813193. (b) Persich, P.; Llaveria, J.; Lhermet, R.; de Haro, T.; Stade, R.; Kondoh, A.; Fürstner, A. Chem. - Eur. J. 2013, 19, 13047-13058.

(41) (a) Heppekausen, J.; Stade, R.; Goddard, R.; Fürstner, A. J. Am. Chem. Soc. 2010, 132, 11045-11057. (b) Heppekausen, J.; Stade, R.; Kondoh, A.; Seidel, G.; Goddard, R; Fürstner, A. Chem. - Eur. J. 2012, 18, 10281-10299.

(42) Schrock, R. R. Chem. Rev. 2002, 102, 145-179.

(43) Certain tungsten alkylidynes react with benzaldehyde, acetone, ethyl formate, and DMF: Freudenberger, J. H.; Schrock, R. R. Organometallics 1986, 5, 398-400.

(44) For other instructive examples, see ref 45 and the following: (a) Ralston, K. J.; Ramstadius, H. C.; Brewster, R. C.; Niblock, H. S.; Hulme, A. N. Angew. Chem., Int. Ed. 2015, 54, 7086-7090. (b) Guo, L.D.; Huang, X.-Z.; Luo, S.-P.; Cao, W.-S.; Ruan, Y.-P.; Ye, J.-L.; Huang, P.-Q. Angew. Chem., Int. Ed. 2016, 55, 4064-4068. (c) Herstad, G.; Molesworth, P. P.; Miller, C. M.; Benneche, T.; Tius, M. A. Tetrahedron 2016, 72, 2084-2093. (d) Hötling, S.; Bittner, C.; Tamm, M.; Dähn, S.; Collatz, J.; Steidle, J. L. M.; Schulz, S. Org. Lett. 2015, 17, 5004-5007. (e) Neuhaus, C. M.; Liniger, M.; Stieger, M.; Altmann, K.-H. Angew. Chem., Int. Ed. 2013, 52, 5866-5870.

(45) For representative examples from our group, see the following and literature cited therein: (a) Chaładaj, W.; Corbet, M.; Fürstner, A. Angew. Chem., Int. Ed. 2012, 51, 6929-6933. (b) Micoine, K.; Fürstner, A. J. Am. Chem. Soc. 2010, 132, 14064-14066. (c) Hickmann, V.; Kondoh, A.; Gabor, B.; Alcarazo, M.; Fürstner, A. J. Am. Chem. Soc. 2011, 133, 13471-13480. (d) Benson, S.; Collin, M.-P.; Arlt, A.; Gabor, B.; Goddard, R.; Fürstner, A. Angew. Chem., Int. Ed. 2011, 50, 87398744.

(46) The ratio of regioisomers in the crude product is $>20: 1$; other stereoisomers could not be detected by NMR.

(47) $[\mathrm{Cp} * \mathrm{RuCl}]_{4}$ disassembles on treatment with an alkyne substrate to give $[\mathrm{Cp} * \mathrm{RuCl}]$ as the catalytically active fragment; see refs 21 and 22; for the preparation of this precatalyst, see: (a) Fagan, P. J.; Mahoney, W. S.; Calabrese, J. C.; Williams, I. D. Organometallics 1990, 9, 18431852. (b) Fagan, P. J.; Ward, M. D.; Calabrese, J. C. J. Am. Chem. Soc. 1989, 111, 1698-1719.

(48) (a) Rummelt, S. M.; Preindl, J.; Sommer, H.; Fürstner, A. Angew. Chem., Int. Ed. 2015, 54, 6241-6245. (b) Sommer, H.; Hamilton, J. Y.; Fürstner, A. Angew. Chem., Int. Ed. 2017, 56, 6161-6165. (c) Sommer, H.; Fürstner, A. Org. Lett. 2016, 18, 3210-3213. (d) Schaubach, S.; Michigami, K.; Fürstner, A. Synthesis 2016, 49, 202-208.

(49) Huwyler, N.; Radkowski, K.; Rummelt, S. M.; Fürstner, A. Chem. Eur. J. 2017, 23, 12412-12419.

(50) Preindl, J.; Jouvin, K.; Laurich, D.; Seidel, G.; Fürstner, A. Chem. Eur. J. 2016, 22, 237-247. (b) Fürstner, A.; Davies, P. W. J. Am. Chem. Soc. 2005, 127, 15024-15025.

(51) (a) Fluorine in Pharmaceutical and Medicinal Chemistry. From Biophysical Aspects to Clinical Applications; Gouverneur, V., Müller, K., Eds.; World Scientific: London, 2012; Vol. 6. (b) Fluorine in Medicinal Chemistry and Chemical Biology; Ojima, I., Ed.; Wiley-Blackwell: Chichester, U.K., 2009.

(52) Sommer, H.; Fürstner, A. Chem. - Eur. J. 2017, 23, 558-562.

(53) For chlorine/tin exchange, see: (a) Takeda, T.; Kanamori, F.; Matsusita, H.; Fujiwara, T. Tetrahedron Lett. 1991, 32, 6563-6566. (b) Madec, D.; Férézou, J.-P. Eur. J. Org. Chem. 2006, 2006, 92-104.

(54) For other studies of this type, see ref 48a and the following: (a) Mailhol, D.; Willwacher, J.; Kausch-Busies, N.; Rubitski, E. E.; Sobol, Z.; Schuler, M.; Lam, M.-H.; Musto, S.; Loganzo, F.; Maderna, A.; Fürstner, A. J. Am. Chem. Soc. 2014, 136, 15719-15729. (b) Micoine, K.; Persich, P.; Llaveria, J.; Lam, M.-H.; Maderna, A.; Loganzo, F.; Fürstner, A. Chem. - Eur. J. 2013, 19, 7370-7383. (c) Fürstner, A.; Nevado, C.; Waser, M.; Tremblay, M.; Chevrier, C.; Teplý, F.; Aïssa, C.; Moulin, E.; Müller, O. J. Am. Chem. Soc. 2007, 129, 9150-9161. (d) Fürstner, A.; Kirk, D.; Fenster, M. D. B.; Aïssa, C.; De Souza, D.; Nevado, C.; Tuttle, T.; Thiel, W.; Müller, O. Chem. - Eur. J. 2007, 13, 135-149. 
(55) Cheng, J.-K.; Loh, T.-P. J. Am. Chem. Soc. 2015, 137, 42-45.

(56) Wu, B.; Feast, G. C.; Thompson, A. L.; Robertson, J. J. Org. Chem. 2012, 77, 10623-10630.

(57) Li, Y.; Yang, X.; Liu, Y.; Zhu, C.; Yang, Y.; Yu, B. Chem. - Eur. J. 2010, 16, 1871-1882. 